\title{
BücherStand I
}

Die folgenden Rezensionen, Berichte und Anzeigen verdanken ihre Entstehung nicht einem Auftrag, sondern der Absicht eines alten Rechtshistorikers, der sich für einige Jahrzehnte von Rechtstheorie und Rechtsphilosophie getrennt hatte (Dieter Simon), und eines jungen Rechtstheoretikers, der sich des gegenwärtigen Zustandes dieser Fächer vergewissern wollte (Benjamin Lahusen), gemeinsam die heutige deutsche Welt der Rechtsphilosophie, der Rechtstheorie und der Rechtsmethodologie zu durchmustern und sich umfassend anzueignen.

Systematiker und andere Vernünftige würden sich dazu eines inhaltlich und chronologisch ausgearbeiteten Planes bedienen, der sorgfältig Buch um Buch abgearbeitet werden müßte. Das wäre eine zweckgemäße, aber zweifellos mühselige Arbeit, deren Gewinn gleichwohl nicht ausgemacht scheint. Denn es steht nicht einmal fest, daß die eben zitierte »Welt« überhaupt besteht. Vielleicht handelt es sich nur um kontingente Eruptionen, die isolierten Interessen, den Zwängen akademischer Karrieren oder wahllos und kurzfristig bedienten Ausbildungswünschen geschuldet sind - bunt, erratisch, solipsistisch - kurzum: theoretisch und praktisch folgenlos. Das herauszufinden ist selbst ein Teil unseres Vorhabens.

Also gaben wir dem Zufall und der Leselust den Vorzug vor dem Plan und der Disziplin. Die Berichte geben das wieder, was andere sich vermutlich mündlich nach Auswahl und Auslese über ihre Abenteuer in der wissenschaftlichen Buchwelt berichten würden. Mit solchen Berichten haben wir in der Tat begonnen. Als die Sammlung anwuchs, entstand der Gedanke an einen umfassenden gemeinsam bestückten Almanach. Insofern sind die Verantwortlichkeiten deutlich. Die Siglen (BL und DS) bezeichnen den Leser und Autor. Die Fragen, Kommentare und Hinweise des jeweils anderen, der manchmal gelesen hatte, aber manchmal auch nicht, sind nicht spurlos, aber für Dritte unerkennbar in den Texten des ersten verschwunden.

Ein Gemeinschaftswerk also, das sich in schneller Folge entfalten soll, um sich allmählich zu einer erkennbaren und befahrbaren Landschaft zu verdichten. Am Ende sollten jedenfalls, wie Christoph Weidlich 1757 seine Chronik titulierte, »zuverläßige Nachrichten von denen ietztlebenden Rechtsgelehrten« stehen. Aber der Zorn der Götter und die Lust der Sterblichen möge einstweilen nur den jeweiligen Inhaber der Sigle treffen.

\section{Hinterkeller}

Keller sind Orte des Vergessens. In den Keller kommt, was oberhalb seiner Decke nicht mehr gebraucht wird. Was im Keller lagert, ist im Alltag nutzlos und wird deshalb unsichtbar gemacht. Und was dem Auge entzogen ist, entschwindet bald dem Gedächtnis. Ein Ausflug in die Unterbauten der Welt verspricht deshalb selten mehr als den Blick auf ausrangierte und abgeworfene Materialisierungen einer vergangenen 
Alltäglichkeit. Und da diese Alltäglichkeiten eben deshalb in den Keller verbracht wurden, weil sie genauso alltäglich waren wie der Alltag der Gegenwart, wird der Gang in den Keller zusehends als überflüssig erachtet. Folglich geraten diejenigen Disziplinen, die sich mit der Erinnerung des Vergessenen beschäftigen, überall dort in Rechtfertigungsnöte, wo sie die Schädlichkeit des Vergessens nicht nachweisen können. Die Rechtsgeschichte etwa ist auf diese Weise zur Kellerdisziplin verkommen, deren Randständigkeit durch die Alternativbezeichnung »Grundlagenfach « nur unzureichend verdeckt wird.

Rechtshistoriker sind deshalb nicht zu beneiden. Sofern sie sich jedoch brav mit Strafrechtsgeschichte oder der Entwicklung der kommunalen Selbstverwaltung in Süddeutschland beschäftigen, ist ihnen immerhin ein Platz im Fußnotenapparat der Einleitungskapitel materiellrechtlicher Lehrbücher sicher. Gänzlich abseitig wird ihr Tun aber dort, wo sie nicht einmal mehr als schmückendes Beiwerk der Dogmatik dienen können, sondern sich im Keller des Rechts noch in ein juristisches Hinterzimmer verkriechen: die Rechtstheorie. Annette Brockmöllers Beitrag zur Rechtstheoriegeschichte ${ }^{1}$ kann deshalb nur als Hinterkeller der Jurisprudenz bezeichnet werden.

Ein mutiger Schritt also, den Brockmöller in ihrer Dissertation gegangen ist. Und ein großer Schritt zugleich: Um die Entstehung der Rechtstheorie dingfest zu machen, hat die Autorin acht Rechtsdenker des 19. Jahrhunderts zum Gegenstand teils längerer, teils ausschweifender exegetischer Ausführungen gemacht, von denen jeder für sich genommen ein taugliches Dissertationsthema abgegeben hätte: Gustav Hugo (47-68), Nikolaus Falck (68-82), Friedrich Carl von Savigny (83-114), Georg Friedrich Puchta (114-136), Rudolf von Ihering (191-238), Adolf Merkel (238-249), Ernst Rudolf Bierling (249-256) und Karl Bergbohm (256-272). Dazwischen liegt ein Kapitel zur enzyklopädischen Bewegung und zur Herausbildung der einzelnen juristischen Disziplinen (137-182).

Schon diese Gewichtung macht deutlich, daß Brockmöllers Schwerpunkt auf der Zeit vor Adolf Merkel liegt. Das ist insofern erstaunlich, als Adolf Merkel mit seiner Allgemeinen Rechtslehre weithin als der Begründer der Rechtstheorie gilt. Diese Einschätzung zu erschüttern, wenn nicht gar zu widerlegen, ist ein großes Verdienst von Brockmöllers Arbeit. In etwa folgende Linie gibt die Lektüre preis (fünf resümierende Thesen finden sich auf $276 \mathrm{f}$.): Mit Kant setzen in der Jurisprudenz Bestrebungen ein, aus der »Rechtsgelahrtheit« eine echte Wissenschaft zu machen, eine Wissenschaft also, für die »in externer Hinsicht [...] der Systemgedanke, in interner Hinsicht die Ausrichtung auf Erkenntnis « maßgeblich wird (27). Als Folge der Kantischen Philosophie ergibt sich zugleich, daß sich die Wissenschaftlichkeit der Jurisprudenz nicht am Naturrecht sondern am positiven Recht orientieren muß.

Mit der Positivierung des Rechts muß die Jurisprudenz aber auch dessen völlige Kontingenz anerkennen. Für die Emanzipierung einer echten Rechtswissenschaft ist diese Abhängigkeit vom berühmten legislativen Federstrich keine gute Vorausset-

1 Annette Brockmöller, Die Entstehung der Rechtstheorie im 19. Jahrhundert in Deutschland. Baden-Baden: Nomos 1997 (Studien zur Rechtsphilosophie und Rechtstheorie Band 14), $297 \mathrm{~S}$. 
zung. Hugo und Falck behelfen sich deshalb mit der Ausflucht in Rechtsphilosophie und Rechtsgeschichte; erst bei Savigny wird die Rechtsdogmatik selbst zur Wissenschaft, was freilich nur deshalb möglich ist, weil sie es infolge der »organisch-geschichtlichen Entwicklung des Rechts « (114) mit einem notwendigen Stoff zu tun hat. Brockmöller zieht daraus den Schluß, Savigny müsse als der »erste Rechtstheoretiker « bezeichnet werden (113).

Fraglich ist dann allerdings, ob außer Savigny überhaupt noch weitere Rechtstheoretiker existieren. Denn schon bei Puchta beginnen die Auflösungserscheinungen dieser durch die stillwirkenden Kräfte garantierten stofflichen Necessitas (116 ff.). Entsprechend muß die Suche nach Rechtswissenschaft von dem Gedanken Abschied nehmen, bei der Produktion von Recht fündig zu werden. Dagegen gewinnt die Vermutung stärkeren Zulauf, die Scientia nehme selbst gar nicht Teil an der Ordnungs- und Systematisierungsaufgabe des Rechtsstoffes, sondern beschränke sich auf dessen Analyse. Auf diese Weise soll eine wissenschaftliche Theorie des Rechts fruchtbar gemacht werden, um den »Geist des Rechts« ausfindig zu machen und »allgemeine Rechtswahrheiten « zu entdecken (82).

Dieses Programm trägt deutliche Züge der Allgemeinen Rechtslehre des ausgehenden 19. Jahrhunderts; seine Anfänge sieht Brockmöller jedoch schon bei Nikolaus Falck (82). Mit ihm beginnen die Bestrebungen, der Rechtswissenschaft einen allgemeinen Teil voranzustellen, der die Grundbegriffe und Strukturen des Rechts destilliert und damit der immer weiter ausgreifenden Verselbständigung der juristischen Einzeldisziplinen einen einheitlichen Kern entgegenhält. Teils noch systematisierend, teils aber auch schon analysierend und beobachtend markieren die juristischen Enzyklopädien um die Jahrhundertmitte einen wichtigen Schritt auf dem Weg zu einem eigenständigen rechtstheoretischen Fach; in ihnen wird »die Tendenz zur Begründung einer Disziplin, die sich mit der Theorie von Recht und Rechtswissenschaft befaßt, explizit« (276).

Der Rückzug auf die Analyse des Vorhandenen setzt jedoch voraus, daß die Existenz bestimmter Rechtsquellen als gesichert gelten kann. Trotz der offenbar werdenden Kontingenz des Rechts ist die fortschreitende Kodifizierung für die Herausbildung der Rechtstheorie somit überaus förderlich. Ihering konnte als einer der ersten von der zunehmenden Gesetzgebung profitieren und sich anstelle der Rechtsquellenproblematik verstärkt einer Bestimmung des Rechtsbegriffs zuwenden (190). Damit sind endgültig die Weichen gestellt für die Untersuchung und Analyse der rechtlichen Strukturen und »allgemeinen Ideen« des Rechts (Brockmöller zitiert Ihering, 236). Folglich, bilanziert Brockmöller, sei die »Herausbildung der Rechtstheorie mit der Rechtslehre Iherings im wesentlichen abgeschlossen « (190).

Die übrigen Gelehrten werden aus diesem Grund nur noch gestreift. In einer Entstehungsgeschichte der Rechtstheorie liegen sie nur noch am Rand. Wichtig ist ihre Darstellung jedoch vor allem deshalb, weil Brockmöller hier deutlich macht, daß die Rechtstheorie in ihren Anfängen keine »positivistische Theorie « war (275). Insbesondere Merkel modellierte seine Allgemeine Rechtslehre ohne eine strikte Trennung von Recht und Moral; der Gedanke, »daß unmoralischem Recht nur moralisch, nicht aber rechtlich die Geltung aberkannt werden könne«, finde sich erst bei Bierling 
und Bergbohm, also nach der Etablierung der Rechtstheorie als eigenständiger Disziplin (275 f.).

Zweifellos verdient Brockmöllers Ausflug ins 19. Jahrhundert Respekt. Ihr kenntnisreicher Gang durch die Werke der Protagonisten ist über weite Strecken von sympathisierender Distanz getragen und zeitigt manch anregendes Ergebnis, das ein ums andere Mal einer Rehabilitierung des Autors gleichkommt. So befreit sie etwa Bierling aus dem psychologisierenden Klammergriff von Larenz und stellt klar, daß Bierlings Geltungstheorie einer Hartschen Grundnorm deutlich näher steht als der Vorstellung, das Recht müsse seine Geltung aus irgendwie gearteten psychischen Tatsachen schöpfen (253 f.).

In methodischer Hinsicht sind jedoch zwei Anmerkungen zu machen, die den insgesamt positiven Blick auf Brockmöllers Arbeit trüben. Die eine betrifft den Gegenstand der Untersuchung, die Rechtstheorie, die andere zielt auf die Auswahl der Quellen und ihre Präsentation.

Eine Definition oder Umschreibung dessen, was Brockmöller sich unter Rechtstheorie vorstellt, fehlt. Dies bringt zwar den Vorteil, daß Brockmöller den Sumpf der Abgrenzungsversuche umschiffen kann, welcher Rechtstheorie, Rechtsphilosophie und Rechtsmethodologie umgibt. Offenkundig geht ihrer Arbeit auf diese Weise aber die Zielsetzung verloren. Brockmöller deutet zwar häufig an, welche Fragestellungen sie für »rechtstheoretisch « erachtet, aber für eine Arbeit, die das Interesse an diesen Fragestellungen und seine Entstehung klären will, ist das wohl zu wenig. So verbleibt es bei wiederholten Gleichsetzungen von Allgemeiner Rechtslehre und Rechtstheorie (etwa: 238); zu Ihering heißt es, »Rechtsphilosophie und Rechtsgeschichte [gingen] ein Bündnis zum Wohle der Rechtstheorie ein « (234); und die Zusammenfassung Bergbohms bleibt unwidersprochen, Rechtstheorie sei »die Sammelstelle für die umherirrenden allgemeinen Rechtsbegriffe und Rechtslehren, ein allgemeinster Teil der ganzen Rechtswissenschaft« (262).

Natürlich kann man sich fragen, ob die Rechtstheorie bis heute über ein Dasein als Auffangbecken für das Altpapier der Rechtsdogmatik hinausgekommen ist. Aber die Entstehungsgeschichte eines Sammelsuriums zu untersuchen, strahlt wenig Attraktivität aus. Sofern man sich jedoch konsequent an dem orientiert, was die Zeitgenossen selbst für Rechtstheorie gehalten und als solche bezeichnet haben, verspricht die Unternehmung wenig mehr Gewinn als die Entdeckung desjenigen, der als erster die Worte Recht und Theorie miteinander verknüpft hat. Auch das ist als Forschungsprogramm wenig ertragreich.

Nun ist Brockmöller weit davon entfernt, einem dieser beiden Extreme nachzueifern. Gleichwohl hätte sie sich (und dem Leser) manchen Umweg ersparen können, wenn sie den Begriff der Rechtstheorie etwas näher umrissen und ihre historische Darstellung ein wenig zielstrebiger ausgerichtet hätte. Auch ihre abschließend vorsichtig vorgetragene Forderung, Rechtstheorie und Rechtsphilosophie wieder zu vereinen, verliert deutlich an revolutionärem Potential, wenn beide Disziplinen vorher nicht begrifflich geschieden sind. Begriffspaare wie Erklärung vs. Begründung, Deskription vs. Präskription, formal vs. material etc. wären hier sicherlich hilfreich gewesen.

Die zweite Anmerkung betrifft die Auswahl der Quellen und ihre Darstellung im Verlauf der Arbeit. Nicht kritisiert werden soll dabei allerdings die Entscheidung für 
diesen und die Exklusion von jenem Denker. Natürlich läßt sich fragen, warum Brockmöller Bierling und Bergbohm berücksichtigt, Stammler und Stahl aber ausgelassen hat (was auch Brockmöller nicht entgangen ist, 19 Fn. 22). Aber solche Fragen würden wohl erst aufhören, wenn Brockmöller jeden Gelehrten eingearbeitet hätte, der sich im 19. Jahrhundert zu juristischen Grundlagenproblemen geäußert hat. Dies wiederum dürfte die Benutzerfreundlichkeit (und Sinnhaftigkeit) der von einem Referenten ja ebenfalls zu erwartenden Selektionsleistung erheblich schmälern.

Fraglich bleibt allerdings, ob die Art und Weise, wie Brockmöller den Leser durch die von ihr ausgesuchten Werke »zentraler Bedeutung « (19) führt, historisch wirklich gewinnbringend ist. Brockmöller beleuchtet die Beiträge ihrer Protagonisten »hinsichtlich folgender Aspekte [...]: Rechtsquellen, Rechtsbegriff, Recht und Moral bzw. Recht und Gerechtigkeit, Gegenstandsbereich der Rechtsphilosophie oder gegebenenfalls der Rechtstheorie, Rechtswissenschaft, rechtswissenschaftliche Methode, Rechtssystem, System der juristischen Disziplinen« (19). Dies geschieht unter bewußtem Verzicht »auf die Darstellung von Personen, Handlungen und weitestgehend auch von Ereignissen« (15 Fn. 9).

Es dürfte kaum überraschen, daß ein solches Vorgehen nicht mehr hervorbringen kann als eine Auflistung dessen, was sich die verschiedenen Gelehrten zu verschiedenen Zeiten zu den genannten Begriffen gedacht haben. Eine Entwicklungsgeschichte oder überhaupt nur eine historische Darstellung kann auf diese Weise jedoch nicht entstehen. Wer sich auf einzelne Personen konzentriert und sich zur Prämisse setzt, sie erst jeder Persönlichkeit zu entkleiden, um dann ungestörter ihr »Werk « betrachten zu können, gerade so, als schwebe es unabhängig in Zeit und Raum, der kann viel aufspüren, doch sicher nicht die »theoriegeschichtlichen Motive« (13) für eine bestimmte Entwicklung oder deren »wissenschaftstheoretische Bedingungen « (5). So muß sich der Leser vielfach mit Auskünften etwa der Art begnügen, daß im Gegensatz zu Savigny festgestellt wird: »Bei Puchta gibt es kein System von Prinzipien« (122), ohne daß die sich sofort aufdrängenden Fragen einer Beantwortung nähergebracht werden, welcher Umstand Puchta veranlaßt haben möge, auf ein System von Prinzipien zu verzichten, warum er sich an diesem Punkt von Savigny abgewandt hat, weshalb ein System von Prinzipien überhaupt etwas Wünschenswertes sein soll und was das alles für die Entstehung einer eigenständigen rechtstheoretischen Disziplin bedeutet. Schlagworte wie »zunehmende Verwissenschaftlichung « sind als Erklärungsprinzipien jedenfalls zu ungenau, um diesen Haufen von Einzelansichten mit einer Struktur auszustatten.

Die Teile, die einer historischen Darstellung am nächsten kommen, sind denn auch diejenigen, in denen Brockmöller sich am weitesten von der Präsentation einzelner Denker entfernt, etwa das Kapitel zur enzyklopädischen Bewegung (137-168), zu den juristischen Disziplinen (169-182) oder zur »Situation der Rechtswissenschaft und Gesetzgebung ab 1840« (183-190). Doch kranken diese Abschnitte bedauerlicherweise an mancherlei Ungenauigkeiten, so etwa wenn es heißt: »Mit [...] den Germanistentagen in Frankfurt (1846) und Lübeck (1847) erreicht der seit Beginn des 19. Jahrhunderts latente Konflikt zwischen Germanisten und Romanisten seinen Höhepunkt« (184; diese These wäre für sich schon diskutierenswert), eine Seite später dagegen zu 
lesen ist: »Bereits 1846 ist der Konflikt zwischen Germanisten und Romanisten jedoch wieder abgeebbt.« (185). (Nebenbei: An Stellen wie diesen macht sich auch der konsequente Verzicht des Verlags schmerzlich bemerkbar, die exorbitanten Preise der »Studien zur Rechtsphilosophie und Rechtstheorie« durch den Einsatz eines Lektors zu rechtfertigen.)

Und dennoch: eine umfangreiche Aufgabe, die Brockmöller mit beachtlichem Erfolg gemeistert hat. Weitere Stellungnahmen können nachgelesen werden in den kurzen Beiträgen von Markus Winkler (JZ 1998, 299) und Jan Schröder (ZNR 1999, 507 f.) sowie in den etwas ausführlicheren Besprechungen von Hans-Peter Haferkamp (ZRG GA 2001, 731-735) und Hermann Klenner (ARSP 1998, 304-306).

\section{Zeitgeschichte}

Zeitgeschichte zu schreiben ist ein schwieriges Geschäft. Der Schreiber steht, auch wenn er sich unbefangen nennen darf, auf jeden Fall den Dingen zu nah, um distanziert beschreiben zu können. Ist oder war er aber sogar unter den Akteuren, befindet er sich gleichsam mit der Nase vor der Wand. Ihren Umfang, ihre Linien, Löcher und Strukturen könnte er sehen, wenn es ihm möglich wäre, einige Schritte zurückzutreten. Aber das schaffen nur jene wenigen, die, mit analytischer Kraft und großem Überblick ausgestattet, sich ein wenig aus dem Malstrom der Gegenwart zu lösen vermögen.

Eric Hilgendorf ist bei seiner wissenschaftsgeschichtlichen Studie zur Rechtstheo$\mathrm{rie}^{2}$ ein ordentlicher Distanzierungsschritt geglückt. Sein Sujet sind die zwei Jahrzehnte zwischen 1965 und 1985, zweifellos die aufgeregteste, aufregendste und fruchtbarste Zeit, die die deutsche Rechtstheorie seit den Tagen des Rudolf von Ihering erlebt hat.

Nach seiner Rechtfertigung für den Epochenschnitt (9-12), versucht sich der Verfasser an einer genaueren Bestimmung des Gegenstandes, dem er seine entwicklungsgeschichtlichen Betrachtungen gewidmet hat (13-20). Vernünftigerweise schlägt er einen Bogen um den unauslotbaren Sumpf der tausenderlei einander widersprechenden, sich überschneidenden oder auch deckenden Definitionen und Definitiönchen, mit denen in Vergangenheit und Gegenwart (vermutlich auch in Zukunft) Rechtstheorie von Rechtsphilosophie und beide wieder von Methodologie - obwohl man hier auf festerem Grund bauen kann - abgegrenzt werden. Selbst die von ihm statt dessen mit gebotener Vorsicht angeführten unterscheidenden »Tendenzen« wird der aufmerksame Leser nur »cum grano salis« akzeptieren, eine Wendung, die, ohne direkt als Lieblingsausdruck des Autors diffamiert werden zu dürfen, doch besorgniserregend häufig in dem Büchlein auftaucht.

Das gilt von der »Entwicklungstendenz von der Rechtsphilosophie zur Rechtstheorie und wieder zurück zur Rechtsphilosophie« (15), die Hilgendorf (angeregt durch Rückerts Bemerkung, zu Beginn des 19. Jahrhunderts sei »Theorie« ein Stichwort für Erneuerung gewesen) der Beobachtung entnimmt, daß die gegen die »Rechtsphiloso-

2 Eric Hilgendorf, Die Renaissance der Rechtstheorie zwischen 1965 und 1985. Würzburger Rechtswissenschaftliche Schriften, Band 53, Würzburg: Ergon Verlag, 2005, 77 S. 
phie« ihrer Väter aufmüpfigen Rechtsdenker der von ihm behandelten Epoche sich gern in »Rechtstheorie « bewegen, während ihre Kinder keine Probleme haben, die anstehenden (zumindest ähnlichen!) Probleme wieder unter dem Etikett ihrer Großväter als »Rechtsphilosophie « zu traktieren.

Der cum grano salis-Vorbehalt gilt aber auch von der »Tendenz« der Rechtstheorie, sich auf analytische, nichtspekulative (vorwiegend antinaturrechtliche) Komplexe zu konzentrieren oder von ihrer Neigung, »eine forcierte Tendenz zur Interdisziplinarität« (17) an den Tag zu legen.

Gut gesichertes und deshalb vorbehaltlos akzeptables Terrain betritt der Autor erst dort, wo er auf die Akzeptanzprobleme der Rechtstheorie zu sprechen kommt. Dabei darf man den nur vereinzelt und mehr aus analytischer Unbedarftheit und aufgeregter Moralität als aus Sachkenntnis geäußerten Vorwurf der »Wertblindheit « der neueren Rechtstheorie sicher ebenso unkommentiert beiseite lassen wie die Furcht Unbelesener, ihr schönes Fach könnte seine klaren Konturen unter den interdisziplinären (vor allem: philosophischen und soziologischen) Anstrengungen der Rechtstheoretiker verlieren und sich in einen Nebel von Vorverständnissen, hermeneutischen Zirkeln und Paradoxien auflösen.

Wichtig scheint lediglich die von Hilgendorf pointiert hervorgehobene Indolenz sowohl der akademischen als auch der praktischen Jurisprudenz gegenüber der Rechtstheorie:

»Viele Juristen halten energisch an bestimmten, in ihrer Jugend erlernten methodischen Haltungen und Argumenten fest, ohne bereit zu sein, eine Revision ihrer Basisüberzeugungen auch nur in Erwägung zu ziehen. Die Beschäftigung mit Grundlagenfragen ist allenfalls ein Thema für Sonn- und Feiertagsreden.«(20)

Das ist korrekt, aber kaum mit der Feststellung zu bekämpfen, man könne aus dem (unbestrittenen) Umstand, daß die juristische Arbeit auf einer Vielzahl unexplizierter Annahmen und theoretischer Prämissen aufruht, ableiten, daß es »auch zulässig sein « (!) müsse, diese »Regeln explizit zu machen, sie systematisch zu untersuchen und zu kritisieren«. Gerade diese Befugnis ist nämlich niemals in Zweifel gezogen worden.

Was weithin bezweifelt wird, ist die Notwendigkeit, sich mit Rechtstheorie zu befassen, ihrer Nützlichkeit, um nicht zu sagen: ihrer Unausweichlichkeit! Die trotzigmürrische Bemerkung des Autors, die Ablehnung der Rechtstheorie durch die meisten (er meint sogar wohlwollend: »durch viele«) Juristen sei »nur ein Indiz dafür, daß sie nicht willens oder in der Lage sind, sich die Grundlagen ihrer eigenen Arbeit bewußt zu machen und sie kritisch zu prüfen« (20), ist vielleicht doch etwas voreilig.

»Faul« und »dumm« kann angesichts der großen Zahl zweifellos fleißiger und kluger Juristen schlechterdings keine erschöpfende Erklärung für die Meidung der Rechtstheorie sein. Hier hätte eine Konsultation des vermutlich bisher tiefschürfendsten und scharfsinnigsten soziologischen Beobachters von Recht, Niklas Luhmann, von Nutzen sein können.

Luhmann, dessen epochale (auch) rechtstheoretische Bedeutung von Hilgendorf allerdings auch sonst nicht angemessen gewürdigt wurde (52/53) - was mit dem formalen Gesichtspunkt, die Hauptwerke des Meisters seien nach 1985 erschienen, nicht 
überzeugend gerechtfertigt werden kann - hat immer wieder die verschiedenen Inszenierungen analysiert, mit denen die Juristen die fundamentalen Paradoxien ihrer fachlichen Existenz - von der Rechtsgeltung, die gilt, weil sie gilt, bis zur »Anwendung « des gerade Erfundenen - unsichtbar zu machen suchen. Rechtstheorie als systematische Bemühung, nicht nur die Wegweiser zum Nichts zu enthüllen, sondern obendrein die schmucke Schminke des Selbstbetrugs von den Gesichtern der Machtverwalter zu wischen, muß diese auf den Tod ängstigen. Und so wie der Sensenmann nicht zugelassen, sondern verdrängt, verschwiegen und versteckt wird, so wird auch die Aufklärung durch Rechtstheorie gemieden: es funktioniert doch, würde der sinnerfüllte Juristenspießer zu seiner Rechtfertigung vorbringen und klammheimlich hoffen, daß es mit ihm niemals zu Ende gehen wird.

Also nicht Faulheit und Dummheit, sondern - in erster Linie und obendrein völlig verständlich - Angst ist die Sicherungskraft, welche sich dem Einzug der Rechtstheorie in besorgte Juristenhirne entgegenstemmt. Sie ist nicht unnütz, sondern fürchterlich. Das hat auch etwas Tröstliches, denn anders als Faulheit und Dummheit läßt sich Angst durch Aufklärung, die Selbstvertrauen und Gelassenheit vermittelt, bekämpfen. Hilgendorf kann hoffen.

In seinem dritten Kapitel (21-33) erörtert der Verfasser die Gründe für den »Aufschwung der Rechtstheorie 1965 - 1985«. Obwohl er sich zu Recht weigert, ein monokausales Modell vorzulegen, und vielfältige Ursachen in Ansatz bringt, wird doch deutlich, daß alle »Strömungen«, »Motive«, »Hintergründe«, »Gründe« und »Ursachen« der frühen 60er Jahre ihren Ursprung im allmählichen Verblassen des gigantischen Schocks finden, den die zwölfjährige Despotie und ihr schauerlicher Untergang verursacht hatten, ein Schock, den der begütigende Mehltau der Adenauerherrschaft nicht mehr länger überlagern konnte.

Die verbreitete »Vorstellung eines längst überfälligen geistigen Neuanfangs«, die »Wiederanknüpfung an die [...] vertriebenen geistigen Strömungen«, der Kampf gegen den Positivismus, dem Radbruch - wie er seinerzeit allgemein verstanden wurde einen Großteil am Erfolg des »gesetzlichen Unrechts « zugeschrieben hatte, die scharfe Wendung gegen das thomistische Naturrecht, das nach 1945 nach und nach die Rolle des Nothelfers übernommen hatte, die beginnende rechtshistorische Betrachtung des Nationalsozialismus und der verführerische (Frankfurter) Neomarxismus - sie alle vereinigte die entschiedene Absage an das seinerzeit tatsächlich oder vermeintlich Gültige, das, wie man es ansah, seine Rechtfertigung in den 30 Jahren zwischen 1930 und 1960 erfahren hatte.

Wie sich dann diese neue Rechtstheorie im einzelnen entfaltete, das wird im zentralen Abschnitt (35-65) in historischer Reihung der »wichtigsten Diskussionsfelder « (von »1. Juristische Rhetorik « bis »12. Rechtsinformatik«) vorgeführt, wobei es ebenso klar wie unvermeidlich ist, daß die einzelnen Episoden »in der Wirklichkeit« häufig miteinander verwoben waren, sich wechselseitig bedingten oder aufeinander bezogen, kurz: der Autor sollte nicht so verstanden und rezipiert werden, als habe er mit seinen glatten Skizzen einen realistischen Diskussionsverlauf wiedergeben wollen. Dies beim benevolenten Leser vorausgesetzt, wird er die einzelnen Abschnitte mit Zustimmung und Gewinn konsumieren. 
Besonders erfreulich ist die nachdrückliche Erinnerung an den Letztbegründer Karl Otto Apel, der gewiß zu Unrecht ganz hinter Jürgen Habermas verschwunden ist (weswegen dieser allerdings nicht gleich zum Chamäleon hätte abgewertet werden müssen). Auch Hans Albert, dem Hilgendorf schon früher gewogen war, wird mehr als ansonsten üblich hervorgehoben, und beifallswürdig ist auch die ständige Mahnung an die überfällige Wiedergutmachung am seinerzeit schmählich verkannten und diffamierten Hans Kelsen.

Friedrich Müller und seine »strukturierende Rechtslehre « kommen mit einem Halbsatz als Nachläufer zur juristischen Hermeneutik (39) sicher ebensosehr bei weitem zu schlecht weg wie Niklas Luhmann bei dem (aus dem skurrilen Gerd Roellecke gepflückten) Vergleich seiner Gesellschaftstheorie mit der Metaphysik Hegels.

Doch wie dem auch sei - jeder Liebhaber der Rechtstheorie hat seine Helden und verfügt über anders geeichte Gewichte. Erst wenn die Zeitgeschichte in Geschichte übergegangen sein wird, kann man »wissen«, wer für den vorläufigen Sieger gehalten werden darf und ob die von Hilgendorf festgestellten (67-69) »Rezeptionslücken« (Logischer Empirismus, Utilitarismus, Feminismus u.a.) immer noch für solche gehalten werden.

Auch die Frage nach dem »Ertrag « der ganzen Mühen wird kaum kommentarlos in der Sicht von Hilgendorf zu den Akten genommen werden. Wenn er sagt: »Carl Schmitt wird bewundert, Hans Kelsen und Gustav Radbruch abgelehnt oder ignoriert « (73), dann werden sich gewiß nicht wenige melden, die Schmitt ablehnen, Kelsen bewundern und Radbruch (zu Unrecht) nicht ignorieren. Auch daß sich eine erneute Renaissance der Rechtstheorie anbahnen könnte (74), ist angesichts des Umstandes, daß der Verfasser dieser Vermutung gerade an ihrer Historisierung gearbeitet und damit zu ihrer Musealisierung beigetragen hat, nicht sonderlich plausibel.

Richtig bleibt, daß »die Rechtstheorie die alten metaphysischen Systemgebäude und theologischen Lehrsätze an den Rand gedrängt hat « (74). Das war freilich schon lange vor 1965 der Fall, wie man vor einigen Jahren von Annette Brockmöller lernen konnte. Ob die Metaphysik allerdings dort bleiben wird, muß angesichts der besorgniserregenden Zunahme religiöser Fixierungen und esoterischer Spekulationen einstweilen dahingestellt bleiben.

\section{Viehweg \& Launhardt}

Helmut Coing gab seiner Rezension den Titel »Über einen Beitrag zur rechtswissenschaftlichen Grundlagenforschung «(ARSP 41, 1954/55, 436-444). Es war, stellt man die kühle Strenge des Rechtshistorikers, Rechtsphilosophen und Zivilrechtlers Coing in Rechnung, eine enthusiastische Besprechung. Sie galt der kleinen 75seitigen Schrift »Topik und Jurisprudenz«, die Theodor Viehweg 1953 als Ausarbeitung eines Vortrages aus dem Jahre 1950 hatte erscheinen lassen. Viehweg habe, so Coing, das »Wesen des juristischen Denkens untersucht « und mit seinen Ergebnissen der Methodologie einen »Weg ins Freie « gewiesen. Die damit formulierte Hoffnung des Juristen, es würden sich Wissenschaftler finden, die sich jenseits von Positivismus (das hieß: Begriffsjurisprudenz) und Soziologie (das hieß: Interessenjurisprudenz) 
auf den Weg in die methodische Freiheit machen würden, ging allerdings nicht in Erfüllung.

Die Zunft verbaute sich den Zugang zu dem Problem, wie sie angemessen denken und verfahren solle, durch Konzentration auf die Frage, was das »Wesen« ihres Denkens ausmache. Es entspann sich eine, teilweise recht heftig geführte, rechtstheoretische Debatte über die Alternative »Problemdenken« oder »Systemdenken«, die unter dem Stichwort »Topikdiskussion« in die Annalen der Rechtstheoriegeschichte eingegangen ist.

Ohne greifbares Ergebnis kam diese Diskussion nach etwa zwei Jahrzehnten zum Erliegen - alsbald nach der von Gerhard Otte 1970 vorgetragenen und bezeichnenderweise im 1. Heft der neugegründeten Zeitschrift »Rechtstheorie« publizierten Zusammenfassung (Zwanzig Jahre Topik-Diskussion: Ertrag und Aufgaben, 1970, 183 ff.).

Einem am Sekundärschrifttum orientierten Rückblick aus der Gegenwart muß sie als ein reichlich unfruchtbares Gezänk um eine kaum plausible Antithetik erscheinen, die schließlich (vor allem durch Martin Kriele, Theorie der Rechtsgewinnung, 1967) in einem Kompromisskonzept (»offenes System«) aufgelöst und im Sowohl-als-auch zur verdienten Ruhe getragen wurde.

Als deutliches Verdienst der Topikdiskussion könnte demgegenüber der Umstand verbucht werden, daß die - mit dem Stichwort »Topik« unvermeidlich in Erinnerung gebrachte - Rhetorik die Aufmerksamkeit der Juristen wieder auf das persuasive Reden und Begründen lenkte und damit die Weichen für jene Geleise stellte, auf denen heute gelegentlich bescheidene Bähnchen mit der Aufschrift »Rechtsrhetorik « oder »rhetorische Rechtstheorie« dahinrollen.

Agnes Launhardt hat in ihrer Dissertation (Topik und Rhetorische Rechtstheorie. Eine Untersuchung zu Rezeption und Relevanz der Rechtstheorie Theodor Viehwegs, Diss. Düsseldorf 2005, XX + 191 S.) genau dieses wissenschaftshistorische Gemälde ins Visier genommen und es mit einer überaus eindringlichen, umfassenden und kompetenten Viehweg-Lektüre auf seine Plausibilität befragt. Die Untersuchung, welche naturgemäß mit den seinerzeit gestellten Fragen beginnt, arbeitet sich schnell zu den nicht gestellten Fragen vor und diskutiert alsdann (wenn auch ohne bemerkenswerten Ertrag) die Möglichkeiten zeitgenössischer Anschlüsse (»Relevanz«).

Nicht zuletzt aufgrund der erschöpfenden Literaturverarbeitung ist ein präzises Bild der »Topikdiskussion« entstanden, das keiner Ergänzung bedarf. Auch wenn die Protagonisten, Mitläufer und Nachbeter sowie deren Leistungen, Missverständnisse und Unverschämtheiten auf der Folie eines gelegentlich allzu optimistisch rational rekonstruierten Viehweg geschildert werden, bleibt der Eindruck, den diese Auseinandersetzungen erwecken - akzeptiert man sie als Normaltypus einer deutschen rechtstheoretischen Grundsatzdebatte - deprimierend. Was absichtliche und unabsichtliche Fehldeutungen, Unterstellungen, Imponiergehabe, Luftblasen und Belehrungsresistenz angehen, unterscheidet sich diese Diskussion in keiner Weise von einer politischen Debatte, bei der die Bereitschaft, sich vom »eigentümlich zwanglosen Zwang des besseren Arguments« (Habermas) überwältigen zu lassen, ebenfalls kaum entwickelt ist.

Launhardt beginnt den ersten Teil ihrer Arbeit (Intention und Rezeption von »Topik und Jurisprudenz«) mit einem »möglichst ungefärbten Überblick über die Gedanken- 
führung Viehwegs«, also mit einer Nacherzählung, über deren Wert man verschiedener Meinung sein kann. Da die Verfasserin jedoch nicht beabsichtigt, die Exegesen, die Viehweg seinen wichtigsten Gewährsleuten (Aristoteles, Vico, N. Hartmann) angedeihen läßt, philosophiehistorisch auf Stringenz und Plausibilität zu überprüfen, sondern seine Konzeption von Problemdenken und Systemdenken zum Ausgangspunkt ihrer Rekonstruktion der Erörterungen nimmt, ist die Nacherzählung als Einleitung und Erinnerung jedenfalls nicht unwillkommen.

Ganz durchzuhalten ist die Kritikabstinenz allerdings nicht. Gelegentlich muß zur Verdeutlichung dessen, was Viehweg dachte, eben doch geprüft werden, was jener Gewährsmann, auf den er sich zur Legitimation seines Entwurfs beruft, eigentlich gemeint hat. Die Arbeit ist also in diesem Punkt nicht völlig konsistent. Und es werden auch Chancen zur Erklärung von Missverständnissen unter den Viehweglesern vergeben.

So hat etwa bei der ersten und Hauptfrage, nämlich bei der Überlegung, ob das juristische Denken seinem »Wesen« nach topisch oder systematisch sei, die umstandslose Erfindung des topischen Denkens durch Viehweg und die Zuschreibung dieses Denkens an die antike Rhetorik bei der Rezeption dieser Frage keine unbeachtliche Rolle gespielt. Launhardt weist mit Recht darauf hin, daß der Gedanke, über die Topik könne die Jurisprudenz mit Rhetorik infiziert werden, »vielerorts eine geradezu reflexhafte Abwehrhaltung « hervorgerufen habe. Als Beleg zitiert sie Canaris, der von dem »schweren Missgriff « faselte, daß Viehweg nicht eindeutig gegen die Rhetorik Stellung bezogen habe, sondern »offenbar auch diese Komponente der Topik [sic!] für seine Analyse der Jurisprudenz nutzbar machen« wolle.

Tatsächlich kennt die antike Rhetorik weder ein bestimmtes, »Topik « genanntes Verfahren noch eine Denkmethode oder ähnliches - schon deshalb nicht, weil es den Begriff »Topik « überhaupt nicht gab. Am besten informiert in dieser Hinsicht der gelegentlich etwas bornierte, aber immer um Klarheit und Vollständigkeit bemühte Quintilian.

Auf die loci (topoi) kommt er im Abschnitt über die Beweisführung (probatio) zu sprechen, dem wichtigsten Teil der Gerichtsrede (genus iudiciale). Unter den Beweisen, die einen Einsatz rednerischen Könnens verlangen (probationes artificiales), ragen die Argumente, also die beweisgebenden Vernunftgründe (rationes probationem praestantes) heraus. Nach diesen Argumenten wird an jenen Orten gefahndet, an denen sie sich aufhalten, wie die Fische, die an manchen Plätzen stehen und an anderen nicht. Der Argumentefischer ist also gut beraten, wenn er sich mit diesen Orten vertraut macht: locos appello sedes argumentorum, in quibus latent, ex quibus sunt petenda (Inst.Or.5.10.20).

Genau in diesem Sinne hat man auch die »topika« des Aristoteles zu verstehen, nämlich als eine Sammlung von (rund 300) Örtern, an denen man Argumente für die Bildung von Prämissen für dialektische oder rhetorische Schlüsse finden kann. Keine Spur von »Topik als Techne des Problemdenkens«.

Neben dieser konkret-örtlich gedachten Bedeutung von locus kennt Quintilian lediglich noch die Verwendung des Ausdrucks im Sinne von locus communis (Inst. Or. 2.4.22). Hiermit wird ein in den Redeübungen immer wiederkehrender typischer Sach- 
verhalt oder eine schablonenhafte Figur (»der Spieler«, »der Ehebrecher« etc.) bezeichnet - eine Verwendung von »topos «, die bis heute bei Philologen und Historikern lebendig geblieben ist, wie beispielsweise eine kürzlich erschienene systematische Beschreibung byzantinischer Heiligenlegenden mit dem Titel »Der hagiographische Topos « signalisiert.

Wenn Viehweg sich demnach für sein »Problemdenken« nicht auf die topoi/loci der griechisch-römischen Rhetorik berufen kann, dann bedeutet das zunächst nur, daß eine anscheinend von ihm als erforderlich oder wenigstens nützlich empfundene historische Legitimation an der griechisch-römischen Antike entfällt.

Es muß allerdings bezweifelt werden, daß die Debatte einen wesentlich anderen Verlauf genommen hätte, wenn Viehweg auf die Zitierung der Antike verzichtet und seinen Versuch, die Jurisprudenz als einen Fall des (primären) Problemdenkens zu erweisen, lediglich an den entsprechenden Anregungen festgemacht hätte, die Nicolai Hartmann für die Philosophie gegeben hat.

Denn Launhardts sanfte Bemerkung, es dränge sich ihr der Eindruck auf, »daß bei manchen Autoren das Bedürfnis, schon den bloßen Gedanken an einen Angriff auf das ,juristische Systemdenken“ abzuwehren, das Interesse an einer genauen Prüfung des viehwegschen Ansatzes überwogen hat «, ist wohlbegründet. Anstelle einer genauen Analyse, wie sich Viehweg die Operationen des juristischen Verstandes zwischen Problem (von dem er naturgemäß ausgehen muß, weil ihn erst dieses auf den Plan ruft) und System (was er zumindest als »Ordnung « anstreben wird) vorstellen könnte, wurde ihm flugs eine grobe Antithetik zwischen Problem und System und ein (nie gehaltenes) Plädoyer für Systemverzicht aus »Systemfeindschaft« unterstellt.

Mit der Folge, daß Viehweg als einer erschien, der reihenweise die heiligen Kühe der Systemdenker (Gesetzesbindung, Gleichheitssatz, Rechtssicherheit etc.) ins Schlachthaus trieb und stattdessen eine unerwünschte Freiheit im Sinne von Willkür in Aussicht stellte. Historisch und philosophisch wenig erleuchtete Scharfrichter, allen voran die beiden Larenzschüler Canaris und Diederichsen, erkannten auf der Stelle, daß Viehwegs Ansichten »jeder juristischen Geltungslehre Hohn« sprachen, weshalb er auch ein »Bekenntnis zur geltenden Rechtsordnung « vermissen lasse, so daß »Billigkeitsrechtsprechung « und »Willkür« drohte, die zu einem »Rückfall in primitive Frühformen des Rechts« führen müssten.

Launhardt widerlegt diese peinlichen Anwürfe umsichtig und vornehm, indem sie zeigt, daß eine sorgfältige Lektüre der Äußerungen Viehwegs ohne Mühe erkennen läßt, daß dieser zu den definitorischen Elementen des Systemdenkens den Eindeutigkeitsanspruch zählt, daß er eine das Wissen limitierende Endgültigkeitsidee nicht hegt und daß er das (für das Rechtsdenken typische) Wechselspiel zwischen Problem und System sehr wohl in Rechnung stellt.

Da seine Widersacher ihrerseits dem Problemdenken nicht jede Berechtigung bestreiten konnten, läßt die penible Feder von Launhardt vor dem inneren Auge des Lesers allmählich das Optimismus/Pessimismus-Syndrom entstehen: Viehweg, der zeigt, daß das Glas halbleer ist, und seine Gegner, die mit großem Getöse klarstellen, daß es in Wahrheit halbvoll sei. Die Verfasserin läßt diesen Argwohn allerdings nicht gelten. Für sie geht es um zwei Gläser, von denen eines voll und eines leer ist. 
Mit großem Scharfsinn und in bravouröser Auseinandersetzung mit Altmeister Kriele, den sie sich als Repräsentanten jener Kompromissler ausgesucht hat, die den Gegensatz von Problemarbeit und Systemarbeit im »offenen System« untergehen lassen wollen, ermittelt sie einen grundlegenden Gegensatz zwischen Problemdenken und Systemdenken (89 ff). Er soll - und das ist durchaus plausibel - in der Gleichzeitigkeit inventiver und deduktiver Elemente beim Problemdenken gegenüber den konsekutiv unterscheidbaren Operationen des Systemdenkens bestehen.

Weniger plausibel ist allerdings, daß der Leser diese Überlegungen im Text von Viehweg finden soll. Wer dort nachliest, wird rasch entdecken, daß er es wenigstens mit einer benigna interpretatio, häufiger aber mit einer radikalen rationalen Rekonstruktion zu tun hat. Mit anderen Worten: Launhardt ist Viehweg.

Das wird noch deutlicher, wenn es im nächsten Abschnitt der Arbeit darum geht, Viehweg gegen die Vorwürfe der Gleichsetzung von Topik und Aporetik einerseits, der überflüssigen Bezugnahme auf die Aporetik von Nicolai Hartmann andererseits zu verteidigen.

Unter den vielen Spielzügen, mit denen Launhardt die Viehweggegner in die Ecke drängt, mag als Beispiel und Beleg für den Umfang, in welchem Launhardt ihren Helden weiter und zu Ende gedacht hat, ihre Deutung eines von Viehweg leichtfertig vorgelegten Hartmannzitats angeführt werden. Hartmann hatte bemerkt, daß die aporetische Denkweise nicht daran zweifle, »daß es das System gibt und daß es vielleicht in ihrem eigenen Denken latent das Bestimmende ist. Darum ist sie seiner gewiß, auch wenn sie es nicht erfaßt $\ll$.

Den Systemdenkern (und nicht nur ihnen) mußte dies als ein gnädiges Eigentor Viehwegs erscheinen. Folgerichtig und ohne Zögern haben Canaris und Kriele sich für ihre metaphysischen Systemkonstruktionen auf dieses Philosophenwort berufen.

Launhardt zeigt kurz, daß das Verhältnis überpositives System versus Rechtsordnung dem (naturwissenschaftlich bewährten) Verhältnis objektives System versus wissenschaftliches System entspricht; daß die Übertragung des letzteren auf das erstere mangels beschreibungsunabhängiger Vorgaben zwangsläufig ins Abseits führt, und endet mit der Feststellung »nach Viehweg « komme »dem , vorausgesetzten System “ im Bereich aporetischer Fragestellungen der Stellenwert eines ,methodologischen Apriori` zu, das es ermöglicht, gewonnene Problemlösungen als angemessen und nicht kontingent zu betrachten, obwohl sich die ihnen letztlich zugrunde liegenden (inter-) subjektiven Vorstellungswelten tatsächlich einer allgemeingültigen und objektiven Beurteilung entziehen $\ll$.

Man hätte das gern bei Viehweg gelesen.

Erst gegen Ende dieses besten und anspruchsvollsten Teiles ihrer Untersuchung lüftet Launhardt ihre Verkleidung ein wenig und entwickelt ihre beifallswürdige Konzeption des Rechtssystems offener unter der Prämisse »ausgehend [!] von der Konzeption Viehwegs «. Ihre Vorstellung, daß man das Rechtssystem funktionell als dogmatisches (also festschreibendes, nicht zetetisch erkenntnisorientiertes) System aufzufassen habe, in dem strukturell eine latente Wirksamkeit des Problemdenkens zu beobachten sei, besitzt schon deshalb Plausibilität, weil sie nicht normativ auf Anleitung, sondern auf Beschreibung und Erklärung angelegt ist. 
Der zweite Teil der Dissertation (Von der Topik zur rhetorischen Rechtstheorie) behandelt die Fortentwicklung des Viehweg'schen Rechtsdenkens. Das ist allerdings weder soweit das Verhältnis der Rechtsphilosophie zur Rechtswissenschaft und zur Rechtsdogmatik betroffen ist, noch soweit es der argumentativen Struktur eines entscheidungsbezogenen juristischen Denkens nachspürt, sonderlich eindrucksvoll, so daß die Begeisterung, mit der die Autorin schildert, daß Viehweg »natürlich« alle Defizite gekannt habe und sich der mangelnden Neuheit seiner Ideen bewusst gewesen sei, etwas anstrengend ist.

Für diese Anstrengung wird man jedoch durch die abschließende, ziemlich detaillierte Schilderung der »Mainzer Schule« entschädigt. Von Ballweg bis Sobota (Katharina Gräfin von Schlieffen) bekommt man einen informativen und präzisen Überblick über die Entwicklungen und Leistungen der Schule in Rechtsrhetorik einerseits, rhetorischer Rechtstheorie andererseits geboten.

Wer sich also auch nur nebenbei für das Schicksal der Rhetorik bei den Juristen von 1950 bis heute interessiert, kann keinen besseren Führer als Agnes Launhardt engagieren.

\section{L'art pour l'art}

Der Boden, auf dem die juristischen Grundlagenfächer gedeihen, hat schon manche Frucht hervorgebracht. Die Rechtsgeschichte kommt von dort, in neuerer Zeit die Rechtssoziologie, noch jüngeren Datums ist die Taufe der Rechtslinguistik und gänzlich ungetauft sind bizarre Gewächse wie Rechtsakustik oder neurobiologische Rechtswissenschaft. Dann steht dort natürlich der Monolith der Rechtsphilosophie, dessen Zusammensetzung sich allerdings auch nicht gerade homogen ausmacht: genannt seien formale und materiale Rechtsphilosophie, Rechtsphilosophie im weiteren und im engeren Sinne, klassische Rechtsphilosophie, Rechtsethik, Rechtswertlehre, Rechtsphänomenologie oder Rechtsideenlehre.

Mit solcherlei Erscheinungen beschäftigt sich neuerdings Andreas Funke, ${ }^{3}$ der es sich zur Aufgabe gemacht hat, inmitten dieses Urwalds von juristischen Nachtschattengewächsen eine allgemeine Rechtslehre auszumachen, die der Rechtsordnung und ihrer postulierten Einheit auf den Grund geht (80): ein »allgemeiner Teil der Rechtswissenschaft «, »Theorie der juristischen Erkenntnis« (75). Den Ort dieser allgemeinen Rechtslehre vermutet er zwischen Rechtsdogmatik und Rechtsphilosophie (11). Verdeckt wird er allerdings durch die eben zitierten rechtsphilosophischen Richtungen, die sämtlich Eingang in Funkes Werk gefunden haben und das Unterfangen einer eindeutigen Abgrenzung nahezu unmöglich erscheinen lassen. Die Suche wird außerdem durch die Vielzahl der Rechtstheoretiker erschwert, die zur Zeit der Wende vom 19. zum 20. Jahrhundert unter dem Oberbegriff der Allgemeinen Rechtslehre geforscht haben und bei Funke nahezu vollzählig versammelt sind (20-38). Dem personellen

3 Andreas Funke, Allgemeine Rechtslehre als juristische Strukturtheorie. Entwicklung und gegenwärtige Bedeutung der Rechtstheorie um 1900 (Grundlagen der Rechtswissenschaft Band 1),Tübingen: Mohr Siebeck, 2004, 338 S. 
Reichtum entsprechend strotzt das Erbe der einschlägigen Denker von begrifflichen und inhaltlichen Differenzen, und man beneidet denjenigen nicht, der aus diesem Durcheinander eine Einheit herauspräparieren möchte.

Doch das Stöbern in der rechtstheoretischen Mottenkiste hat sich gelohnt. Die Hinterlassenschaften bekannterer Rechtslehrer fördert Funke dabei genauso zutage wie Kuriositäten gänzlich vergessener Wissenschaftler. Ans Licht kommen juristische Prinzipienlehre, juristische Grundlehre, historische allgemeine Rechtslehre, strukturale allgemeine Rechtslehre, reine Rechtslehre, Rechtsverhältnislehre, analytische Rechtstheorie und sogar eine »Morphologie und Biologie des Rechts « (31); die Urheber dieses Grundlagenkabinetts sind wissenschaftshistorische Größen wie Merkel, Bergbohm, Bierling, Somló, Stammler, Radbruch oder Kelsen, die sich in Funkes Darstellung neben versprengten Vertretern aus dem Schattenreich der theoretischen Bedeutungslosigkeit wiederfinden: Alexander Nicol-Speyer etwa oder Bernhard Stark, über welche die Fußnote nur zu berichten hat, »nähere Informationen über die Person « hätten »nicht ausfindig gemacht werden« können (31 Fn. 153, 33 Fn. 163).

Damit zerrt Funke so manchen Denker ans Licht, dessen Werk im letzten Jahrhundert keinen Eingang in die wissenschaftliche Diskussion gefunden hat. Schon dies ermöglich interessante Einblicke in die Entwicklungsgeschichte der Rechtstheorie. Darüber hinaus sind auch die bekannteren Repräsentanten der Rechtslehre gewöhnlich nicht unbedingt Objekt übertriebener Aufmerksamkeit, und umso erfreulicher ist es, wenn ihre Werke von Funke mit gewisser Ausführlichkeit und bemerkenswerter Souveränität dargestellt werden. Nach einer längeren Einleitung (1-38) benötigt Funke so immerhin 80 Seiten, um »Genese und Inhalt der strukturtheoretischen Fragestellung « auszubreiten (39-119). Den gleichen Raum hat er der strukturtheoretischen Methode (120-196) und ihrem Gegenstand (197-279) eingeräumt und auf diese Weise sichergestellt, daß auch Einzelheiten und Partikularitäten angemessen behandelt werden können.

Den Überblick verliert Funke dabei allerdings nicht. Durch die Skizzierung eines »Zentrums der Allgemeinen Rechtslehre« (18-29) kann er auch die Forscher aus der Peripherie zu Wort kommen lassen, ohne aus den Augen zu verlieren, was sie zu seinem Forschungsprogramm beizutragen haben. Für den rechtstheoretisch Interessierten sind Funkes Studien deshalb von hohem Gewinn. Nicht nur die zwergenhafte Rechtstheorie der Gegenwart kann ohne das Studium ihrer riesenhaften Vorgänger schwerlich angemessen bewertet werden. Auch die Überväter der Vergangenheit und ihr gedankliches Treiben erklären sich zu einem Gutteil erst durch einen Blick auf die Schultern, auf denen sie sich niedergelassen haben. Für eine vertiefte Auseinandersetzung mit Kelsen etwa dürfte die Beschäftigung mit Bierling und Somló überaus hilfreich sein - beispielsweise wenn man dadurch erfährt, daß Somló die Trennung von Recht und Moral in seinem Begriff der Rechtsnorm deutlich konsequenter durchgeführt hat als nach ihm Kelsen (218 f.).

Funke macht auf diese Weise deutlich, welches Potential in der Allgemeinen Rechtslehre für die weitere Forschung im Grundlagenbereich steckt. Ihre positivistische Ausrichtung, ihr formaler Umgang mit dem rechtswissenschaftlichen Material und die Ansätze funktionaler Betrachtung des Rechts machen die Allgemeine Rechts- 
lehre in vielerlei Hinsicht zum Wegbereiter gegenwärtiger Theorieströmungen. Manche ihrer Inhalte könnten sicherlich mit den Begrifflichkeiten der modernen Systemtheorie deutlich besser gefaßt werden, als dies ihren Begründern selbst möglich war. Insbesondere die Begriffe des Rechts und seiner Geltung oder der Stufenbau der Rechtsordnung dürften von der Unterscheidung zwischen Beobachtung erster und zweiter Ordnung erheblich profitieren, wie auch die Allgemeine Rechtslehre insgesamt, die sich ihrem Programm gemäß als Beobachtung zweiter Ordnung verstehen kann. Doch Funke kommt das Verdienst zu, durch seine differenzierte und detaillierte Darstellung darauf aufmerksam gemacht zu haben, daß hier für die Rechtstheorie der Gegenwart noch einiges zu holen ist. Knapp und luzide zusammengefaßt finden sich die Ergebnisse der Arbeit in den beiden Schlußkapiteln (280-292).

Am Ende von Funkes Reise durch die rechtsgelehrte Vergangenheit steht jedoch eine Umschreibung der Allgemeinen Rechtslehre, von der noch nicht ausgemacht ist, ob sie mehr als nur intuitiv nachvollzogen werden kann. Viel ist von »einheitlichen Grundbegriffen« (86) die Rede, von Strukturen und Organisationsprinzipien, von einer »Immanenz des Rechts« (7), von einer »rationalen, systematischen Rechtsdogmatik « (86) - Allgemeine Rechtslehre als »eine von Substantialität und Normativität befreite Begriffsjurisprudenz« (113), als »Methodologie der Rechtsdogmatik« (115), wohl grundlegend als Metawissenschaft der Rechtswissenschaft. Die Vorstellung, der Rechtsdogmatik oder gar der gesamten Rechtswissenschaft durch die strukturierende Beobachtung der Allgemeinen Rechtslehre Kohärenz, Rationalität und Homogenität zu verpassen, ist zwar überaus attraktiv - zugleich aber auch ein recht optimistisch formuliertes Programm, das sich von einer Hypostasis des Rechts abhängig macht, deren Möglichkeit in den letzten Jahren erheblich an Plausibilität verloren hat. Deshalb müßte sich auch eine Strukturtheorie des Rechts mehr Klarheit darüber verschaffen, wessen Strukturen sie eigentlich untersuchen will. Denn die einfache Ersetzung des untergegangenen Erkenntnisgegenstandes durch die »interpretative Praxis« der Rechtsanwender (117 mit Fn. 442) übersieht, daß es hier um mehr geht als um den bloßen Austausch verschiedener Vorfindlichkeiten: um einen Paradigmenwechsel von Kognition zu Kommunikation nämlich. Diese Umstellung sollte auch in einer Allgemeinen Rechtslehre Berücksichtigung finden, welche »die Basis und das Rahmenwerk für alles weitere « (Funke zitiert Alexy, 88) liefern will: die Suche nach dem Grund des Rechts kann von der Entdeckung seiner Grundlosigkeit nicht unbeeindruckt bleiben.

Auch Funke ist dies freilich nicht entgangen. Das Ziel der Allgemeinen Rechtslehre schränkt er deshalb auf Erklärung statt Rechtfertigung der Rechtsordnung ein (45): »Das Recht wird so genommen wie es ist « (42). Diese Ausflucht in die Positivität des Rechts verlagert die Schwierigkeiten allerdings nur, löst sie aber nicht. Denn die Gesetztheit des Rechts liefert der Allgemeinen Rechtslehre nur durch die Vermittlung der Rechtsdogmatik einen tauglichen Erkenntnisgegenstand (78); die Allgemeine Rechtslehre kann allenfalls beobachten, wie die Rechtsdogmatik Recht beobachtet. Wenn es sich die Allgemeine Rechtslehre daraufhin zur Aufgabe macht, das von der Dogmatik produzierte Recht als Rechtsordnung zu begreifen und zu analysieren, dann zeitigt dies zwei Probleme, die noch der Bearbeitung harren: 
Einerseits bedeutet die Abhängigkeit von der Positivität des Rechts, daß auch die von der Allgemeinen Rechtslehre destillierten Grundbegriffe in ihrer Existenz von der gesetzgeberischen Tätigkeit abhängen. Dies läßt sich zwar prinzipiell durch ein dynamisches Verständnis des Rechtssystems auffangen (80 f.); von einer »Unfähigkeit des Gesetzgebers, über gewisse strukturtheoretische Erkenntnisse zu verfügen « (137), kann jedoch keine Rede sein.

Und sofern doch davon die Rede ist, kommt das zweite Problem in Sicht: Die wissenschaftliche Strukturierung und Systematisierung des Rechtsstoffes ist traditionell Aufgabe der Rechtsdogmatik selbst, und der Emanzipierung einer Allgemeinen Rechtslehre dürfte es nicht zuträglich sein, wenn sie in den Gewässern der Dogmatik fischt. Der Unterschied zwischen Allgemeiner Rechtslehre und Rechtsdogmatik ist dann jedenfalls nur gradueller Art. Und das wiederum provoziert die Frage, warum neben einer praktisch ausgerichteten Rechtswissenschaft auch eine theoretisch angelegte Disziplin notwendig oder wenigstens nützlich sein soll.

Diese Frage ist offenkundig so alt wie die Allgemeine Rechtslehre und wahrscheinlich wie die gesamte Rechtstheorie. Auch Funke behandelt sie beiläufig (etwa: 81, 114) und scheint dem »Standardeinwand « (81) der rechtsdogmatischen Unbrauchbarkeit begegnen zu wollen, indem er die Allgemeine Rechtslehre in den Stand einer Metadogmatik erhebt. Dieser Versuch erklärt sich vermutlich daraus, daß die Berechtigung rechtswissenschaftlicher Arbeit nur dann nicht angezweifelt wird, wenn sie etwas zur Bewältigung aktueller Rechtsfragen beizutragen hat, und es deshalb immer ratsam scheint, Anschluß an die Erfordernisse der Rechtspraxis zu suchen oder wenigstens zu behaupten. Folgerichtig künden auch die Herausgeber der Reihe »Grundlagen der Rechtswissenschaft « (Horst Dreier, Ulrike Seif, Michael Stolleis), deren erster Band Funkes Arbeit ist, von der praktischen Nützlichkeit rechtstheoretischer Forschung und frohlocken im Klappentext, die »Beschäftigung mit Grundlagenfragen« helfe »bei der Beantwortung konkreter Rechtsfragen«. Auf einen Standardeinwand also eine Standardantwort - wobei die Behauptung, Rechtstheorie könne Fälle lösen und sei im Grunde doch Rechtspraxis, der Bestätigung harrt, seit sie aufgestellt wird.

Wenn aber die praktische Dienlichkeit juristischer Reflexion trotz aller Versuche nicht zu beweisen ist, dann ist die Schlußfolgerung, Rechtstheorie sei überflüssig, nur eine der möglichen Konsequenzen. Die andere ist die Verabschiedung von dem Ausgangspunkt, es könne nur das gut sein, was nützlich sei; eine Prämisse, deren rigorose Durchsetzung ohnehin neben den Grundlagenfächern auch einem Großteil der Dogmatik das Gütesiegel verweigern müßte: andere Ansichten, Minderheitsmeinungen, an denen die Literatur genauso verbissen festhält wie sie vom Bundesgerichtshof ignoriert werden, unzählige Beiträge, in denen der Autor die Mitteilung zum Fortschritt erhebt, er habe seine Ansicht noch immer nicht geändert, 150 Jahre studentische Langeweile mit Rose und Rosahl - all das müßte dem utilitaristischen Hackebeil zum Opfer fallen, würde es überall so unbekümmert geschwungen wie über dem Haupt der juristischen Grundlagenfächer. Und damit ist noch nichts über die prinzipielle Daseinsberechtigung einer Dogmatik gesagt, die sich widerstandslos bis fröhlich der immer weiteren Zersplitterung des Wissens hingibt und sich mit dem Verzicht darauf, ein 
kohärentes und widerspruchsfreies Rechtssystem zu bilden, schon lange von der vornehmsten der ihr herkömmlich zugedachten Aufgaben verabschiedet hat.

Das Gerede von der rechtspraktischen Nützlichkeit ist deshalb so undurchdacht wie unbegründbar. Die Brauchbarkeit theoretischer Anstrengungen kann nicht erwiesen werden; sie kann sich nur selbst erweisen - oder eben nicht. Bis sie das getan hat, kann man sich mit Alexander Someks Hinweis auf die »intellektuelle Gesundheit« trösten, der die Rechtstheorie dienlich ist (Das Ganze des Rechts, $\operatorname{Rg} 7,184-186,186$ [Rezension zu Funke]). Oder aber Somló befragen, der schon 1917 eine »Binsenweisheit « genannt hat, was heute gerne als Erkenntnisgewinn gefeiert wird: daß nämlich »die letzte Grundlage eines Systems von (Rechts-)Normen nicht eine Norm dieses Systems sein kann« (Juristische Grundlehre, Leipzig 1917, 320). Sofern sich jedoch die Rechtstheorie um diese außerrechtliche Grundlage bemüht, kann sie etwas in die Forschungsperspektive einschließen, was der juristischen Sichtweise verborgen bleiben muß: eine Einheit des Rechts nämlich. Klar ist, daß die Rechtstheorie dann nicht mehr Recht, sondern Wissenschaft betreibt. Aber nur die institutionelle Anbindung dieser Perspektive an das Recht nährt die Hoffnung, daß so etwas wie Rechtswissenschaft doch noch möglich ist.

\section{Zeitenwandelresistent}

Nicola Rowe hat eine Lücke entdeckt. ${ }^{4} \gg$ Keine der heute anerkannten Auslegungslehren bietet dem Normausleger eine in ausreichendem Maße fundierte Erklärung dafür, wie auszulegen ist, wenn sein Ermittlungsapparat, die Sprache, selbst im Wandel begriffen ist.« (23) Die canones der Auslegung sind nach Rowes Ansicht also unvollständig, da sie diesem »seltenen, aber dennoch rätselhaften Problem« (23) nicht zufriedenstellend beikommen können. Das läßt aufhorchen, steht doch zu befürchten, daß ein nur lückenhafter Bestand an Methoden dem zweiten Teil der Bezeichnung Rechtswissenschaft die Daseinsberechtigung entzieht. Um diese Gefahr zu bannen, stellt Rowe dankenswerterweise die bisher übersehene Frage, wie »eine gesetzliche Norm auszulegen [sei], wenn sich die semantische Tragweite eines ihrer Worte seit dem Erlaß gewandelt hat«, und wie es erklärt werden könne, daß der »Richter den sprachlichen Wandel eines Wortes oft nach[zeichne]«, also »sprachwandelkonform« auslege (23).

Schon diese Formulierungen lassen vermuten, daß Rowe weder vom Recht noch von der Sprache Belangvolles zu berichten hat. Bestätigt wird diese Ahnung im Verlauf der restlichen 170 Seiten. Sinnvoll gestellt werden kann die Ausgangsfrage schließlich nur dann, wenn eine im Regelfall statische Sprache und sicher feststellbare Wortbedeutungen unterstellt werden, die sich nur im Ausnahmefall ändern, und diese Annahmen gehören in der Tat zu Rowes Prämissen. So kann sie freimütig von der »potentiellen Zulässigkeit einer Bedeutung « (37) sprechen, vom »freien sprachlichen

4 Nicola Rowe, Recht und sprachlicher Wandel. Entwicklung einer institutionellen Auslegungstheorie. (Studien zur Rechtsphilosophie und Rechtstheorie Band 34), Baden-Baden: Nomos, 2003, 209 S. 
Wandel«, der »innerhalb der Wortlautgrenze « (!) stattfindet (78), oder von der Seltenheit der Fälle, »in denen der semantische Wert der Worte des Normtextes einem sprachlichen Wandel unterzogen worden ist « (78). Damit dokumentiert sie, daß sie in einer Welt lebt, in der Äußerungen, welche nicht dem linguistischen Reglement oder den Definitionen der Duden-Redaktion entsprechen, für unzulässig erklärt werden können, die Sprache von einer externen Instanz ab und zu einem Wandel unterzogen wird und Wortbedeutungen im übrigen wie Pilze im Wald herumstehen und sich einem jedem offenbaren, der nur lange genug nach ihnen sucht.

Der empirisch vorgehende Sprachforscher wird auf diese Weise zum Geburtshelfer und zur Kontrollinstanz jeder Theorie der juristischen Interpretation: »Kritik und Analyse sind nur dann möglich, wenn die Grundlage einer Theorie auch unabhängig von den Behauptungen des Autors festgestellt werden kann.« (34) Wenn also Rowes sprachwandelkonforme Anforderungen an die Rechtsanwendung letztlich auf der Frage fußen, »wann denn in zeitlicher Hinsicht die Wortlautgrenze zu ziehen sei« (49), so bedeutet diese Historisierung der semantischen Beschränkungen keinesfalls deren Transzendierung: zu grenzenlos ist Rowes Glaube an die Möglichkeiten der menschlichen Erkenntnis und die Wahrheiten der empirischen Forschung. Ihre Welt ist das Universum des Faktischen, ihre Wirklichkeit heißt Realität, und selbstverständlich können die Begriffskerne der Vergangenheit mit den gegenwärtigen ohne größere Schwierigkeiten verglichen werden. Aus der Empirie wird also eine Art Meta-Rechtstheorie, und selbst phänomenologisch schwer faßbare Sujets wie der Wille des Gesetzgebers, der Zweck des Gesetzes oder der Savignysche Volksgeist werden als Theoriebausteine folgerichtig deshalb kritisiert, weil sie empirisch nicht nachweisbar seien $(54,83,90)$.

Der Vorrang der Empirie geht schließlich sogar so weit, daß aus Unvertretenem Unvertretbares wird $(83,85)$ und die sogenannten »Mindermeinungen « $(61)$ schon deshalb keine kritische Auseinandersetzung erfordern (etwa: 60, 72), weil sie weder »in der Lehre noch in der Praxis befürwortet« (56) werden. Ein solch starkes Bekenntnis zu jener Art von strukturellem Konservatismus, die ohnehin jedem normativen Denken und damit natürlich zuvörderst dem Rechtssystem anhaftet, läßt den »modernen Leser « (145) Schlimmstes befürchten. Tatsächlich wird hier auch deutlich, warum sich die Gesellschaft nach Rowes Ansicht dafür rechtfertigen soll, daß sie die Gegenwart nur im Hier und Jetzt konstruieren kann und ihr außer der Sprache, die sie spricht, keine weitere zu Verfügung steht. Die rechtstheoretische Empörung über diesen Umstand ist ebenso sinnvoll wie etwa die Entrüstung darüber, daß im Jahre 2007 Rechtsfälle produziert werden, für die das BGB von 1896 nicht konzipiert wurde.

$\mathrm{Da} ß$ sich Rowe über die durch die Unaufhaltsamkeit der Zeit bedingten Änderungen der Welt echauffieren kann, liegt vermutlich daran, daß in ihrer theoretischen Welt das Jahr 1960 noch nicht vergangen ist. Wie selbstverständlich nennt sie im Zuge ihrer Darstellung der objektiv-teleologischen Auslegung als Vertreter »in neuerer Zeit« Radbruch sowie Coing, der sich laut Fußnote anno 1959 zum Thema geäußert hat (62). So verwundert es auch nicht, daß Rowe für die Lösung des in ihrer Welt bestehenden Problems auf die Institutionenlehre Maurice Haurious zurückgreift, mit deren Hilfe sie sich vollends in die metaphysische Welt der Eigentlichkeit begibt, um dort 
auf dem »sicheren methodologischen Boden« der Wortlautgrenze (167) bedeutungsschwanger sprachzuwandeln, gerade so, als sei nach dem Tod Haurious im Jahre 1929 weder im Bereich der Sprach- noch der Rechtstheorie Entscheidendes geschehen.

Gänzlich fern der ihr so wichtigen Empirie stützt Rowe ihre Ausführungen auf das »idealistische Postulat abstrakt-absoluter Ideen « und eine daraus abgeleitete »Trennung zwischen dem objektiven Inhalt der Idee und deren subjektiven Indizien« (171). Damit reiht sie sich mühelos ein in die von ihr gegeißelte rechtswissenschaftliche Tradition, in welcher der juristischen Hermeneutik nur der Platz eines »Stiefkindes « eingeräumt sei (33). Ihr »Drei-Phasen-Modell« der Rechtsanwendung (38 ff.) teilt den Vorgang der Auslegung in die Phasen der Auswahl möglicher Deutungen, der Subsumierung des Falles unter die Norm und der Ergebniskorrektur durch übergeordnete Prinzipien wie das der verfassungskonformen Auslegung. Rowe geht also davon aus, der Rechtsanwender trete unbefangen an den Gesetzestext heran, um ihm vorurteilsfrei und methodisch sauber das Ergebnis des konkreten Falles zu entnehmen - ein Modell, in das selbst hermeneutische Gemeinplätze wie das Vorverständnis oder der Zirkel des Verstehens noch keinen Eingang gefunden haben.

Dennoch erfordert die Vorbereitung folgender These immerhin 160 Seiten: »Die gewandelte Bedeutung ist deswegen in Erwägung zu ziehen, weil sie den Einfluß der Träger auf die nach außen zugängliche Form der objektiven Idee darstellt.« (161) Die Rechtsnorm wird also Ausdruck einer objektiven Idee, die als Leitidee der ohne größere Erklärungen als Institution definierten Rechtsnorm (122 f.) sowohl »von den Objekten, die sie verkörpern, als auch von den Individuen, die sie begreifen, unabhängig « ist (142) und zudem nicht erfunden, sondern nur entdeckt werden kann (143). Abgesehen von der allgemeinen Abwegigkeit solcher Behauptungen ist kaum erklärlich, warum der Einfluß eines veränderten Sprachgebrauchs auf die Gesetzesauslegung gerade durch den Rekurs auf objektive und unwandelbare Ideen erhellt werden soll.

So unglücklich wie der Inhalt des Buches, so misslungen ist seine Form. Der Umstand, daß das Recht der Sprache »ausgeliefert« (23) ist, wird von Rowe eindrucksvoll bestätigt. Ihre Sprache ist hölzern, umständlich und oft unverständlich; neben stilistischen Fehlgriffen (»Ausscheidung des Gesetzgebers« [84]), sprachlichen Wirrungen (»sie [die Auslegungstheorie; BL] wäre dann unvollständig, wenn die potentielle Zulässigkeit der gewandelten semantischen Tragweite eines Wortes, das für die Bedeutung eines Normtextes ausschlaggebend ist, trotz ihrer Thesen nicht ersichtlich wäre.« [36 f.]) und schlichtem Nonsens (»Es ist den Urteilen zu entnehmen, daß Bedeutung, die das Wort family zum Zeitpunkt der Anwendung sogar vor der geltungszeitlichen Bedeutung bevorzugt werden soll, es sei denn, das Gericht ist ,plainly satisfied ', daß die moderne Bedeutung aus anderen, im Urteil nicht näher erläuterten Gründen, nicht angebracht wäre.« [74]) enthält die Arbeit so viele unglückliche Formulierungen (»sprachwandelkonforme Auslegung «, »anwendungszeitliche Bedeutung «), daß Rowe offensichtlich selbst nicht ganz überblickt, was sie eigentlich sagen will und die Begrifflichkeiten mehrfach durcheinanderbringt (beispielsweise »entstehungszeitlich « und »geltungszeitlich«: 54, 79, 161).

Bei solcherlei sprachlichen Unzulänglichkeiten überrascht es wenig, daß Rowe gegen Ende der Arbeit immer wieder in offene Widersprüche zu ihrer eigenen Fragestel- 
lung gerät - etwa wenn sie von den die Norm »konstituierenden Worten« (160) spricht und gar nicht bemerkt, daß aufgrund der sprachlichen Konstitution des Rechts der Zusammenhang zwischen sprachlichem und rechtlichem Wandel weder selten noch rätselhaft ist und sich das Problem, auf das die Arbeit antworten möchte, in Luft auflöst.

Daß die Arbeit auch im übrigen sehr schlampig ausgeführt wurde, ist kaum mehr verwunderlich. Man ist daran gewöhnt, daß wissenschaftliche Schriften nur selten einem Lektor unter die Augen kommen; erstaunlich ist jedoch, daß augenscheinlich auch die Durchsicht der Druckfahnen für überflüssig erachtet wurde.

Jedenfalls ist nur so erklärlich, daß das Buch über kaum eine Seite verfügt, die nicht mehrere Druckfehler, vertauschte Worte, fehlerhafte Sätze oder verrutschte Fußnoten enthält. Anzumerken ist dazu nur folgendes: Windscheid hieß mit Vornamen Bernhard und nicht Paul (180), und die von Rowe vermutlich an sich selbst gerichtete fettgedruckte Frage, ob denn Peter Benson Maxwells Werk »Maxwell on Interpretation of Statutes « nach 1969 noch einmal neu aufgelegt wurde (47 Fn. 37), ist zu verneinen.

Was dem Leser bei so vielen unreifen Verwirrtheiten übrig bleibt, ist die Ausflucht in die Interpretation. Allerdings: »Bei vorliegender Absurdität scheint die Wortlautgrenze der Auslegung einen Äußerstrahmen zu setzen.« (48) Auch dieser Ausweg befreit den Leser also nur so weit vom Diktat des Textes, wie es die »stabile Wortlautgrenze« (195) erlaubt. Die Empfehlung kann deshalb nur heißen: Gar nicht erst lesen.

\section{Alle 14 Tage}

Alle zwei Wochen ändert sich irgendwo in Deutschland eine höchstrichterliche Rechtsprechung. Genauer: in Leipzig oder in Karlsruhe, am Bundesverfassungsgericht, am Bundesgerichtshof oder am Bundesverwaltungsgericht. So hat es Lorenz Kähler herausgefunden, der die Rechtsprechung dieser drei Obergerichte aus den Jahren 19952001 einer umfassenden empirischen Analyse unterzogen hat. ${ }^{5} 191$ Entscheidungen konnte Kähler im Untersuchungszeitraum ausmachen, in denen die Gerichte eine frühere Rechtsprechung ausdrücklich änderten (101), und damit etwa 27 im Jahr: alle zwei Wochen ändert sich die Rechtsprechung.

Absolut betrachtet operiert dabei der Bundesgerichtshof mit 20 Änderungen im Jahr am änderungsfreudigsten, in weitem Abstand gefolgt vom Bundesverwaltungsgericht mit rund sechs Änderungen im Jahr (43 in sieben Jahren). Traditionsverliebt erscheint dagegen das Bundesverfassungsgericht mit gerade einmal einer einzigen Rechtsprechungsänderung pro Jahr (acht in sieben Jahren).

Nun sind solche absoluten Zahlen weder leicht zu gewinnen noch unmittelbar aussagekräftig. Schon die Feststellung, wie eine Rechtsprechungsänderung definitorisch erfaßt werden kann, erfordert einige theoretische Anstrengung: Die Gerichte schreiben nicht immer ausdrücklich, daß sie von einer vorherigen Entscheidung abweichen, inwieweit sie das tun, ob der vorliegende Fall einer bereits beurteilten Konstellation

5 Lorenz Kähler, Strukturen und Methoden der Rechtsprechungsänderung (Studien zur Rechtsphilosophie und Rechtstheorie Band 36), Baden-Baden: Nomos, 2004, 428 S. 
wirklich gleichsteht oder ob in relevanten Details eine differenzierte Betrachtung vonnöten ist. Darüber hinaus geht es bei der Feststellung einer Rechtsprechungsänderung im Kern um den Vergleich von zwei Rechtslagen: derjenigen vor der ändernden Entscheidung und derjenigen danach. Rechtslagen aber wachsen bekanntermaßen nicht auf Bäumen, von denen man sie pflücken und anschließend gegeneinander abwägen könnte wie einen Haufen Äpfel; vielmehr ist bereits die Behauptung, eine bestimmte Rechtslage sei so und so beschaffen, in aller Regel das Ergebnis eines erheblichen interpretatorischen Aufwandes, dessen Erfolg wegen der Vorliebe der Judikatur, die Blicke der Analysten mit einem Gewölk von Mehrdeutigkeiten und Leerformeln zu vernebeln, längst nicht in allen Fällen gesichert scheint.

Diesen Schwierigkeiten begegnet Kähler im ersten Teil seiner Arbeit (21-91). Dort bemüht er sich um die Formen und Bedingungen, unter denen eine Abweichung von der bisherigen Rechtsprechung stattfindet. Die Untersuchung ist dabei weitgehend theoretisch angeleitet, das heißt Begriff und Typologie von Rechtsprechungsänderungen werden unabhängig davon inspiziert, ob sie für eine empirische Analyse der Gerichtsurteile fruchtbar gemacht werden können. So beschreibt Kähler etwa stillschweigende (50-52), verdeckte (52-54) und dahingestellte (54 f.) Änderungen, welche im Gegensatz zur ausdrücklichen (49 f.) Abkehr von einer Entscheidungstradition empirisch schwerlich untersucht werden können (was Kähler auch weder behauptet noch versucht).

Für den weiteren Gang der Arbeit ist es sicher von Gewinn, daß Kähler sich seine theoretischen Erkundungen nicht von praktischen Notwendigkeiten eingrenzen läßt. Jedenfalls wird durch die verschiedenen Differenzierungen und Verästelungen der Änderungsdogmatik deutlich, welch bescheidener Teil der Urteilspraxis empirisch angemessen behandelt werden kann und wie groß die Zahl der richterlichen Entscheidungen ist, die einer an harten Fakten orientierten Studie von vornherein unzugänglich bleiben muß. Darauf wird zurückzukommen sein. Zunächst interessiert jedoch die Frage, welche Hindernisse zu überwinden sind, bevor ein theoretisch taugliches Konzept einer Rechtsprechungsänderung erstellt werden kann.

Kähler beweist hier einiges methodologisches Problembewußtsein. Unvollständige Begründungen (31 f.), implizite Prämissen, widersprüchliche Aussagen (32 ff.), vage und irreführende Formulierungen macht er früh als das tägliche Brot des Rechtsprechungsempirikers aus. So zeigt er etwa, daß einem nur vergleichsweise herangezogenen Urteil nicht ohne weiteres Rechtsansichten entnommen werden können, die das aktuelle Urteil tatsächlich stützen, Kontinuität also nur suggeriert wird (53 f.).

Gleichwohl wird bereits im Rahmen des theoretischen Teils sichtbar, daß Kähler in seiner Untersuchung von einem nur schwer erschütterbaren Glauben an die Möglichkeit angeleitet wurde, die Rechtsprechung, ihre Tätigkeit, ihre Gründe und Begründungen realitätsgetreu zu vermessen und zu berechnen. Dazu gehört zunächst die Überzeugung, Entscheidungsprozesse und ihre Begründungen seien prinzipiell regelgeleitet, und diese basalen Regeln stünden in irgendeinem systematischen Verhältnis zueinander. Aus dieser Gewißheit folgert Kähler, eine Änderung »der angewandten Regeln [sei] desto besser festzustellen, je präziser sie formuliert und je genauer sie in ein aufeinander abgestimmtes Regelsystem einordenbar sind «(35). An der prinzipiel- 
len Tragfähigkeit einer solchen Dogmatisierbarkeit einzelner Rechtsmeinungen scheint Kähler nicht zu zweifeln.

Dem entspricht ein nicht recht überzeugendes Vertrauen in die Rationalität der richterlichen Entscheidungspraxis. Eine Differenzierung zwischen dem, was Gerichte sagen, und dem, was sie tun, hält Kähler für überflüssig. Er räumt zwar ein, daß es neben den normativen Gründen einer Entscheidung noch andere, »historische, soziologische und ähnliche Erklärungen « geben könne; doch für die Rechtfertigung einer Entscheidung seien »diese nicht veröffentlichten ,wahren ' Gründe meist irrelevant, da ansonsten kein Grund bestünde, sie nicht in die Entscheidung aufzunehmen« (77). Dies ist freilich eine Unterstellung, die in ihrem Optimismus kaum mehr nachvollziehbar ist. Insofern ist auch nicht ganz klar, ob Kähler in seiner Definition »Eine Rechtsprechungsänderung tritt auf, wenn eine Gerichtsentscheidung von einer rechtskräftigen Gerichtsentscheidung zur selben Frage erstmalig abweicht« (25) die »Abweichung « und die »selbe Frage « nicht einer rechtstheoretisch kaum mehr plausiblen Ontologisierung unterzogen hat, um beides empirisch leichter faßlich zu machen.

Letztendlich kann dies jedoch dahinstehen. Denn die im zweiten Teil seiner Arbeit (92-187) folgende empirische Analyse hat Kähler weitgehend unabhängig von den im ersten Teil angestrengten theoretischen Überlegungen durchgeführt. Nicht nur deshalb ist dieser Abschnitt ausgezeichnet geglückt. Um nicht im Sumpf der Interpretationen und Wertungen zu versinken, hat sich Kähler hier auf eine Untersuchung derjenigen Urteile beschränkt, in denen eine vorhergehende Rechtsprechung ausdrücklich abgeändert wurde (93). Dazu hat er die Urteile von Bundesverfassungsgericht, Bundesverwaltungsgericht und Bundesgerichtshof aus den Jahren 1995-2001 auf bestimmte Begriffe hin untersucht, welche auf das Abweichen von einer Rechtsprechungstradition hinweisen könnten - etwa »Klarstellung « oder »Korrektur« (96 ff.) -, um in einem zweiten Schritt zu überprüfen, ob in den derart herausgefilterten Urteilen tatsächlich eine Rechtsprechungsänderung vorgenommen wurde. Nach der Entscheidung über einige Zweifelsfälle (98-101) konnte Kähler in dem Berg von insgesamt 17.000 Entscheidungen im Untersuchungszeitraum auf diese Weise die eingangs erwähnten 191 rechtsprechungsändernden Entscheidungen ausmachen (101), die er im folgenden einer gut fundierten quantitativen wie auch qualitativen Analyse unterzieht.

Dabei hat er wenig von dem, was sich irgendwie empirisch erforschen läßt, ausgelassen: Änderungsquoten werden untersucht, verglichen und auf ihre Ursachen hin befragt (104 ff.), der Umfang der aufgegebenen Rechtsansichten wird vermessen (ganz oder teilweise, 110 ff.), die für die jeweilige Änderung angeführten Gründe werden katalogisiert, gezählt (112 ff.) und den Gründen der Ausgangsentscheidung gegenübergestellt (126 ff.), die Häufigkeit von Rechtsprechungs- (115 ff.) und Literaturzitaten (124 ff.) wird tabellarisch erfaßt und ausgewertet, das Alter der Ausgangsentscheidungen bestimmt (144 ff.), die Konsistenz innerhalb des Instanzenzugs (147 ff.) und innerhalb der einzelnen Senate (149 ff.) überprüft, der Ausgang des Falles (für oder gegen den Kläger) archiviert (151 f.), und die jeweiligen Leitsätze werden auf Hinweise zur vorgenommenen Änderung durchforstet (152 ff.).

Schon beim Sammeln und Anhäufen all dieser bemerkenswerten Fakten und Details ist Kähler überaus sorgfältig und genau vorgegangen. Seine besondere Stärke liegt al- 
lerdings in der analytischen Durchdringung und Bewertung des von ihm gewonnenen Tatsachenmaterials. Hier liefert Kähler tiefschürfende und überzeugende Deutungen des Geschehens und kommt dabei nicht selten zu aufschlußreichen Ergebnissen. So gelingt es Kähler beispielsweise, in vielen Rechtsprechungsänderungen eine bestimmte Struktur ausfindig zu machen: In einem ersten Schritt träfen »Gerichte eine Entscheidung, der implizit eine neue Ansicht zugrunde liegt oder zumindest mit ihr vereinbar ist« (120). Dies begründeten sie - wenn überhaupt - damit, daß sie vorliegend über einen Sonderfall zu entscheiden hätten oder gar nicht von der alten Rechtsprechung abwichen. In einem zweiten Schritt jedoch nähmen die Gerichte dann auf die angebliche Ausnahmekonstellation bezug, um damit die Aufgabe der ursprünglichen Rechtsansicht zu begründen. Auf diese Weise könne auch die Rechtsprechungsänderung den Eindruck erwecken, sie setze die bisherige Rechtsprechung fort, indem sie einmal »die Konsistenz der angewandten oder formulierten Normen [betone], ein anderes Mal die Konsistenz der erzielten Ergebnisse und bisweilen die Konsistenz der die Normen stützenden Gründe oder der bereits in obiter dicta ausgesprochenen Grundsätze« (120). Eine Tradition also, die auch dann noch Tradition ist, wenn sie genau das Gegenteil von dem sagt, was sie vorher gesagt hat.

Ein ähnlich erhellendes Beispiel stellt Kählers Analyse der gerichtlichen Rechtfertigung von Rechtsprechungsänderungen dar: Der Große Senat für Zivilsachen hat dazu einmal die Formulierung in die Welt gesetzt, die Aufgabe einer ständigen Rechtsprechung setze im allgemeinen »deutlich überwiegende oder sogar schlechthin zwingende Gründe « voraus. Nun könnte man meinen, daß ein Gericht, das die bisherige Rechtsprechung ändern will, irgendwo in seiner Urteilsbegründung die Formel des Großen Senats erwähnt und dann versucht, darunter seine besonderen Gründe für eine Abkehr von der Rechtsprechungstradition zu subsumieren. Kähler hat indes herausgefunden, daß nicht eine einzige (!) der von ihm gefundenen Änderungsentscheidungen die vom Großen Senat entworfene Regel auch nur erwähnt (134). Vielmehr fände die Formel nur dort Eingang in die Spruchpraxis, wo sie dazu diene, die Änderung einer Rechtsprechung abzulehnen. Es drängt sich der Verdacht auf, daß die erhöhten Anforderungen für eine Rechtsprechungsänderung kaum mehr als rhetorische Zwecke erfüllen.

Mit diesen Ergebnissen der quantitativen Analysen im Hintergrund sind auch die qualitativen Untersuchungen, die Kähler durchführt, durchaus nachvollziehbar. Kähler kommt insbesondere zu dem Schluß, die Gerichte seien stets darum bemüht, ihrer Tätigkeit ein kohärentes Gepräge zu geben (155 ff.), etwa indem sie die zu entscheidenden Streitfragen durch immer weitere Differenzierung als bisher noch nicht beurteilte Sonderfälle darstellten (156) oder indem sie durch immer gleiche abstrakte Formulierungen eine narrative Kontinuität erzeugten, der infolge unterschiedlicher Interpretationsweisen aber keine normative Kontinuität entspräche (161).

Bemerkenswert ist bei alledem, daß Kähler eine große Zahl von Ergebnissen bestätigt, zu denen die gemeinhin als praxisfern und nutzlos verschrieene Rechtstheorie schon vor längerer Zeit gekommen ist: die immer weitere Zersplitterung und Atomisierung des rechtlichen Wissens nämlich, die immer ausgreifendere Einzelfallrechtsprechung unter Berufung auf »sämtliche Umstände des Einzelfalls«, die Unmöglich- 
keit einer vollständigen Dogmatisierung rechtlicher Argumente (vgl. 167-171) oder die Notwendigkeit, die jeder Entscheidung zugrundeliegende Paradoxie während der Entscheidungs»findung « möglichst umfassend zu invisibilisieren (siehe etwa 173).

$\mathrm{Zu}$ rechtstheoretischem Triumphgeheul besteht gleichwohl kein Anlaß. Zum einen waren all diese Befunde schon seit langem bekannt und die vor allem aus den vermeintlich praxisnäheren Fächern vorgebrachten Gegenargumente noch nie sonderlich plausibel. In aller Regel beschränkten sie sich auf die (in andere Worte gepackte) Feststellung, es könne nicht sein, was nicht sein dürfe; und da die Unzulässigkeit eines solchen Schlusses allzu schnell zutagetritt, war es vor allem der gesunde Menschenverstand, dem in verzweifelter Anrufung immer wieder die schwerlich zu erfüllende Aufgabe zugemutet wurde, die Ausdifferenzierung des Rechtssystems rückgängig zu machen und Expertenwissen wieder in allgemein zugängliches Laienwissen zu verwandeln.

Zum anderen jedoch ist an dieser Stelle in Erinnerung zu rufen, daß der empirischen Analyse nur ein verschwindend kleiner Teil der Urteilspraxis offen steht. Ein Blick auf die Spitze des Eisbergs ist zwar in mancher Hinsicht informativ, sagt aber über die Massen unter der Wasseroberfläche nichts aus (außer daß sie durchschnittlich sieben Mal so groß sind wie der sichtbare Teil). Entsprechend wenig normatives Potential ist den Untersuchungen Kählers zu entnehmen.

Er selbst faßt seine quantitativen Analysen in der folgenden Prognose zusammen: »Gerichte werden ausdrückliche Änderungen überwiegend vollständig und nicht nur teilweise vornehmen, sie durch eine bessere statt durch eine andere Erkenntnis des Rechts legitimieren, keine unwiderlegten Gründe erwähnen, welche gegen die Änderung sprechen, und mit ihrer Entscheidung sowohl von einer eigenen Ausgangs- wie von der instanzgerichtlichen Entscheidung abweichen. Zudem ist zu erwarten, dass ausdrückliche Änderungen beim Bundesgerichtshof und Bundesverwaltungsgericht häufiger als beim Bundesverfassungsgericht auftreten.« (154 f.). Diese Voraussage erinnert ein wenig an den Sketch von Loriot, in dem ein Nachrichtensprecher berichtet, vergangene Nacht seien »sämtliche Häftlinge aus allen deutschen Strafanstalten ausgebrochen « und dem Zuschauer als Fahndungshinweis die Information gibt, die Sträflinge seien durchschnittlich 1,71 m groß, hätten insgesamt 685 Blinddarmnarben und 1367 Zahnlücken.

Analytisch ist Kählers Aufklärung über die Praxis und ihr Tun jedoch von hohem Gewinn. Wer an Rechtsvergleichung interessiert ist, sollte zudem das dritte Kapitel der Arbeit zur Kenntnis nehmen, in dem sich Kähler mit Rechtsprechungsänderungen in den USA auseinandersetzt (188-240; am Supreme Court »durchschnittlich etwa eine Präjudizienaufgabe pro Jahr«, 211).

Deutlich weniger Worte sind über das letzte Kapitel der Arbeit zu verlieren (Die Rechtfertigung von Rechtsprechungsänderungen, 241-387). Dort legt Kähler die analytische Brille ab und verlegt sich darauf, den Ergebnissen seiner empirischen Untersuchungen eine normative Wendung zu verleihen. Schon deshalb wäre dieser Teil im Rahmen seiner Studie nicht unbedingt nötig gewesen, kann doch eine Darstellung der »Strukturen und Methoden« sich ohne weiteres auf eine Sichtung und Rekonstruktion des Materials beschränken. Eindeutig von Nachteil ist allerdings, daß der schon im 
ersten Teil nicht vollständig ausgeräumte Verdacht, Kähler habe das Recht vor Beginn seiner Untersuchungen erst einmal gehörig ontologisiert, im letzten Teil der Arbeit zur Gewißheit gerinnt. Überdies wirkt es ein wenig ermüdend, wie die von Kähler so scharfsinnig ausgemachten Strategien der Rechtsprechung, aus den aufmüpfig ungleichen Fällen des Lebens eine kontinuierliche Urteilstradition zu konstruieren, zunehmend zum Gegenstand seiner Empörung werden.

Einen Großteil seiner Ausführungen zum »Recht der Rechtsprechungsänderung « (241) verwendet Kähler auf die Frage, inwieweit die Rechtsprechung in Deutschland künftig an Präjudizien gebunden sein sollte (245-325), was er mit guten Gründen verneint. Stattdessen fordert er eine nicht zuletzt spieltheoretisch untermauerte Kooperationspflicht der Gerichte (340-381). Dabei kommt Kähler zwar einmal mehr seine dogmatische Sorgfalt zugute; doch wird die Freude an seiner argumentativen Beharrlichkeit allzu oft durch unhaltbare rechtstheoretische Prämissen getrübt, welche von der Akkuratesse seiner Darstellung nur ungenügend verdeckt werden. So heißt es etwa zum Prinzip des Vertrauensschutzes, es hindere den Richter nicht an neuen Interpretationen, denn der Richter dürfe »das allgemeine Vertrauen auf ein bestimmtes Normverständnis nur berücksichtigen, wenn die entsprechenden Normen auf einen bestimmten Stand der Rechtsprechung oder eine bestimmte Auffassung des Rechtsverkehrs « verwiesen (292). »Fahrlässigkeit« etwa müsste dann heißen »Fahrlässigkeit im Sinne der bisherigen Rechtsprechung « und nicht einfach nur Fahrlässigkeit. Fahrlässigkeit soll also auch außerhalb einer rechtsprechenden Instanz einen faßbaren Gehalt haben, was den Verdacht nahe legt, Kähler wähne sich im Besitz des Schlüssels zum juristischen Begriffshimmel, in dem die Urformen der einzelnen Rechtsinstitute hängen und unabhängig von dem bisherigen mangelbehafteten Verständnis der Menschen in Reinform auf die Erde gebracht werden können.

Ähnlich kommentiert Kähler den von ihm so schön herauspräparierten argumentativen Taschenspielertrick, auch die Änderung einer Tradition als ihre Fortführung erscheinen zu lassen und die erhöhten Anforderungen an eine Änderung nur dann zu erwähnen, wenn die bisherige Praxis nicht abgeändert werden soll: Es sei nur dann rechtmäßig, die Fiktion der Unabänderlichkeit weiter aufrechtzuerhalten, »wenn das geltende Recht den Richter zu einer solchen Fiktion ermächtigen würde, was aber nicht ersichtlich ist, da es neben dem für jedermann einsichtigen Recht ein geheimes Richterrecht und intransparente Richterhierarchien schüfe (335). Der dahinter stehende Versuch, rechtstheoretische Einsichten mittels materiellrechtlicher Verbotsnormen zu widerlegen, gipfelt in dem absurden Anwurf, es grenze »an Rechtsbeugung, wenn man eine Entscheidung im Einklang mit einer Tradition beschreibt, von der man weiß, dass sie der aktuellen Entscheidung entgegensteht« (364). Mit der gleichen Argumentation könnte man Bürger bestrafen, die Rechtsfälle produzieren, für die keine Normen bereitstehen, oder Richter aus dem Verkehr ziehen, die weiterhin judizieren, obwohl sie wissen, daß das Postulat der Gesetzesbindung nur eine politische Funktion hat (welche übrigens gleichfalls nicht rechtlich angeordnet ist).

Si tacuisset, möchte man über den Verfasser dieses letzten Teils sagen, und dem Leser zum Abschluß noch einmal in Erinnerung rufen, daß er es hier trotzdem mit einem guten Buch zu tun hat, das bedauerlicherweise schlecht ausgeht. Doch da hier kein 
Krimi in Rede steht, dem man ein schlechtes Ende nur ungern verzeiht, sondern lediglich ein rechtstheoretisches Werk, das auch ohne guten Ausgang seine Verdienste hat, ist dieser Befund nicht weiter schlimm.

\section{Endorphine}

Jeder Jogger kennt sie, die endogenen Morphine, kurz Endorphine, die nach etwa dreiBig Minuten gleichmäßigen Trabens seinen Körper durchströmen und ihm vorgaukeln, er könne noch dreißig Stunden so weiterlaufen wie bisher. Man weiß, daß das Gehirn diese Stoffe ausschüttet. Warum es das tut, weiß man eher nicht. Zur Belohnung, sagen viele. Aber wofür wird der Jogger belohnt? Dafür, daß er so brav gelaufen ist und etwas für seinen Blutkreislauf getan hat? Soll er nicht vielleicht für weitere Anstrengungen unempfindlich gemacht werden, weil das Gehirn fürchtet, daß er allmählich nachläßt? Oder soll er süchtig gemacht werden (Morphin!), damit er immer wieder läuft und auf diese Weise dafür sorgt, daß die Joggingbedarfsartikelindustrie weiterhin schwarze Zahlen schreibt? Leider weiß man immer noch nicht, was das Gehirn sich beim Denken eigentlich so denkt.

Eine bisher weniger bekannte Leistung der Endorphine hat Hans Peter Schwintowski in seiner Juristischen Methodenlehre ${ }^{6}$ zu Tage gefördert. »Endorphine haben für Rechtssysteme wahrscheinlich eine große Bedeutung «, heißt es dort zusammenfassend auf Seite 209. Die den Jurastudenten anscheinend hinreichend bekannten Gelehrten »Gruter und Danielli haben die These vertreten, daß möglicherweise gewisse opiumhaltige Stoffe im Gehirn - Endorphine - altruistisches und gesetzestreues Verhalten belohnen« (204). Eine Sensation - wenn auch nur »möglicherweise«, wie Gruter und Danielli irgendwann irgendwo zum Besten gegeben haben.

Aber gesetzt (denn Nachweise fehlen), es verhielte sich genau so: Man benimmt sich gesetzestreu und bekommt dafür einen Schluck Endorphine aus der Gehirnflasche. Was liegt näher, als diesen Mechanismus zu verstärken und auf diese Weise in den Individuen eine innere, beständige Sehnsucht nach der Befolgung der Gesetze zu wecken, eine Sehnsucht, die sichtlich jeglichen Untertanengeist aus dem Felde schlagen würde.

Wenn wir die Belohnungsmechanismen kennen würden, »könnte es möglich werden, das Beachten der Menschenrechte, der Presse- und Meinungsfreiheit, eines fairen wirtschaftlichen Wettbewerbs und einer gerechten Teilhabe als elementare Bausteine eines Rechtssystems unabänderlich zu implementieren« (208). So weit sind wir aber noch nicht. Die schöne neue Welt grüßt leider immer noch aus weiter Ferne. Aber die Aufgabe ist klar, meint Schwintowski. »Um Recht und Rechtsverhalten verstehen zu können, muß man also jene Gehirnsysteme untersuchen, die für Belohnung und Bestrafung zuständig sind « (206).

Wer sich störrisch aufführt (vor allem als Jurist) und von den Dopaminen und Peptiden, dem Captoril und Prozac, Naloxon etc. nichts wissen will (zumal er Genaueres

6 UTB Basics 2636, Frankfurt a. M.: Verlag Recht und Wirtschaft 2005, 243 S. 
ohnehin nicht erfährt), dem verpaßt der Autor dieser Methodenlehre noch schnell eine saftige Drohung: »Diejenigen, die sich dem Wissen um die neuronalen und chemischen Grundlagen unseres Rechtssystems verschließen, verweigern damit nicht nur einen Erkenntnisschritt, sondern geben vor allem jenen Despoten eine neue Chance, die wie Adolf Hitler und viele andere das Rechtssystem zur Durchsetzung ihrer menschenverachtenden Ziele mißbrauchen« (209).

Der demokratisch gesinnte Jurist, der sich nicht falscher Verdächtigung aussetzen will, tut also gut daran, sich nicht bloß um die Endorphine, sondern auch um die Hirnforschung ganz allgemein zu bemühen, denn schließlich ist nicht zu leugnen, »daß Rechtssysteme, die typischerweise auf Sprache beruhen, in ähnlicher Weise wie Sprache in unseren Gehirnen entwickelt werden.« (203)

Man hat zwar schon mehrfach vermutet, daß Recht den Köpfen der Menschen (und dort den Hirnen, soweit solche in den Köpfen befindlich) entspringt und nicht vom Himmel fällt, aber der Vorgang kann anscheinend doch noch präziser gefaßt werden. Einen Hinweis bekommt der Leser schon im Vorwort zur Methodenlehre, wo ihm die alsbaldige Bekanntschaft mit einer Studie in Aussicht gestellt wird, die »zeigt, daß juristische Information an anderen Stellen im Gehirn verarbeitet wird als allgemeinsprachliche Information« (6), ein Hinweis, der später dadurch zur Gewißheit gerinnt, daß der Autor feststellt: »diese Befunde wurden inzwischen von einigen anderen Forschergruppen auf der Welt bestätigt« (44).

Der aufgeregte Leser folgt nur allzu gern der Frage von Schwintowski: »Aber welche Schlußfolgerungen können wir daraus ziehen?« (44). Die Folgerung des Verfassers: »Der Satz ,ein Mann schlägt Holz ‘ wird an einer anderen Stelle verarbeitet als der Satz ,Ein Mann schlägt seine Frau“" (44) ist zwar unmittelbar einleuchtend, für den engagierten Mitdenker aber doch erst ein geringer Gewinn. Wenn die Jurisprudenz tatsächlich an einer anderen Stelle im Gehirn sitzt als die »allgemeinsprachliche Information «, dann müßte das doch auch für die Medizin, die Geographie, die Theologie und die Mathematik, kurz: für das gesamte Spektrum unseres akademischen Wissens gelten, da man, bei allem Respekt für die Bedeutung und die Größe der deutschen Rechtswissenschaft, doch nicht unterstellen möchte, daß die Natur nur die Juristen mit einem Sondersitz privilegierte, sondern daß sie auch den Rest des universitären Kosmos' mit einem (wenn auch sicher deutlich kleineren) Besitztum ausgestattet hat. Und wenn dem so wäre, eröffneten sich dann nicht wundersame und vielversprechende Tausch- und Handlungsmöglichkeiten?

Man könnte unangenehme Rechtshistoriker durch (medikamentöse) Eliminierung ihres Rechtsbesitzes in brauchbare Allgemeinhistoriker verwandeln, Philosophen enteignen, Germanisten in die Physik transferieren etc. Schwintowski äußert sich leider in dieser Hinsicht überhaupt nicht, und der enttäuschte Leser muß sich bis fast an das Ende des Buches (218 ff.) vorkämpfen, um Genaueres über die FMRI-Studie (Functional Magnetic Resonance Imaging) zu erfahren. Man liest, daß die bildgebenden Verfahren bei verschiedenen Tests, in denen es um moral judgement (Verfasser: »moralische Sätze «) und semantic judgement (Verfasser: »semantische Sätze«) gegangen war, am Ende ergeben hätten: »moralisches Urteilen aktiviert ein verteiltes Netzwerk im Gehirn [...] Semantische Sätze aktivieren diese Areale nicht in gleicher Weise« (221). 
Das ist nun freilich im Hinblick auf das, was »gezeigt « werden sollte, ein sehr ärmliches Ergebnis (weil es z. B. einfach damit zusammenhängen könnte, daß moralische Normen auf Handeln zielen und damit »mehr « mobilisieren), aus dem, wie der Verfasser schließlich bekennen muß, sich »zur Zeit keine wirklich spektakulären Schlußfolgerungen ziehen « lassen (222), oder, wie er an einer anderen Stelle seiner neurobiologischen Berichterstattung bemerkt: »Letztlich sind dies aber zur Zeit alles noch Spekulationen « (218).

Womit wir jetzt bei der Frage angekommen wären, was dies alles in einer juristischen Methodenlehre zu suchen hat, die doch, wenn man den Titel irgendwie ernst nimmt, die Aufgabe hätte, jungen oder auch älteren Juristen deskriptive und normative Auskunft über die Methode zu geben, die sie bei der »Rechtsfindung « anwenden bzw. anwenden sollten.

Korrekterweise muß berichtet werden, daß sich die neue Methodenlehre dieser Verpflichtung nicht völlig entzieht. Das Buch enthält 17 Kapitel, von denen nur die drei letzten (Kap. 15: Gehirnstrukturen als Modell für soziale Regel- und Rechtssysteme; Kap. 16: Die chemisch-neuronalen Grundlagen von Rechtssystemen; Kap. 17: Neurobiologie und Recht) der Gehirnforschung den, wie Schwintowski glaubt, schuldigen Respekt zollen.

Die ersten 14 Kapitel behandeln korrekt und leider ohne viel Schwung oder Originalität die verschiedenen Teilgebiete der klassischen Methodenlehre (Auslegung, Subsumtion, Begründung), so wie sie überall angeboten werden. Aber auch rechtsphilosophische (Kap. 11: Der Zusammenhang zwischen juristischer Methode und Gerechtigkeit), rechtshistorische (etwa: Codex Hammurabi, Gesetz von Gortyn, 12Tafelgesetz, Talmud und manches andere), ökonomische (Kap. 12: Der Nutzen der Ökonomik für die Rechtswissenschaft) und sogar kosmologische Aspekte (119 ff.: »Irgendwelche begrifflichen Kategorien, mit denen wir unsere menschlichen Lebenskategorien ordnen, verbinden sich für das ewige All mit diesem allen nicht«) kommen in relativer Breite zur Sprache.

Bei solch tapferer Interdisziplinarität wundert es nicht, daß die Breite zu Lasten der Tiefe und nicht gerade selten auch auf Kosten der Präzision geht. So, wenn der Syllogismus mit dem modus ponendo ponens illustriert wird (61) oder das berühmte Münchhausen-Trilemma sich folgende Fassung gefallen lassen muß: »Würde Recht wirklich die Folge einer vorgelagerten idealen Grundnorm sein, so würden wir übrigens über Naturrecht nicht diskutieren können, es wäre uns nämlich angeboren. Dieses Grundproblem, das Schopenhauer in seiner Dissertation herausgearbeitet hatte, das Gödel in einen weltberühmten mathematischen Beweis gegossen hat, nennen wir heute, Hans Albert folgend, Trilemma der Erkenntnis« (118).

Die Erkenntnis auf der Seite derjenigen, die der Lehre juristischer Methoden begierig sind, dürfte sich angesichts der Masse solcher unreifer Bildungsfrüchte in engen Grenzen halten. Dementsprechend gering ist die Ausschüttung von Endorphinen, die sich beim Lesen einstellt. Ratschlag: Lieber Joggen! Zu diesem Buch ist inzwischen noch zu vergleichen: Benjamin Lahusen, Goldene Zeiten, in: Kritische Justiz 39 (2006) 398-417. 


\section{Sackgassenkritik}

Nicht ohne Resignation stellt Edward E. Ott am Ende seiner jüngsten Arbeit zur juristischen Methodenlehre ${ }^{7}$ fest: »Als Resultat vorliegender Abhandlung kann festgehalten werden, dass weder die traditionelle juristische Methodenlehre noch bedeutendere neuere Richtungen dieser Lehre die Voraussetzungen einer logisch aufgebauten und praktikablen juristischen Methode erfüllen.« Ein frustrierendes Resumée: Weder die klassische Lehre noch ihre Nachfolger bieten dem Rechtsanwender brauchbare Anweisungen, die ihn darüber aufklären, wie Rechtsfindung wirklich funktioniert, ja schlimmer noch: »in der Lehre« sei die Tendenz vorherrschend, »die richterliche Freiheit zu begünstigen und die Gesetzesbindung zu lockern«. Dabei könne sich die Lehre zwar »auf renommierte Vorgänger und ein großes Arsenal von prätentiösen Lehrmeinungen stützen«, deren Einlassungen als »treffend, grundlegend, Aufsehen erregend oder sogar bahnbrechend gelobt « würden - allein, Gegenmeinungen nähme man nicht zur Kenntnis, sie würden »zumeist nicht einmal einer Erwähnung wert befunden«, $»$ falsch aufgefasst « oder »als abwegig dargestellt « (VI).

Auf welche Gegenmeinungen Ott hier so verbittert anspielt, verrät ein Blick ins Verzeichnis der abgekürzt zitierten Literatur (XV-XVIII). Dort werden 39 Titel aufgeführt, von denen immerhin 12 von Ott selbst stammen - man ahnt bereits hier, daß Ott die herrschende Lehre im Verlauf seiner Ausführungen vor allem mit Ott widerlegen und dabei gleich ein wenig Werbung in eigener Sache machen will, um die von der herrschenden Lehre frech totgeschwiegenen Ansichten wieder angemessen ins Gespräch zu bringen: etwa seine »Leitsätze der juristischen Fallbearbeitung «, in denen dem Leser die »Methode der Auslegung und der weiteren Rechtsfindung [...] in konziser Weise « nähergebracht wird (137) - »eine umfassende Theorie auf kleinem Raum« (genauso übrigens wie seine Habilitationsschrift) (148 Fn. 569).

Doch darüber hinaus offenbart das Literaturverzeichnis noch einen weiteren Umstand: Anders als das Resumée vermuten läßt, kritisiert Ott in seinem Buch einzig das Rechtsanwendungsmodell der traditionellen juristischen Methodenlehre. Außer den bekannten Anhängern der klassischen Methodenlehre sind in seinem Buch jedenfalls keine »bedeutenderen neueren Richtungen« auszumachen, weder dieser noch irgendeiner anderen Lehre. Das ist ein recht erstaunlicher Verzicht, denn wer wie Ott das klassische Methodenverständnis kritisieren oder gar widerlegen will, kann sich dabei ja mittlerweile ebenfalls auf ein großes Arsenal von prätentiösen oder bahnbrechenden Lehrmeinungen stützen. Doch daß Ott diese Ansichten (bewußt oder unbewußt) ausläßt, erklärt sich recht schnell, wenn man die Stoßrichtung seiner Kritik betrachtet.

Sträflich vereinfacht ließen sich in den methodologischen Scharmützeln der Rechtstheorie bisher zwei Lager unterscheiden: hüben die Rechtsanwender, welche die richterliche Entscheidungstätigkeit nicht nur rationalisieren wollen, sondern auch meinen, sie seien prinzipiell dazu in der Lage; drüben die Rechtserzeuger, die den Rechtsan-

7 Edward E. Ott, Juristische Methode in der Sackgasse? 46 fragwürdige Theorien in der heutigen juristischen Methodenlehre. Zürich: Orell Füssli 2006, 246 S. 
wendern zwar den guten Willen nicht absprechen wollen, in Anbetracht erkenntnis-, sprach-, system- oder sonstiger rechtstheoretischer Erkenntnisse jedoch bestreiten, eine genuine Rechtsanwendung könne jemals erreicht werden. Die einen wollen also und meinen auch, sie könnten, die anderen wollen genauso, meinen aber, jedenfalls die Rechtsanwender könnten nicht.

In diesem Stellungskrieg eröffnet Ott nun überraschend eine neue Front: Anders als die übrige Rechts- und Methodenkritik wirft er der herrschenden Rechtsanwendungslehre nicht vor, sie könne ihr Ziel gar nicht erreichen, auch wenn sie noch so sehr wolle, sondern er bezichtigt sie vielmehr der Böswilligkeit. Denn daß die Anwendung von Gesetzen prinzipiell objektiv und rational vonstatten gehen kann, steht für Ott genauso außer Frage wie der Umstand, daß die herkömmlichen Methoden dafür ungeeignet sind. Wer diese Methoden dessen ungeachtet weiter propagiert, dem kann es folglich gar nicht darum gehen, eine rationale Rechtsanwendung zu ermöglichen, sondern genau im Gegenteil darum, richterlicher Willkür Tür und Tor zu öffnen.

Nicht nur deshalb führt kein Weg daran vorbei, Otts Werk rundherum als kurios zu bezeichnen. In seinen Analysen befinden sich fast schon naive Theorielosigkeit und erstaunliche Literaturunkenntnis einerseits sowie treffende Problemschilderungen und präzise Kritik an der herrschenden Lehre andererseits in einem verwirrenden Nebeneinander, das durch die mitunter bis zur Unverständlichkeit unbeholfene Sprache (»Es ist einfach, einer Theorie, deren Akzeptanz nur in der Undeutlichkeit des Denkens gesehen werden kann, eine partielle Zustimmung zu verschaffen, wenn sie umfunktioniert wird «, 158) kaum leichter zu durchschauen ist - ein Durcheinander, das auch im Aufbau des Buches seine Entsprechung findet: vier Teile gibt es, nämlich »Problematische Schlüsse in der Juristischen Methodenlehre«, »Fragwürdigkeit der Theorien«, »Weitere unbefriedigende Ansichten in der neueren Methodenlehre« und schließlich »Grundsätzliche Unzulänglichkeiten in Kommentaren zu Art. 1 ZGB «, wobei nicht ohne weiteres gesagt werden kann, warum ein Thema im einen statt im anderen Kapitel auftaucht. Auf diese Weise stapeln und überlagern sich die Fragwürdigkeiten, Mängel, Unzulänglichkeiten und Fehler, bis sie sich insgesamt auf 46 addiert haben, was freilich auch nur deshalb möglich ist, weil manche Probleme fast schon quälend redundant behandelt werden (etwa Ziff. 6 über Begriff und Methode der Wertung, Ziff. 38: »Mangel an sachhaltigen Hinweisen über die Methode der Wertung « [im Berner Kommentar], Ziff. 44: »Ungenügende Angaben über die Wertung « [im Basler Kommentar]).

Auch inhaltlich ist Ott beim Zusammenscharren dieser Fehlersammlung bisweilen recht befremdlich vorgegangen. So faßt er die verschiedenen Ausprägungen der klassischen Methodenlehre ohne weitere Erklärungen unter dem Oberbegriff »hermeneutische Lehren « zusammen und verfrachtet sie auf diese Weise in ein Theorielager, das von wenigen so hartnäckig bekämpft wird wie von eben jener klassischen Lehre, welche sich von den Verstehenszirkeln und Vorverständnissen der Hermeneutik ja gerade lösen will. Ebenfalls als verfehlt darf der Vorwurf gelten, die klassische Lehre operiere zu oft mit rechtsexternen Begründungen. In welchen Abhandlungen der traditionell rezeptionsunwilligen klassischen Lehre Ott den Rekurs auf Erkenntnislehre, Sprachwissenschaft, wissenschaftstheoretische Entwicklungen oder moderne Linguistik nachgelesen haben will (17), verschweigt er sicherlich nicht ohne Grund. 
Abgesehen von dieser mißglückten Einordnung ist allerdings manche Kritik an der klassischen Lehre durchaus zutreffend und einprägsam formuliert, etwa wenn es zum Lückenbegriff heißt, er signalisiere fälschlicherweise »eine Ausnahme in einem festgefügten Ganzen«, und Ott dieser Vorstellung entgegenhält: »Von einem zum grossen Teil leeren Parkplatz wird auch nicht gesagt, es seien Parklücken vorhanden.« (79) Ebenso richtig ist Otts Hinweis darauf, daß Gerechtigkeitsfragen im juristischen Alltag eine untergeordnete Rolle spielen, und materialen Kriterien demzufolge weder Maßstäbe für die juristische Methodik entnommen werden können (163), noch umgekehrt methodische Grundsätze richterlicher Ungerechtigkeit Einhalt zu gebieten vermögen (165 f.).

So richtig aber Ott die Probleme manches Mal schildert, so unbefriedigend sind die Alternativlösungen, die er anbietet. Den Mängeln der traditionellen Methodik (»Die Ergiebigkeit der Auslegungselemente wird stark überschätzt«, 178) hält er konsequent die Rückbesinnung auf die Schönheit des theoriefreien Raums entgegen. Entweder beruft er sich auf den »klaren Wortlaut« oder den »klaren Anwendungsbereich « der Norm, oder aber er ersetzt hinlänglich bekannte Leerformeln (»objektiver Dritter«, »mehrheitlicher Konsens«) durch andere hinlänglich bekannte (»Wertung «) oder bisher unbekannte Leerformeln (»Sachverhaltsadäquatheit«, »besondere materielle Dringlichkeit«, »ausserordentliche Zusatzmomente im Sachverhalt «).

Insbesondere die Ausführungen zum Wortlaut sind verblüffend. Schon aus dem Wortlaut des Begriffs »Auslegung « ergebe sich, daß bei klarem Wortlaut eine Auslegung entbehrlich sei (13). Erfreulicherweise sei der Wortlaut der Norm oft klar (36) und Abgrenzungsprobleme selten (4). Damit verbleibt dem Rechtsanwender regelmäBig ein »klarer Anwendungsbereich der Norm«, in dem er nicht auslegen, sondern nur lesen müsse. Hieran soll auch der Umstand nichts ändern, daß der Wortlaut nach Ott nur »im Hinblick auf den zu beurteilenden Sachverhalt« klar sein kann und zudem vor seiner Anwendung erst »vervollständigt und überprüft« werden muß. Eben deshalb aber kann die Methodenlehre aus dieser Differenzierung zwischen Ablesen und Auslegen auch keinen Gewinn ziehen. Sofern man davon ausgeht, daß der Richter vor einem vorgefertigten Sachverhalt sitzt und ihm nur Normen angeboten werden, deren einschränkende oder widersprechende Nachbarn genauso entfernt worden sind wie »offensichtliche Textfehler« (102), dann ist die Rede vom »klaren Wortlaut« nicht mehr als eine Banalität, welche die eigentlichen Schwierigkeiten der Rechtsanwendung schon ihrem Ansatz nach verfehlen muß.

In dem Bereich aber, in dem der Richter mehr tun muß als nur lesen, weist Ott ihn an zu werten: Interessenabwägungen sind zu treffen und Folgeerwägungen zu leisten. Die Wertung diene dazu, die »sachliche Angemessenheit« des Urteils zu beurteilen, und sei »das wertvollste Rechtsfindungsargument « (22). Im einzelnen vollziehe sich diese Wertung in vier Schritten (25 ff., 184 ff.): Subsumtionsversuch, Ermittlung der Interessenkonstellation, Erforschung der spezifischen Auswirkungen der Normanwendung, Interessenabwägung zwischen den »Nachteilen bei den Betroffenen und den allfälligen Vorteilen der Allgemeinheit«. Warum für diese nun wirklich nicht originellen Forderungen ein solcher Aufwand betrieben werden muß, bleibt genauso Otts Geheimnis wie eine Antwort auf die ebenfalls nicht neuen Fragen, an welcher »Sache« 
sich die sachliche Angemessenheit der Entscheidung bestimmen soll, anhand welchen Maßstabes die Interessen der Parteien bewertet werden können oder von welcher Sicherheit Angaben über die - in der Regel ja unbekannten - Folgen einer richterlichen Entscheidung begleitet sind.

Ott scheint in allen diesen Fragen keine Probleme zu sehen. Denn da er schon frühzeitig deutlich gemacht hat, daß er von außerjuristischen Theorieangeboten nicht allzu viel hält (17), kann er sich weiter fest darauf verlassen, daß die Rechtserkenntnis seiner Richter ohne zugehörige Theorie abläuft. Unterstützt wird diese Hoffnung freilich von dem einigermaßen glückseligen Bild der richterlichen Praxis, das Ott vorschwebt: »der Richter bzw. die Richterin prüft die Probleme in zweckmässiger Reihenfolge und sachverständig, grenzt die Bereiche seiner Tätigkeit richtig ab, übersieht keine wesentlichen Gesichtspunkte, richtet seine Bemühungen auf Grundsätze der optimalen Förderung bzw. Nachteilsverminderung aus, verhütet Doppelbewertungen und andere gedanklich[e] Fehlleistungen und vermeidet so auch Subjektivität und Willkür. Seine Begründungen werden nach sinnvollen Kriterien nachprüfbar, die Rechtssicherheit wird gefördert und fragwürdige Auseinandersetzungen werden vermieden.« (28) Nachdem Ott also meint, der gerichtlichen Praxis schon jetzt die Verwirklichung aller Idealvorstellungen bescheinigen zu können, verwundert es nicht, daß er sich selbst nicht in der Pflicht sieht, die Methodendiskussion um mehr als nur um selbstverständliche Desiderate zu bereichern. Subjektive Wertungen seien auszuschließen, unerwünscht seien auch »Bewertungen nach politischen Interessen«, »Abstützen auf Schlagworte «, »Abstellen auf überspannte Wertvorstellungen «, »die Verwendung von Scheinargumenten, die Verleitung durch sachfremde Nützlichkeitserwägungen« oder »das Eingehen eines $>$ Kuhhandels< (186).

Die Methodenlehre darf solche Empfehlungen getrost übersehen. Sattsam bekannte Gemeinplätze sind ebenso wenig hilfreich wie ein offen eingestandenes Abgleiten in die Theorielosigkeit. Der nicht-schweizerische Leser mag sich zwar hier und da an Einblicken in die Schweizer Methodendiskussion erfreuen (z. B. der Streit um die Zulässigkeit der teleologischen Reduktion, Ziff. 22 und 29), doch wird diese Freude schnell dadurch getrübt, daß Ott nicht mehr anzubieten hat als die üblichen (und auch hierzulande bekannten) Verdächtigen. Ähnliches gilt für den Genuß an seiner nicht selten treffenden Kritik der klassischen Lehre: auch hier wird der Gewinn dadurch relativiert, daß mit den kruden Ansichten der traditionellen Methodologie nichts widerlegt wird, was nicht schon vorher widerlegt gewesen wäre. Und letztlich macht Otts Gang in die Sackgasse sogar noch einen Vorzug der herrschenden Lehre deutlich: So fragwürdig ihre Ansichten auch sind, welche Ott zu 46 Theorien addiert hat, so kann man den meisten von ihnen eines immerhin nicht absprechen: daß sie »Theorien « sind. Von Otts Ausführungen dagegen läßt sich das nicht immer behaupten.

\section{Methodenarchiv}

Wer sich über den Inhalt der klassischen juristischen Methodenlehre informieren will, der greife zum Kramer. ${ }^{8}$ Vorbildlich in Präzision und Klarheit finden sich dort auf 276 kleinformatigen Seiten die Vorstellungen und Ideale der Rechtsanwendungslehre 
knapp, fußnotenreich und großbuchstabig zusammengefaßt und kompetent präsentiert. Da der Autor Schweizer ist und an der Universität Basel lehrt, eröffnet das Büchlein dem hiesigen Leser zudem die Möglichkeit, die sträfliche Ignoranz der deutschen Methodenlehre gegenüber ihren ausländischen Pendants zu mildern und insofern eine empfindliche Rezeptionslücke zu schließen. Kurz: Kramer hat einen Grundriß vorgelegt, dessen Lektüre hohen Gewinn verspricht.

Fragt sich nur: für wen. Wer profitiert heutzutage noch von einer Darstellung der klassischen Methodenlehre? Die Kürze des Buches von Kramer verhindert zwar die intellektuelle Verstopfung des Lesers durch überflüssigen Gedankenballast, doch ändert das nichts an dem Umstand, daß der Gegenstand des Buches schon seit Jahren das Zeitliche gesegnet hat. Alle Einprägsamkeit und Feinsinnigkeit der Skizze, die Kramer entwirft, kann nicht darüber hinwegtäuschen, daß seine Linien und Striche die Umrisse einer Leiche nachzeichnen. Ein Toter ist es, der hier so luzide dargestellt wird, ein lebloses Theorienwrack, das hin und wieder mit einem neuem Anstrich ausgestattet wird, um den Leser zu blenden durch den kurz aufblitzenden Glanz alter Zeiten.

Wie auf dem methodologischen Friedhof üblich, besteht dieser neue Anstrich auch bei Kramer zunächst darin, sämtliche Inhalte der Methodenlehre für flüssig zu erklären. Anschließend werden die dergestalt verflüssigten Begrifflichkeiten des Rechtsanwendungsmodells um eine unendliche Vielzahl weiterer Flüssigbegriffe ergänzt, die den Eindruck erwecken sollen, sie könnten die festgestellten Defizite auslöschen. Und letztlich wird der methodologische Brei garniert mit dem bei jeder Gelegenheit gebetsmühlenartig wiederholten Eingeständnis, ein letztes $\mathrm{Ma} \beta$ an »richterlicher Eigenwertung « könne weder ausgeschlossen noch in jedem Falle »verobjektiviert«, müsse dann aber zumindest offen zugestanden werden. Wenn schon keine Methode, dann wenigstens ehrlich.

So viel Flüssigkeit braucht natürlich eine Form, und die findet Kramer wenig überraschend bei den »klassischen Interpretationselementen « (47 ff.) - eine Form freilich, die selbst flüssig ist, denn selbstverständlich ist schon die Grenzziehung zwischen Rechtsanwendung und Rechtsfortbildung unscharf (47). Darüber hilft jedoch die ebenso automatisierte wie zweifelhafte Berufung auf Savigny hinweg (50), und so darf sich der Leser im folgenden an der Flüssigkeit der einzelnen Auslegungselemente erfreuen: an Begriffshof und Begriffskern, an negativen, positiven und neutralen Kandidaten (»Noch einmal sei betont, dass die Übergänge zwischen den drei Bereichen fliessend sind «, 56), an deren Relativierung durch die Warnung vor »naiver Wortgläubigkeit« (72), am »System möglichst kohärenter Wertentscheidungen« (77), an Kramers Vermittlung zwischen dem Willen des Gesetzgebers und dem Willen des Gesetzes (119), am Telos des Gesetzes, den der Interpret »in nicht allzu seltenen Fällen« in »offen darzulegender Eigenwertung « festzustellen hat (124), und an den »Konturen einer Rangfolge«, wonach »primär vom Wortlaut auszugehen«, dabei aber auch »auf die Kontextbedeutung abzustellen ist $«$, in jedem Falle jedoch der Telos berücksichtigt werden muß und »oft ganz entscheidende Aufschlüsse« von der Entstehungsge-

8 Ernst A. Kramer, Juristische Methodenlehre. Bern: Stämpfli, München: C. H. Beck, Wien: Manz, 2. Auflage 2005, 285 S. 
schichte zu erwarten sind (152). Zusammengefaßt führt das zu Ergebnissen wie diesem: »Es braucht wohl kaum noch betont zu werden, dass ein unzulässiges Judizieren contra rationem legis gerade auch dann konstatiert werden muss, wenn sich die Entscheidung in scheinbarer Gesetzestreue auf den Wortlaut einer Vorschrift beruft, während es ebenso klar ist, dass diese Wortinterpretation den Zweck der Vorschrift verfehlt.«(204)

Nach der Liquidierung der bestehenden Kategorien wird in einem zweiten Schritt eine solche Vielzahl weiterer (flüssiger) Begriffe eingeführt, daß es einerseits schwer fällt zu glauben, hier werde wirklich an einer toten Lehre gebastelt, und andererseits für das Versagen der einen Kategorie immer ein Ausweichplan bereitsteht. Exemplarisch darf dafür die fast schon beängstigend ausdifferenzierte Lückentheorie gelten, die folgendes stattliche Lückenarsenal ihr eigen nennt: Lücken de lege lata, Lücken de lege ferenda, Lücken intra legem, Lücken intra verba legis, Delegationslücken, offene Gesetzeslücken, verdeckte Gesetzeslücken, Ausnahmelücken, echte Lücken, unechte Lücken, technische Lücken, Kollisionslücken, teleologische Lücken, bewußte Lücken, unbewußte Lücken, Anschauungslücken, anfängliche (primäre) Lücken, nachträgliche (sekundäre) Lücken (162 ff.). Daß auch diese Abgrenzungen nicht exakt vorgenommen werden, kann man sich schon denken (165 f.).

Für jedes Problem steht also eine Lücke bereit, sogar die Lückenausfüllungsregeln selbst sind lückenhaft (174). Eine interessante Aufgabe wäre es sicherlich, auch unter den Lücken eine Rangfolge ausmachen zu wollen (Vorrang der Lücken de lege lata, Lücken intra legem aber auch zu berücksichtigen, Delegationslücken in jedem Falle heranzuziehen, offene Gesetzeslücken jedoch nicht zu vergessen etc.), doch dürfte ein solches Vorgehen vermutlich daran scheitern, daß mit jeder methodologischen Veröffentlichung die Entdeckung neuer Lücken ins Haus stünde und damit jede Rangfolge im Wettlauf mit der Wirklichkeit ins Hintertreffen geriete.

Gesteht man nun noch offen ein, wann der Übergang von der Fremd- zur Eigenwertung stattfindet, entfaltet sich das »relativ geordnete Argumentarium« (265) zu beeindruckender Größe und läßt keinen Zweifel daran, daß »Rationalität und Regelhaftigkeit des richterlichen Geschäfts « (276) bei der klassischen Methodenlehre gut aufgehoben sind. Ober besser: waren. Denn auch Kramers neuer Aufguß kann allenfalls Erstaunen darüber hervorrufen, mit welchem simplen Trick die klassische Methodenlehre trotzig für sich in Anspruch nimmt, modern und aufgeklärt zu sein - indem sie nämlich einfach frech behauptet, gescheiterte Methode sei auch schon Methode, sofern man das Scheitern nur offen eingesteht.

Womit nun endlich die Frage beantwortet werden kann, für wen dieses Buch einen Gewinn darstellt. Die Antwort kann nur lauten: für den Historiker. Er bekommt hier die Möglichkeit, sich irgendwann einmal kurz und dennoch umfassend über die Befindlichkeiten einer ganzen Wissenschaftsepoche zu informieren: über ihren Unwillen, sich vom alten Paradigma zu lösen, über ihr orientierungsloses Strampeln im unbekannten Gewässer, über ihr unvermeidliches Fluchen ob der beständig weitertickenden Uhr (auch Kramer versäumt es nicht, die »postmodernen Zeiten « spöttisch zu erwähnen, 109) und über ihre krampfhaften Versuche, die schon längst als Leiche enttarnte Methodenlehre als quicklebendigen Jüngling erscheinen zu lassen. Dabei 
wird dem Historiker sicherlich auch die rechtstheoretisch längst üblich gewordene Verschlagwortung der Geschichte auffallen - eine Praxis, die es nicht zuläßt, vom »Gewaltenteilungsprinzip« zu sprechen, ohne Montesquieu in Klammern dahinter zu setzen (37), oder »Begriffsjurisprudenz« zu sagen, ohne »Bovigus « hinzuzufügen (136-138).

Das alles mag der Historiker verwundert zur Kenntnis nehmen und sich daran erfreuen, daß er dieses Kuriositätenkabinett auf so engem Raum so zuverlässig zusammengetragen sieht. Wer sich dagegen mit dem lebenden Recht beschäftigen will, wird nicht um eine Einsicht herumkommen, die das Buch irgendwo in seinen Tiefen für den Richter bereithält, die aber genauso gut für den Rechtstheoretiker gilt, der Kramers Buch gelesen hat: »Dass ihm auch so noch ein sehr weites und schwieriges Arbeitsfeld verbleibt, versteht sich von selbst.«

\section{In der Dienstleistungsgesellschaft}

Am Ende der juristischen Ausbildung steht ein Examen. In diesem Examen werden Fälle geprüft. Ein Sachverhalt erzählt ein bestimmtes Geschehen und schließt mit einer bestimmten Frage, etwa: »Wie ist die Rechtslage?«, oder: »Kann A von B Herausgabe der Vase verlangen?«, oder: »Hat die Klage Aussicht auf Erfolg?«. Das Examen wird weithin als unangenehm empfunden. Die Klausuren sind lang, das für ihre Bearbeitung erforderliche Wissen ist uferlos, immer mehr Detailkenntnisse werden verlangt, immer feinere dogmatische Differenzierungen sind zu meistern - keine schönen Aussichten für die Studenten. Deshalb vertrauen sie sich zu großen Teilen professionellen Vorbereitern an, die den Prüfungsstoff unter dem Gesichtspunkt der Examensrelevanz auf ein (immer noch kaum zu bewältigendes) Mindestmaß reduzieren und den Studenten gegen Bezahlung die Lösung von Fällen beibringen.

In diesem Kreislauf zählt der Erwerb von Fallösungswissen viel und alles andere wenig. Die entscheidende Frage zielt schließlich immer auf das Wie der Rechtslage und nicht etwa darauf, warum sie so ist, wie sie zustande gekommen ist, ob sie nicht auch ganz anders sein könnte, auf welche Weise sie vom Juristen aufgefunden wurde, ob ein anderer Jurist die Dinge genauso sieht oder ob ihr eine Änderung gut zu Gesicht stünde. Solche Fragen sind prinzipiell prüfungsirrelevant und deshalb für den Studenten, der schon genug mit Baurecht, Wirtschaftsstrafrecht und Gesellschaftsrecht zu tun hat, nicht von Interesse.

Wer dennoch ein Buch über all diese Fragen schreiben will, gerät in Erklärungsnot. Warum sollte ein Student seine ohnehin knappe Zeit mit einem solchen Werk verschwenden? Karl-Ludwig Kunz und Martino Mona haben sich von dieser Überlegung nicht abschrecken lassen und trotzdem eine »Einführung in die theoretischen Grundlagen der Rechtswissenschaft « geschrieben. ${ }^{9}$ Dieser Umstand alleine wäre kaum der Rede wert; rechtstheoretische oder -philosophische Einführungen werden schließlich

9 Karl-Ludwig Kunz/Martino Mona, Rechtsphilosophie, Rechtstheorie, Rechtssoziologie. Eine Einführung in die theoretischen Grundlagen der Rechtswissenschaft. Bern, Stuttgart, Wien: Haupt (UTB 2788) 2006, 308 S. 
immer wieder geschrieben. Bemerkenswert ist jedoch die Art und Weise, mit der Kunz und Mona dem studentischen Leser die Nützlichkeit ihres Buches deutlich machen. Die üblicherweise vorgetragene Behauptung, die Beschäftigung mit den rechtswissenschaftlichen Grundlagen sei letztendlich doch bei der Lösung von Fällen dienlich, bezeichnen die Verfasser plastisch als »Service-Modell der Grundlagenfächer « (2 Rn. 37 ff.), in welchem letztere zu bloßen Hilfswissenschaften und Zuliefererbetrieben für die Rechtspraxis degradiert würden (2 Rn. 44).

Gute Rechtstheorie ist danach nur solche, die sich in ein Praxismäntelchen einkleiden läßt - diese Vorstellung machen sich Kunz und Mona völlig zu Recht nicht zu eigen, sondern setzen sich im Gegenteil in erfrischender Weise für eine Emanzipation der Reflexion von ihrem Gegenstande ein: Statt um »handlungsbezogenes Werkdenken« gehe es um »zuschauendes Erkenntnisdenken«, um »Kontemplation und Reflexion aus theoretischer Distanz«, um den Blick von außen auf die Erkenntnisbedingungen des Rechts, um »eine Entzauberung der sich mitunter als Gerechtigkeitsmaschine verklärenden Rechtswelt« (2 Fn. 27 ff.). Nur dort, wo die Grundlagenfächer »nicht auf den Praxisnutzen getrimmt werden«, könnten sie praktische Relevanz erlangen (8 Rn. 2).

Man kann nur hoffen, daß Kunz und Mona mit ihrem beherzten Bekenntnis zur Autonomie der Theorie möglichst viele Leser erreichen und ihr mutiger Einsatz für das »Reflexions-Modell der Grundlagenfächer« (2 Rn. 22 ff.) belohnt wird; schließlich ist es keineswegs selbstverständlich, eine studentische Einführung in die Grundlagen des Rechts mit dem Satz zu beginnen: »Die Beschäftigung mit theoretischen Grundlagenfragen des Rechts wirft selten konkreten Ertrag ab« (1 Rn. 1). Aber nur dieser Weg verspricht, die »persönliche Entscheidungsverantwortung des Rechtsanwenders « (2 Rn. 27) sichtbar zu machen und die »Bildung der juristischen Urteilskraft« (1 Rn. 6) um eine ethische Komponente zu bereichern.

Doch damit nicht genug: Genauso erfreulich wie die Indifferenz gegenüber angeblichen Erfordernissen der Praxis sind die Inhalte, die Kunz und Mona den Studenten zu vermitteln haben. Mit der Einsicht, Ausgangspunkt der theoretischen Reflexion sei oft die »Rebellion des Rechtsgefühls« (2 Rn. 61), billigen die Verfasser dem jeder Rechtsanwendung eigentümlichen irrationalen Moment schon früh einen prominenten Platz zu und scheuen im folgenden nicht davor zurück, Kontingenzerlebnisse und Gewißheitsverluste ins Zentrum der Rechtstheorie zu rücken. Auch das ist durchaus selten und muß Kunz und Mona hoch angerechnet werden. Erneut zeugt es von einigem Mut, Erkenntnisse wie »Die Annahme, das Recht sei in Rechtstexten enthalten wie die Marmelade im Glas, führt in die Irre « (2 Rn. 12) oder »Es ergibt sich somit, dass weder die Nützlichkeit oder gar Notwendigkeit noch die Verzichtbarkeit von Strafe rational begründbar ist « (8 Rn. 71) in die juristische Ausbildung zu integrieren und die Rechtsverwalter schon früh mit der Unentscheidbarkeit ihrer Entscheidungen zu konfrontieren.

Gleichwohl ist zu bedauern, daß die weiteren Ausführungen nicht immer von der Frische und dem Schwung des Beginns geprägt sind. Kunz und Mona identifizieren drei Dimensionen des Rechts (2 Rn. 5 ff.), nämlich Normativität, logische Systematizität und Faktizität, denen die Dreiteilung der theoretischen Grundlagenfächer nach- 
folge (2 Rn. 22): die Rechtsphilosophie betrachte die moralische Qualität der rechtlichen Normativität, die Rechtstheorie beschäftige sich »mit der wissenschaftlichen Vernünftigkeit des Rechts« (2 Rn. 24), die Rechtssoziologie schließlich»mit der tatsächlichen Geltung des Rechts«. Diese Unterteilung erscheint in ihrem Dogmatismus ein wenig zu starr. Was sich analytisch stimmig ausmacht, dürfte in der praktischen Ausführung nur unter erheblichen Schwierigkeiten voneinander zu unterscheiden sein; zudem hängen Fragen etwa des logischen Zusammenhangs von einzelnen Rechtsnormen mit Fragen der Gerechtigkeit unmittelbar zusammen, so daß der Rechtsphilosophie kaum das Monopol für materiale Fragen zugebilligt werden kann.

Ebenfalls mehr intuitiv als praktisch nachvollziehbar ist die strenge Unterteilung in positivistische und nichtpositivistische Herangehensweisen, die Kunz und Mona vornehmen ( 3 Fn. 3 ff.). Der Positivismus beruhe auf der erkenntnistheoretischen Prämisse, der Gegenstand der wissenschaftlichen Erkenntnis sei unabhängig vom Erkennenden vorhanden und könne deshalb streng wertneutral und objektiv erkannt werden ( 3 Rn. 7). Eine nichtpositivistische Erkenntnishaltung gehe dagegen davon aus, »der Mensch und die Dimensionen der Menschlichkeit ließen sich nicht wie passive ,Objekte" kausalgesetzlich bestimmen« (3 Rn. 8).

Schon für den philosophischen Positivismus sind diese Aussagen angreifbar, war doch das Dilemma, daß keine Beobachtung ohne Theorie stattfinden könne, früh bekannt; der rechtswissenschaftliche Positivismus aber konnte nie davon ausgehen, er habe wirklich Fakten zum Gegenstand, da allzu offenkundig war, daß die Tatsachen des Rechts Normen sind. Auch ist nicht recht schlüssig, warum eine nachkantische Strömung solch unkritische Prämissen zur Grundlage haben, die historisch ältere Theorie in epistemologischer Hinsicht jedoch die kritischere Haltung einnehmen sollte. Wie zweifelhaft solche Unterstellungen sind, wird offenbar, wenn Kunz und Mona sich gezwungen sehen, dem Rechtspositivismus und dem klassischen Naturrecht methodische Ähnlichkeit zu attestieren (5 Rn. 36).

Entsprechend sind auch die Folgerungen aus dieser grundlegenden Differenzierung nicht durchgängig überzeugend. Die rechtsphilosophische Unterscheidung von Verbindungs- und Trennungsthese darf noch als unproblematisch gelten. Die Identifizierung der positivistischen Rechtstheorie mit ihrem sprachanalytischen Zweig (3 Rn. 26) wird wohl schon mehr Widerspruch provozieren, nimmt die Rechtstheorie mittlerweile doch erheblich mehr in den Blick als nur die »formale Rationalität der Rechtssprache«. Und ein wenig kryptisch bleibt die Definition, ein nichtpositivistisches Verständnis der Rechtstheorie bestimme »die Vernünftigkeit des Rechts im Sinne des Gebots seiner Gestaltung nach Maßgabe einer menschengerechten Vernunft« (3 Rn. 28).

Ebenfalls nicht vollständig nachvollziehbar ist die Unterteilung der Rechtssoziologie in einen positivistischen Zweig, der sich mit der Faktizität des Rechts befasse, und einen nichtpositivistischen Ableger, der sich als Teil der verstehenden Sozialwissenschaften begreife ( $3 \mathrm{Rn} .33$ f.). Eine Unterscheidung von theoretischer und empirischer Rechtssoziologie wäre womöglich näher liegend gewesen.

Doch wie immer man zu der Zuordnung und Benennung der einzelnen Positionen stehen mag, so ist jedenfalls anzuerkennen, daß Kunz und Mona überhaupt den Ver- 
such einer Differenzierung zwischen den verschiedenen erkenntnistheoretischen Grundhaltungen und ihren Konsequenzen in den jeweiligen Disziplinen wagen. Schon diese Systematisierungsbestrebungen sind keineswegs selbstverständlich; außerdem halten die Verfasser ihre anfänglich getroffenen Unterscheidungen bis zum Ende konsistent durch. Für eine erste Orientierung ist ihre Einteilung deshalb auch dann nützlich, wenn man sie sich selbst nicht zueigen machen will.

Deutlich weniger Worte sind über die Darstellung der historischen Entwicklung zu verlieren (Kapitel 4). Kunz und Mona geben hier korrekt und ohne besondere Originalität die von einem solchen geschichtlichen Überblick zu erwartenden Meinungen und Meinungsträger wieder. Garniert wird die Chronik durch hier und da eingestreute $\mathrm{Zi}$ tate aus Originalwerken der Philosophie (z. B. 4 Rn. 29) und der schönen Literatur (z. B. 4 Rn. 18). Das Kapitel zur Rechtstheorie hätte vielleicht etwas ausführlicher geraten können; besser gelungen ist demgegenüber die Darstellung der Entstehung einer eigenständigen rechtssoziologischen Disziplin, die insbesondere der Kelsen-EhrlichDebatte begrüßenswert viel Platz einräumt (4 Rn. 222-238). Insgesamt ist dem historischen Kapitel jedoch kaum mehr zu entnehmen als die andernorts ebenfalls vorgetragenen Gemeinplätze, was seinen Nutzen einigermaßen einschränkt. Zudem enthält es die eine oder andere fragwürdige These, so etwa die Aussage, die Begriffsjurisprudenz habe sich zur Zeit Webers auf ihrem Höhepunkt befunden (4 Rn. 254). Nicht unerwähnt bleiben soll in diesem Zusammenhang auch die überaus störende Zitierweise; was der Leser mit zahllosen Angaben wie »Hume 1978«, »Thomasius 1963«, »Schiller 2002《, »Thomas von Aquin 1985b«, »Augustinus 1955« oder »Kant 1988b« anfangen soll, bleibt rätselhaft.

Insbesondere über Radbruch (5 Rn. 11-34) führt der Weg zu den aktuell erhältlichen Gerechtigkeitstheorien (Kapitel 6). Nachdem Kunz und Mona konzise zusammengefaßt haben, warum materiale Gerechtigkeitsformeln keine Hilfe versprechen (6 Rn. 312), kommen alternative Modelle zur Sprache. Neben den prozeduralen Idealen von Rawls, der Diskurstheorie von Habermas und Apel sowie den Vorstellungen von Liberalismus und Kommunitarismus findet sich hier überraschenderweise auch ein $\mathrm{Ab}$ schnitt über die juristische Hermeneutik (6 Rn. 37-58), welche Kunz und Mona über ihre ideologiekritische Funktion (6 Rn. 47) hinaus als Scharnier zwischen prozeduralen und diskursethischen Verständnissen der Gerechtigkeit begreifen (6 Rn. 50). Wer sich über moderne Gerechtigkeitstheorien informieren möchte, wird von Kunz und Mona deshalb mehr als zufrieden gestellt.

Dies gilt auch für denjenigen, der sich einen Überblick über »neue theoretische Konzepte ohne traditionellen Gerechtigkeitsbezug « verschaffen will (Kapitel 7). Die Überschrift verspricht, daß sich Kunz und Mona in ihrer Darstellung von den sonst nicht selten anzutreffenden Versuchen abheben, Theorieangebote wie die Systemtheorie anhand althergebrachter Kategorien zu bewerten. Dieses Versprechen lösen sie leider nicht vollständig ein: Der im übrigen gut geratene Überblick über die Systemtheorie (7 Rn. 8-46) findet seinen Abschluß einmal mehr in dem Vorwurf, eine autopoietisch erzeugte Legitimität müsse durch »normative Legitimationsbemühungen« ergänzt werden (7 Rn. 46). Immerhin machen Kunz und Mona dabei deutlich, daß die Systemtheorie ihrem Selbstverständnis nach deskriptiv ist und ihr deshalb 
keine normativen Aussagen über die Qualität von Rechtsordnungen zu entnehmen sind.

Schon ob ihrer Seltenheit gewinnbringend ist die Darstellung des Rechts der Risikogesellschaft (7 Rn. 47-69); mehr wie ein Fremdkörper nimmt sich die ökonomische Analyse des Rechts aus (7 Rn. 70-100), die durch ihre Nähe zum Utilitarismus den klassischen Bezug zur Gerechtigkeit wohl nicht ganz so radikal aufgegeben hat, wie Kunz und Mona dies suggerieren.

Von den abschließend beleuchteten aktuellen Herausforderungen (Kapitel 8) sind vor allem die Ausführungen über die Erforderlichkeit von Strafe von Interesse (8 Rn. 46-86), in denen die Verfasser zu dem erfreulich klar formulierten Ergebnis kommen, die neue Strafmentalität signalisiere die Ankunft eines spätmodernen Verständnisses von Strafe, »welches auf zivilisatorischen Begründungsschnickschnack verzichtet, Vergeltungsrituale zelebriert und dabei ungeniert auf populistische Wirkung schielt « (8 Rn. 86). Dem eingangs verkündeten Ziel, die Rechtspraxis kritisch zu reflektieren, werden Kunz und Mona jedenfalls ohne weiteres gerecht.

Ihrem Werk ist deshalb zu bescheinigen, daß es einer weiteren Verbreiterung der rechtswissenschaftlichen Grundlagenfächer beste Dienste leistet. Das Selbstbewußtsein, mit dem Kunz und Mona das Recht zur praxisenthobenen Rechtsreflexion für sich (und alle anderen Juristen) in Anspruch nehmen, hat durchaus mitreißende Wirkung. Für den Studenten dürften außerdem die Literaturempfehlungen zu Beginn jedes Kapitels von einigem Vorteil sein, da sie sich nicht - wie sonst gebräuchlich - auf eine Nennung der Standardautoren beschränken, sondern konkrete Texte oder Textausschnitte aufführen, deren Lektüre auch bei knappem Zeitbudget realistisch ist. Bei allem Mißtrauen gegenüber dem Service-Modell der Grundlagenfächer - dieses Buch ist in der rechtstheoretischen Dienstleistungsgesellschaft angekommen.

\section{Alle Jahre wieder}

Die Geschichtswissenschaft erlebt in regelmäßigen Abständen eine Debatte, die eigentlich geeignet wäre, die Grundlagen des Faches zu zerstören, und dennoch selten mehr als ein kurzes Aufschrecken der Beteiligten bewirkt. Auslöser ist in der Regel der wißbegierige Blick eines Kollegen über den historiographischen Tellerrand hinaus, hinein in die fundamentalen Fragen von Möglichkeit und Grenzen geschichtlicher Erkenntnis. Denn die transdisziplinäre Perspektive beinhaltet destruktives Potential: sie öffnet Tür und Tor für all die postmodernen Umtriebigkeiten der übrigen Disziplinen, für Wahrheitsskepsis und Unvollständigkeitsdogmen, für Paradoxien und Widersprüche, für Unschärfen und Relativismen - und plötzlich muß man sich herumschlagen mit hermeneutischen Zweiflern und konstruktivistischen Spöttern, die all die schönen Quellen, Fakten, Tatsachen und Realitäten auflösen wollen in Diskurs und Stil und keck behaupten, auch das Existierende existiere nicht.

Doch dann, wenn der Erkenntnis der letzte Gegenstand geraubt und das Nichts allgegenwärtig geworden ist, dann schlägt die Zunft zurück: mit Evidenzen und Offenkundigkeiten, deren Plausibilität niemand bestreiten könne, mit beruflichem Ethos und wissenschaftlichen Standards, die eine argumentative Dissolution der Welt verböten, 
und schließlich, um das drohende Regiment des Fiktiven endgültig am Veto der Quellen scheitern zu lassen, mit einer historischen Tatsache, die jedem Wahrheitsagnostiker den Wind aus den Segeln nehmen muß: Auschwitz. »Der Holocaust war kein Diskurs! - damit ist der Relativismus zwar nicht widerlegt, aber immerhin in die schäbige Nähe des Revisionismus gerückt und seine Anhänger aus dem Kreis der ernstzunehmenden Forschergemeinschaft ausgeschlossen.

Dieser Versuch, mit Auschwitz eine dem gestaltenden Zugriff des erkennenden Subjektes entzogene Welt des Objektiven zu begründen, beschränkt sich selbstverständlich nicht auf die Geschichtswissenschaft. Auch in der Rechtswissenschaft bedient man sich gerne der historischen Erfahrung, um den relativistischen Vorletztbegründern den Garaus zu machen. Einen Beitrag zu dieser Form der Vergangenheitsbewältigung leistet in jüngerer Zeit Jörg Neuner. ${ }^{10}$ Immerhin 80 Seiten räumt Neuner der Frage ein, ob der Positivismus in Anbetracht der nationalsozialistischen Gesetzgebung noch haltbar sei oder nicht vielmehr durch einen wertbezogenen Rechtsbegriff ersetzt werden müsse (5-84). Die NS-Gesetze dienen dabei einerseits als historischer Beleg dafür, daß Art. 20 Abs. 3 GG eine bewußte Unterscheidung zwischen »Recht« und »Gesetz« mache (6 ff.), andererseits als »Falsifikationsmodell« (19 ff.) für die nähere Bestimmung dessen, was man sich unter dem Begriff des Rechts vorzustellen habe. Auf diese Weise gewinnt Neuner eine ganze Reihe fundamentaler Rechte, deren fragmentarische Aufzählung »zusehends und zwangsläufig zur Aneinanderreihung der klassischen, sowohl in der Weimarer als auch in der Bonner Verfassung garantierten Menschenrechte « (25) gerät.

Nun möchte Neuner diese Rechte natürlich nicht nur gewinnen oder der Disposition des Gesetzgebers entziehen, denn das könnte er schließlich deutlich einfacher durch einen Blick in den Sartorius; vielmehr geht es ihm darum zu zeigen, daß Richter an entgegenstehende Gesetze nicht gebunden seien (45). Dies ist insofern erstaunlich, als es in den letzten Jahren Ziel der meisten rechtsmethodologischen Anstrengungen war, die Möglichkeiten einer richterlichen Gesetzesbindung überhaupt erst zu begründen, und nicht, die ohnehin wenig begrenzende Wirkung der positiven Gesetze durch die Behauptung naturrechtlicher Notwendigkeiten weiter zu schwächen. Im Gegensatz zur klassischen Zielsetzung, die Gesellschaft vor dem Rechtsanwender in Schutz zu nehmen, möchte Neuner den Rechtsanwender also vor dem Gesetz schützen.

Diese für eine methodologische Arbeit verblüffende Absicht erklärt sich aus Neuners Verständnis der historischen Zusammenhänge, die zu der »vorangegangenen planmäßigen Lebensvernichtung durch die Staatsorgane « geführt haben, und dem »nicht unerheblichen Anteil« der Justiz an diesen Vorgängen (7). Wer sich nun unter diesem Anteil der Justiz ihre willfährige Gefolgschaft oder ihre opportunistische Anbiederung an die neuen Machthaber vorstellt, der wird von Neuner eines Besseren belehrt. »Eingehend « (7 Fn. 12) erläutert Neuner seine Sicht der Dinge so (32-35): Radbruch habe »uneingeschränkt recht « mit seiner Behauptung, der Positivismus habe den deutschen Juristenstand wehrlos gegen gesetzliches Unrecht gemacht. Der gängige

10 Jörg Neuner, Die Rechtsfindung contra legem. München: C. H. Beck, 2. Auflage 2005, $220 \mathrm{~S}$. 
»Vorwurf einer historischen Fehlbeurteilung « sei »leichtfertig « und entbehre »jeder Grundlage«. Zwar hätten die Gerichte »mitunter eine , unbegrenzte Auslegung ' betrieben« und seien »im verhängten Strafmaß zum Teil sogar über die Vorstellungen der Reichsführung « hinausgegangen. Dies ändere aber nichts an den »zahllosen gesetzeskonformen Unrechts-Urteilen«.

Eine Schlußfolgerung aus diesen »historischen Fakten« fehlt. Das paßt zu Neuners Stil, der, bevor er mit Radbruch den Positivismus als Ursache des justiziellen Unrechts ausgemacht hat, die »unbestreitbare geschichtliche Tatsache« verkündet, »daß weder der Relativismus noch der Positivismus geistiger Ahnherr der NS-Rechtsideologie war «. Zudem sei »kein Wort darüber zu verlieren, daß gerade unter dem Deckmantel des Naturrechts größtes Unrecht in der Geschichte immer wieder heraufbeschworen wurde«. Dies gelte auch für die Nationalsozialisten und ihre Berufung auf die Rechtsidee.

Nachdem er trotz dieser Zugeständnisse den Positivismus für die Wehrlosigkeit der Juristen verantwortlich gemacht hat, schwingt sich Neuner zu der Behauptung auf, der Relativismus widersetze sich einer Bestimmung des Rechtsbegriffs und trage »in Verbindung mit dem Positivismus bei einmal etablierten Unrechtssystemen zu deren Stabilisierung bei«. Die damit eigentlich naheliegende Verteufelung des Positivismus wiederum erspart Neuner sich und dem Leser und erklärt im nächsten Satz, es gehe nicht um eine »historische Anklage gegen den Positivismus«. Vielmehr sei die These »Gesetz ist Gesetz« nach Auschwitz neu zu bewerten - dies wiederum, obwohl »klar « sei, »daß sich ,Auschwitz ' weitgehend außerhalb des positiven Rechts vollzog «.

Nun ist Neuner zuzugeben, daß es sich bei seiner Beschäftigung mit dem Nationalsozialismus in der Tat nicht um eine historische Anklage gegen den Positivismus handelt. Dazu hätte er wenigstens an irgendeiner Stelle definieren müssen, was er sich unter »Positivismus « vorstellt. Genau das tut er aber nicht, sondern begnügt sich damit, in den einschlägigen Passagen die üblichen Schauermärchen zu wiederholen, dem Positivismus seien teleologisches Rechtsdenken, Interessenjurisprudenz, Analogiebildungen oder Gewohnheitsrecht fremd, da er sich auf die »inhaltsleere Verpflichtung gegenüber dem Buchstaben des Gesetzes« (146) beschränke. Auf dieser Grundlage kann Neuner den Positivisten entgegenhalten, die befriedende Wirkung des richterlichen Urteils müsse mit materialen Gerechtigkeitskriterien verbunden werden, da das Urteil ansonsten auch durch »Losentscheid oder Münzwerfen« (70) herbeigeführt werden könnte. Mechanismen, die üblicherweise unter dem Stichwort »Legitimation durch Verfahren « zu finden sind, scheinen Neuner - im Gegensatz zum Positivismus fremd zu sein.

Außerdem sind Neuners historische Ansichten über die Justiz und ihr Tun während des »Dritten Reiches« zu abwegig, um als Klageschrift tauglich zu sein. Dies betrifft nicht nur die Rolle der Juristen. Auch seine Aufzählung »spezifischer NS-Gesetze« (19 ff.) suggeriert fälschlicherweise, daß sie beliebig fortgesetzt werden könne und letztlich das gesamte gesellschaftliche Leben im »Dritten Reich « mit nationalsozialistischen Gesetzen überzogen gewesen sei. Zudem übersieht Neuner erneut die legitimierende Kraft des Verfahrens. Die Gleichsetzung von Gesetz und Recht verzichtet zwar auf materiale Anforderungen an die Gesetzgebung, nicht aber auf die Errungen- 
schaften der formalen Gerechtigkeit, welche ja nicht von ungefähr einer der ersten Amtshandlungen des nationalsozialistischen Regimes zum Opfer fielen. Infolgedessen kann einer Aufzählung von Gesetzen, die unter Mißachtung materialer Gerechtigkeitskriterien und rechtsstaatlicher Formvorschriften erlassen wurden, nur entnommen werden, daß solche Gesetze ungerecht sind. Das freilich wird auch kein Positivist bestreiten. Was Neuner erreicht, ist deshalb nicht viel mehr als die Widerlegung eines positivistischen Zerrbildes mit einer historischen Karikatur.

Sind Neuners Ansichten somit historisch und rechtstheoretisch weitgehend vernachlässigenswert, erfordern seine Äußerungen über die nationalsozialistische Justiz gleichwohl zwei Anmerkungen: Bei allem Respekt vor den guten Absichten, die Neuners Versuch einer historischen Begründung naturrechtlicher Fundamentalnormen motiviert haben mögen, ist es starker Tobak, den Juristen des »Dritten Reiches« Wehrlosigkeit gegenüber dem legislativen Unrecht ihrer Zeit zu bescheinigen. Die tragende Rolle der Juristen bei der Etablierung der nationalsozialistischen Herrschaft, ihr vorauseilender Gehorsam bei der Umsetzung der neuen und der Umformung der alten Gesetze sind ausreichend beleuchtet, um eine passive Ergebenheit der Justiz in ihr unrechtsverbreitendes Schicksal für ausgeschlossen zu halten. Daß Neuner bei diesem Forschungsstand längst überwunden geglaubte Argumentationsmuster wiederauferstehen läßt, ist wirklich ärgerlich.

Ferner ist der Ansicht Neuners zu widersprechen, das »theoretische Fundament für die NS-Rechtsideologie « seien weder Relativismus noch Naturrecht gewesen, »sondern es war schlechtweg eine Rechtsperversion sui generis« (45). Abgesehen davon, daß die nationalsozialistische Rechtslehre durchaus naturrechtlich geprägt war, vermögen solche pathetischen Bekenntnisse nur einem Geschichtsbild Vorschub leisten, in dem das »Dritte Reich « ein historischer Betriebsunfall und die Nazis Außerirdische waren, die am 30. Januar 1933 auf der Erde gelandet und am 9. Mai 1945 wieder verschwunden sind. Die ebenfalls eingehend untersuchten personellen und sachlichen Kontinuitäten nach der sogenannten »Stunde Null« legen andere Schlußfolgerungen nahe.

So falsch der historische Ausgangspunkt, so belanglos die Konsequenzen: Die Notwendigkeit metaphysisch begründeter Rechtswerte belegt Neuner ausgerechnet mit der Anweisung aus Wittgensteins Tractatus, man müsse darüber schweigen, wovon man nicht sprechen könne (32). Daß Wittgenstein sich hierbei gerade auf metaphysische Letztbegründungsversuche bezieht, unterschlägt Neuner natürlich. Außer der Metaphysik werden das Richterrecht (70 ff.), »vorherrschende sozialethische Vorstellungen« (73 ff.) und die Natur der Sache als Rechtsquellen bemüht (77 ff.). Die Nähe der letzteren zum konkreten Ordnungsdenken von Carl Schmitt thematisiert Neuner aus verständlichen Gründen nicht. Und im Ergebnis: nichts Neues. Wie alle Naturrechtler läßt sich Neuner von der Natur das diktieren, was er ihr vorher eingeflüstert hat: kein Sonderstrafrecht, keine rassenspezifische Differenzierung, dafür Religions-, Gewissens- und Meinungsfreiheit, Freizügigkeit, freie Wahl des Lebenspartners, Recht auf Leben (25), »Selbstbestimmung und Selbstbindung im Vertrag, Äquivalenzund Vertrauensprinzip«, »Schuldprinzip, Schadenshaftung«, »Teilhabe, Gleichbehandlung und Verhältnismäßigkeit, sozialer Ausgleich«, »Rechtsschutz, Verfahrens- 
grundsätze« (45). Warum die Entdeckung dieser Rechte 84 Seiten erfordert und warum ihre Begründung dann auch noch »metaphysisch « genannt wird, bleibt Neuners Geheimnis.

Der Vollständigkeit halber ist auf die beiden folgenden Kapitel des Werkes hinzuweisen, in denen sich Neuner mit der richterlichen Bindung an das Gesetz (85-138) und den »Möglichkeiten und Grenzen der Gesetzesderogation« (139-182) befaßt. Dort wird zu Beginn der Sinn der Gesetzesbindung darin ausgemacht, der Richter habe »den Wert der Rechtssicherheit auf der Grundlage einer demokratisch legitimierten Regelvorgabe zu verwirklichen « (88). Dies ist folgerichtig, hat Neuner doch schon im ersten Teil hinreichend deutlich gemacht, daß er von formalen Gerechtigkeitskriterien nicht viel hält. So nimmt er hier wiederholt Bezug $(109,129)$ auf seinen bereits im ersten Kapitel vorgetragenen Anspruch, der Richter müsse eine Entscheidung treffen, die »von einem objektiven Richtigkeitsanspruch getragen« ist (81). Schon eine Entscheidung, die »sich nur dem Vorwurf der Unvernunft nicht aussetzt«, wäre »schlechterdings inakzeptabel« (81). Auch das Nachwort zur zweiten Auflage (186-197) ist in dieser Hinsicht nicht relevant änderungswillig (190 f.).

Diese bekanntlich von Dworkin in die Welt gesetzte Zielvorgabe für die richterliche Urteilstätigkeit wird erstaunlicherweise nicht von dem Versuch begleitet, objektive Kriterien anzugeben, anhand derer die Richtigkeit einer Entscheidung gemessen werden könnte. Menschenrechte, materiale Gerechtigkeit und Metaphysik sind als Maßstab jedenfalls nur in einer Gesellschaft tauglich, die es ausschließlich mit der strafrechtlichen Bewältigung untergegangener Diktaturen zu tun hat, mit Massenmord, Genozid, obrigkeitlicher Willkür und herrschaftlicher Tyrannis. Für die Probleme der modernen Gesellschaft, in der technologischer Fortschritt und unüberschaubare Ausdifferenzierung zu immer mehr und immer gerechtigkeitsferneren Konflikten führen, bleibt Neuners Modell ohne jede Aussage.

Immerhin offenbart Neuner mit seiner »right answer thesis « (129), daß er die Rechtsfindung als Problem der Erkenntnis (und nicht der Kommunikation) betrachtet: Seine juristische Methodenlehre zielt auf »ein Höchstmaß an Rationalität und kritischer Reflexion auf die juristischen Erkenntniswege und Erkenntnismittel« (89). Diese Erkenntniswege näher zu untersuchen, fällt Neuner freilich nicht allzu schwer, weil er nicht nur darauf verzichtet, den Gegenstand der Rechtserkenntnis auf seine Existenz hin zu untersuchen, sondern generell erkenntnistheoretische Überlegungen für überflüssig erachtet. Deshalb kann er die Welt streng unterteilen in Subjekt und Objekt und den kognitiven Bemühungen des Rechtsanwenders überall dort Erkenntnisgegenstände gegenüberstellen, wo andere bestenfalls heuristische Fiktionen ausmachen können: im Willen des Gesetzgebers (103 ff.), in der Einheit der Rechtsordnung (105 ff.) und in objektiven Normzwecken (110 f.).

Auf diese Weise werden das Recht und seine Erkenntnis mit Händen greifbar, so daß es größerer theoretischer Anstrengungen nicht mehr bedarf, um die »einzig richtige Entscheidung « (72) in jedem Einzelfall zu finden. Und wer bei so viel gegenständlicher Evidenz immer noch eine rechtserzeugende Beteiligung des Rechtsanwenders für möglich hält, der muß sich an dem zu Stein gewordenen Recht Neuners die Zähne ausbeißen. Der Einzug der Hermeneutik ins Recht etwa scheitert an den »auto- 
nomen methodologischen Entscheidungsmöglichkeiten der Juristen «, derentwegen »auf eine unkritische Übernahme hermeneutischer Prämissen [...] zu verzichten« sei. Stattdessen habe man zu »analysieren, wie entsprechend den Vorgaben des Grundgesetzes die mit der Gesetzesbindung implizierten Werte optimal ausgeschöpft werden können « (89 f.). Grundgesetz statt Gadamer also, denn Neuners Verfassung schert sich nicht um interpretatorische Vorverständnisse.

Wer sein Recht auf einem solchen Fundament errichtet, der muß auch die sprachtheoretische Kritik an der Wortlautgrenze nicht fürchten. Da die »radikalen Linguisten« (97) aus Heidelberg genauso blind sind für Neuners Offenkundigkeiten wie die gesamte bedeutungsskeptische Sprachphilosophie, sind sie einer Auseinandersetzung nicht wert. Mit der Behauptung, Sprache sei regelgeleitet (101) und stehe einer »auBersprachlichen Wirklichkeit« (99) gegenüber, sind auch Schiffauer und Hegenbarth widerlegt, und Neuner kann es sich gemütlich machen in der Wärmstube der »modernen Rechtslinguistik « (96) und ihrer Unterteilung in positive, neutrale und negative Kandidaten. Soviel theoretische Enthaltsamkeit läßt sich selbstredend auch nicht von der Frage beirren, wie man über eine außersprachliche Wirklichkeit sprechen können soll oder warum eine fließende Wortlautgrenze (96) die Bezeichnung »Grenze« verdient hat.

Am Ende seiner rechtstheoretischen Geisterfahrt gelangt Neuner zu der Feststellung, eine Entscheidung contra legem liege dann vor, »wenn die Regelungsabsicht des historischen Gesetzgebers mißachtet wird, sofern diese mit dem möglichen Wortsinn der Gesetzesnorm noch vereinbar ist oder im Wege der Analogie oder Restriktion durchgesetzt werden könnte « (132). Wann eine solche Entscheidung zulässig ist, stellt Neuner im abschließenden Kapitel dar; etwa dann, wenn ansonsten ein Verstoß gegen die Menschenwürde vorläge (141) oder physisch Unmögliches verlangt würde (141 ff.). Wandlungen der Gesamtrechtsordnung sind zu berücksichtigen (151 ff.), Willkür ist verboten (157 ff.), und letztlich ist eine Gesetzesderogation auch gerechtfertigt, »sofern der Gesetzgeber ersichtlich ohne eigenständige Willensbildung fehlerhafte Vorgaben der Ministerialbürokratie übernommen hat«, letzteres aber nur »in besonders gelagerten Ausnahmefällen« (181).

Mit solchen Weisheiten sind in der Methodendiskussion der Gegenwart keine Fortschritte zu erzielen. Aus der Suche nach materialer Gerechtigkeit, die Neuners gesamtes Werk durchzieht, können keine methodischen Anleitungen für den Richter gewonnen werden. Der Richter legt nicht ergebnisoffen aus, bis er die richtige Entscheidung gefunden hat, sondern er operiert unter Entscheidungszwang. Auslegen und Entscheiden sind jedoch verschiedene Tätigkeiten: Während erstere regelgeleitet vorgehen kann, ist eine normative Bindung bei letzterer ausgeschlossen.

Dem eine metaphysische Allesnorm oder die Werteordnung der Grundrechte (27) entgegenzuhalten, verschärft das Problem nur. Denn die Berufung auf Werte dient bekanntermaßen dazu, den Entscheider der Entscheidung unsichtbar zu machen. Mit einem metaphysischen Rechtsbegriff ist »Methodenklarheit und Methodenehrlichkeit« (185) deshalb von vornherein nicht zu erreichen. Und so bleibt es dabei: Auch wenn immer wieder ihre Auferstehung gefeiert oder sogar ihr zwischenzeitliches Ableben bestritten wird (187 Fn. 6) - die klassische Methodenlehre ist tot. 


\section{Inbrünstig verbellt}

Der kalte Krieg? Doch, man erinnert sich noch, wenn auch mit zunehmender Mühe. Das war in unserer Region zu jener Zeit nach 1960, als die Kommunisten den »antifaschistischen Schutzwall« bauten, um ihre Bürger am Davonlaufen zu hindern. Als die (relativ schlichten) Antikommunisten in der BRD »den Linken« eben jene Davongelaufenen zum Tête-à-tête empfahlen und, wenn dies nichts half, nahe legten, doch schleunigst »nach drüben « zu gehen; als den Antikommunisten die (guten) Anti-Antikommunisten entgegentraten mit der verwegenen Behauptung, die »da drüben « hätten ihre Weltrevolutionspläne längst aufgegeben und im übrigen soviel Angst vor uns wie wir vor ihnen; und als sich schließlich die (intellektuellen) Anti-Anti-Antikommunisten zu Wort meldeten, um einerseits die heilige Einfalt der Anti-Antikommunisten zu verspotten, die ungeachtet der Toten an der Mauer von friedlicher Koexistenz, wenn nicht gar von Konvergenz der Systeme träumen würden, andererseits aber, um das Brüllen der grimmigen Antikommunisten als indezent und sachwidrig zurückzuweisen.

Es war eine turbulente Zeit, die auch die Juristen, zumal die historisch und theoretisch Interessierten unter ihnen, nicht kalt ließ. Der Nachkriegsschock hatte seine lähmende Kraft eingebüßt. Der Terminus »Aufarbeitung « verließ sein angestammtes Revier der Kleider und Mäntel und drang in die Wissenschaften ein. »Linke« und »Rechte« wurden auch außerhalb der Politik sichtbar. Es war das erste und vielleicht sogar das letzte Mal in der Geschichte der Bundesrepublik, daß die Juristen verunsichert in großem Umfang »Nachbarwissenschaften« diskutierten und rezipierten. Soziologie und Ökonomie, Philosophie und Pädagogik, Psychologie und Politik wurden Gegenstand hilfesuchenden interdisziplinären Begehrens. Rechts- und justizkritische Literatur quoll aus allen Regalen, Erkenntnistheorie und Sprachphilosophie wurden um Rat angegangen - ein kritischer Druck, der erst mit Beginn der 80er Jahre deutlich nachließ und sich schließlich in der behäbigen Ruhe jenes Jahrzehnts, ohne sichtbare Spuren zu hinterlassen, auflöste.

\section{$I$.}

Eben am Beginn dieser Wende ins Gemächliche und Verflossene publizierte ein österreichischer Gelehrter ein umfangreiches Methodenbuch, vielleicht die dickste juristische Methodenlehre, die jemals in deutscher Sprache verfaßt wurde: Franz Bydlinski, Juristische Methodenlehre und Rechtsbegriff, 1. Auflage 1982 (Stand 1981), 2. Auflage 1991 (mit Nachwort), Wien, New York: Springer Verlag, 671 S. Als das Buch ausgearbeitet wurde, war die Debatte um die »Gewißheitsverluste« (Haverkate) des Rechts in vollem Gange; als es auf den Markt kam, hatte sich der Sturm bereits gelegt, so daß das Werk den Zeitgenossen gleich als Hüter der Vergangenheit erschien, als monumentales Dokument »eines fest bestimmten konservativen dogmatischen Standpunktes, von dem aus die Rechtswissenschaft [...] als eine rationale geisteswissenschaftliche Disziplin verteidigt wird « (Engisch).

Das »durch und durch antimoderne Buch« (Mayer-Maly) zerfällt in drei Teile (»Bücher«) von nahezu gleichem Umfang. 
Das 1. Buch, mit dem Titel »Zum Stand der Grundlagendiskussion« (1-177), kann aus heutiger Sicht nur noch historisches Interesse beanspruchen. Für Nachgeborene zweifellos erstaunlich und lehrreich ist allerdings die wütende Gereiztheit, mit der die traditionelle Jurisprudenz seinerzeit auf die Herausforderungen durch ihre (vielfach, aber nicht immer, politisch motivierten) Kritiker reagierte. Bydlinski faßt diese Nachdenklichen unter der Bezeichnung »Antidogmatiker« zusammen und knüppelt die solcherart gezeichneten und gekennzeichneten Wissenschaftler lautstark und ohne Rücksicht auf Subtilitäten hinsichtlich der jeweiligen Positionen kurzerhand zusammen. Dabei wimmelt es nur so von »verfehlt«, »unbrauchbar«, »in keiner Weise dargetan«, »einfach unsinnig «, »lächerlich«, »schlechthin phantastisch« etc., während der eigenen Position gebetsmühlenhaft die »größtmögliche Rationalität« attestiert wird (natürlich ohne jemals ein Wort darüber zu verlieren, was Rationalität in diesen Kontexten besagen und bewirken soll).

Besonders hart trifft die Bydlinskische Wut verständlicherweise die Häretiker, also diejenigen, die, nachdem sie jahrelang das Richtige gedacht und gemacht haben, ohne einen für B. verständlichen Grund vom wahren Glauben abgefallen sind und begonnen haben, irgendwelchen »verstiegenen « erkenntnistheoretischen Götzen zu opfern. Josef Esser figuriert hier als negativer Held. Gerade weil ihm herausragende dogmatische Arbeiten von großer Eleganz und praktischer Treffsicherheit zu verdanken sind, bleibt es für Bydlinski vollständig rätselhaft, wieso ein solcher Gelehrter sich in ständigem Abstieg von seinen Schriften »Grundsatz und Norm « bis hin zu »Vorverständnis und Methodenwahl « in eine juristische Hermeneutik verirren konnte, die der Mann aus Wien als »kaum nachvollziehbar« empfindet. Die Unfähigkeit oder besser: Unwilligkeit des Dogmatikverteidigers, zwischen Akteur und Beobachter zu unterscheiden und demgemäß Rollenhandeln und kritische Selbstreflexion (zumal wenn sie in einer einzigen Person zusammentreffen) angemessen zu würdigen, zeitigt allerdings noch manches andere Opfer.

»Erkenntnistheoretisch verstiegen « setzen solche Kollegen des armen Bydlinski, obwohl »deutlich ad absurdum geführt«, auf »irreale erkenntnistheoretische Anforderungen«, statt der »größtmöglichen Rationalität« zu hofieren. Der rhetorische Kunstgriff, mit dem Bydlinski sich zu solchen Anwürfen legitimiert, besteht in seiner Selbststilisierung als praktisch arbeitender, philosophisch durchaus (wenn auch nicht zu sehr) interessierter, obgleich nicht sonderlich versierter Jurist, der die »elitären Erkenntnisansprüche « naturgemäß unter dem Gesichtspunkt ihrer fachlichen Nützlichkeit prüft. Dergestalt als altruistischer Verfechter der Simplizität maskiert, deutet er voller Abscheu auf die skeptischen Steine, die ihm statt des erwarteten Glaubensbrotes gereicht werden.

Zeigt sich bei den Häretikern immerhin noch ein gewisser, den intellektuellen Leistungen der wissenschaftlichen Gegner geschuldeter Respekt, so haben diejenigen nichts zu hoffen, die Bydlinski im Verdacht hat, ideologischen Vorurteilen anheim gefallen zu sein. Sie, die »Ideologen aller intellektuellen Kaliber«, unter denen selbstverständlich die »Marxisten chaotischer Observanz« einen prominenten Platz angewiesen erhalten, verbreiten ihren »tendenziösen Unsinn« in der Absicht, durch »rechtsfeindliche Propaganda « ihre »Machtgier« und ihre »Hybris« zufrieden zu stellen. 
Die schon fast mitleiderregenden Ausfälle, mit denen der Autor sich über die »monomanische Besserwisserei« seiner »Rechtsfeinde« hermachte, lassen ihn vor seinen eigenen, breit und lamentierend ausgebreiteten Weisheiten erblinden: »Nichts ist einfacher, aber auch sinnloser, als die eigene subjektive Wertung für die allgemeine zu erklären«. (399) Wie wahr! Leider fehlt dieser Einsicht die selbstbezügliche Wendung.

Am Ende des 1. Buches steht dann die Rechtsdogmatik als wissenschaftliche Jurisprudenz »im engeren Sinne« triumphierend auf dem Siegespodest, während den antidogmatischen Verlierern dieser Post-McCarthy-Kampagne gnädig zugestanden wird, daß sie zwar in der Lage seien, Rechtsfragen »durchaus und endlos zu diskutieren«, aber nicht, sie einer »begründeten Lösung zuzuführen«, so daß es im wesentlichen bei dem bleiben kann, was, nach Bydlinskis kühner retrospektiver Vision, die Juristen seit $»$ Jahrtausenden « zu tun pflegen: Sie widmen sich der »Rechtsgewinnung «.

II.

Wer in der Rechtsgewinnung seine Lebensaufgabe gefunden hat, der braucht, wie nicht zweifelhaft sein kann, eine konkrete Vorstellung von »Recht«. Er muß über einen »Rechtsbegriff« verfügen, wenn er in der Lage sein soll, jenen Rechtssatz aufzufinden (oder besser: zu bilden), der im berühmten Justizsyllogismus als erste Prämisse eingesetzt wird. Denn irgendein normativer Satz (und damit jeder beliebige) kann wohl kaum in Frage kommen.

Das zweite Buch des Methodenwerkes ist dementsprechend dem Rechtsbegriff, seiner methodologischen Bedeutung und seiner Gewinnung gewidmet (179-391):

Bydlinski vollzieht also jetzt einen Schwenk von der Verteidigung der alltäglichen Mühen in der Ebene der Dogmatik zu den Genüssen der Höhe theoretischer und philosophischer Betrachtung derselben. Diese Metamorphose des Autors vom Praktiker zum Philosophen bringt dem Leser den Gewinn einer durchweg etwas milderen sprachlichen Gangart, ein Vorteil, den er allerdings dadurch wieder verliert, daß er strapaziösen Weitschweifigkeiten ausgesetzt wird.

Das philosophische Unternehmen wird von Bydlinski als »Versuch, zu einem Brückenschlag zwischen Rechtstheorie und Rechtsdogmatik« zu gelangen, qualifiziert. Das verführerische Bild vermag freilich das Unbehagen nicht zu beseitigen, welches sich bei dem Bemühen einstellen muß, sich vorzustellen, wie rechtliches Handeln (»Dogmatik«) und die kritische und systematische Beobachtung und Erklärung desselben (»Theorie«) durch eine »Brücke« (?) so verbunden werden sollen, daß beide ihre naturgemäß getrennten Ufer behalten können.

Tatsächlich entwirft der Verfasser nichts anderes als eine säkularisierte Naturrechtslehre, die sich von den zerknirschten Naturrechtsbekenntnissen »jeglicher Observanz« der Nachkriegszeit nur durch die Wortwahl, nicht aber durch die Funktion unterscheidet. Statt der Brücke gibt es also eine Vereinigung, wobei das positive Recht am Ende deutlich den Kürzeren zieht.

Ausgangspunkt der Überlegungen des Verfassers ist die kaum zu bestreitende Feststellung, daß für den gesuchten Rechtsbegriff eine Beschränkung ausschließlich (!) auf die gesetzten, positiven Normen nicht genügen kann. Jedenfalls zeigt schon jede eingehendere Analyse von Urteilsbegründungen, daß offenkundig neben den »nackten« 
Normen noch allerhand Regeln anderer Art zur Anwendung gekommen sind: Auslegungsregeln, Optimierungsregeln (»Prinzipien«), Folgeerwägungen etc. Sie stehen, so Bydlinski, unverbunden neben dem positiven Recht - eine Feststellung, die allerdings nur dann einigermaßen plausibel ist, wenn man diesem eine schwer vorstellbare ontologische Borniertheit auferlegt.

Kelsen, der in diesem zweiten Buch die inbrünstig verbellte Stellung erhält, die Esser im ersten Buch einnahm, sollte von solcher Beschränktheit gewesen sein, daß er geglaubt haben könnte, die Rechts»anwendung « könne sich im Zitieren des gesetzten Rechts erschöpfen, eines Rechts, das obendrein, entblößt aller Regeln der Interpretation, nach Ansicht seines entrüsteten Widersachers »praktisch mangels Erkennbarkeit seines Inhalts völlig irrelevant « geworden ist?

Auf dieser Karikatur des »positivistischen Ansatzes« errichtet Bydlinski seinen, wie er es nennt, »werthaltigen « oder »wertabhängigen« Rechtsbegriff, nachdem er auf rund 25 Seiten beim »naturrechtlichen Ansatz« um Anregungen eingekommen ist. (Es ist nicht ohne Ironie, daß ausgerechnet B. von dieser modernistischen Übersetzungsmissgeburt des angelsächsischen »approach « üppigen Gebrauch macht.) Die erforderliche Ergänzung des positiven Rechts wird dadurch bewerkstelligt, daß die im Stufenbau der Rechtsordnung an der Spitze stehende »Grundnorm « mittels der »Rechtsidee« (bestehend aus den Elementen »Rechtssicherheit«, »Zweckmäßigkeit « und »Gerechtigkeit«) in eine materiale, korrigierende, ergänzende und legitimierende Generalanweisung verwandelt wird. Mit ihr läßt sich dann in der Tat, wie Bydlinski mühelos zeigen kann, das gesamte methodologische und transpositive »Rechtsgewinnungsmaterial« (in seiner Sprache könnte man hinzufügen: und nicht nur seine eigene, sondern alle Ideologien verschiedenster Observanz) »ableiten «.

Bydlinski hat seine Auffassung von der »Rechtsidee« als Bestandteil des Rechtsbegriffs zunächst nicht als Naturrecht deklariert und sie hinter und in seinem »Rechtsbegriff « verschwinden lassen. Einige Rezensenten (vgl. etwa Rill und Walter) haben das aber sogleich entdeckt und unter diesem Gesichtspunkt kritisch gewürdigt. Nur Mayer-Maly (Anmerkungen zu einer Theorie der wirklichen Jurisprudenz, Juristische Blätter, 106, 1984, 1-9) hat dem Verfasser das Naturrechtsetikett entschieden verweigert - zweifellos in wohlwollender Absicht, denn sonst hätte er seine vernichtende beiläufige Bemerkung über rationalistische Naturrechtslehren auch auf Bydlinski anwenden müssen. Allerdings hat Bydlinski selbst wenige Jahre später durch sein Werk »Fundamentale Rechtsgrundsätze« (Zur rechtsethischen Verfassung der Sozietät. Wien, New York: Springer Verlag, 1988, 327 S.), mit dem er das hier in Rede stehende 2. Buch seiner Methodenlehre umfassend absichern wollte, allen Zweifeln ein Ende bereitet, indem er bekannte, daß er sich um die »Wiederbelebung eines gemäßigten Naturrechtsdenkens « bemühe.

Anstelle von Mayer-Maly hat dann Ogorek nachgewiesen (R. Ogorek, Gesucht: Rechtsethik, westlicher Typ, RJ 9, 1990, 403-427), daß die Mayer-Maly 'sche Sentenz, es sei für die rationalistischen Naturrechtslehren ein grundlegender Irrtum »notorisch«, nämlich das »Absolut-Setzen der zur Zeit und am Ort der Entstehung einer Theorie anerkannten Rechtssätze «, auch im Fall Bydlinski keine Ausnahme erfährt. Auch er ist dem Zentraldilemma aller Naturrechtsdenker erlegen, die offenbar aus der 
»Natur« DES Menschen trotz größter Mühen immer nur wieder sich selbst mit ihren jeweiligen historischen und sozialen Urteilen und Vorurteilen ans Tageslicht ziehen können. Auf Bydlinski bezogen heißt dies: »Von den vagen Humanisierungshoffnungen abgesehen, stellt dieser Wiederbelebungsversuch naturrechtlichen Denkens in erster Linie die binnenjuristische und damit unterkomplexe Verarbeitung eines diffusen Unbehagens an der Rolle dar, die dem Recht und seinen professionellen Verwaltern im heutigen Staat zugewiesen ist « (Ogorek, 427).

III.

Im dritten und letzten Buch des Werkes folgt dann jener Teil, aus dem die traditionellen Methodologien in der Regel und zu Recht ausschließlich bestehen: »Die Methoden der Rechtsgewinnung « (391-653).

Will man sich vergewissern, welche Position ein Autor auf diesem Feld besetzt, lohnt es sich kaum, die beliebigen Auffassungsvarianten über die Zahl und die Namen der »canones der Auslegung « zu studieren oder die diffizilen Taxinomien des Lückenphänomens einer genaueren Betrachtung zu unterziehen. Umstandsloser gelangt zum Ziel, wer sich auf eine rasche Gretchenfrage konzentriert. Sie zielt auf zwei Sachverhalte:

Einmal auf die Frage, wie es der Autor mit der Wortlautgrenze (Wortsinngrenze) hält. Hier, am viel beschworenen »noch möglichen Wortsinn « entscheidet sich, ob der Autor dem Interpreten Grenzen zieht, wie diese aussehen und was er von der Welt der »Rechtsfortbildung «, der Analogien und der juristischen Schlüsse hält - kurzum: Die Entscheidung für Essentialismus oder Nominalismus ist unvermeidlich.

Der zweite kritische Punkt ist die Frage nach der Rangfolge der Auslegungsregeln, besser noch, nach einer Hierarchie derselben. Denn an dieser Frage hängt die Entscheidung, ob diese Regeln normative Anweisungen sind, denen man folgen muß, oder statistische Beobachtungen von Argumenten, die man benützen kann oder auch nicht. Mit anderen Worten: An dieser Stelle kann man sehen, ob ein Autor von einer »Methode « handelt, die diesen Namen verdient, d. h. von einem Weg, der zu gehen ist, will man zum Ziel gelangen.

Die erste Frage wird von Bydlinski in durchaus faustischer Weise bearbeitet. Mit einem Redeschwall, der darauf abzielt, das Hirn des Fragers so nachhaltig zu vernebeln, daß er bereit ist, die ausbleibende Antwort für einen Fehler seiner eigenen Frage zu halten.

Die diesseits und jenseits der durch den möglichen Wortsinn markierten Grenze anfallenden »methodischen Vorgänge« könnten, so meint der Autor, »strukturell allerdings zum Teil übereinstimmen«. Man müsse sich schon fragen, »warum gerade der ,mögliche Wortsinn“ eine besondere Grenze« bezeichnen solle. Auch lasse die herrschende Abgrenzung nach dem Wortsinn durchaus Zweifel offen - freilich nur im ungünstigen Fall. Überhaupt sei zutreffend, »daß die Grenze zwischen Auslegung und Analogie [...] praktisch fließend ist«, denn schließlich sei auch »die Grenze des möglichen Wortsinns fließend«. Folgerung aus soviel Flüssigkeit? »Das ist aber unvermeidlich und daher kein Einwand«. Warum sollte auch der Hinweis, daß bei Vornahme der Operation der Tod des Patienten unvermeidlich sei, ein »Einwand « sein? 
Die Antwort ist ohnehin recht einfach (zumal anderen Methodologen bislang ebenfalls nichts Besseres eingefallen ist): Ungeachtet aller Schwierigkeiten ist es »aus rechtlichen Gründen notwendig für die juristische Methodenlehre, an der Wortsinngrenze festzuhalten«. Was sein muß, das muß sein, sagt der politisch gewitzte Methodologe. »Daß diesseits und jenseits der Grenze logisch oder hermeneutisch teilweise übereinstimmende Vorgänge zu beobachten sind, braucht an diesem Kriterium als einem juristisch zweckgerechten nicht irre zu machen« (467-471).

Nach dieser Kapitulation der Einsicht vor der Absicht oder der Theorie (vermutlich: »verstiegen«) vor der Praxis (vermutlich: »größtmöglich rational«) stellt man die zweite Gretchenfrage ohne große Hoffnung. Und in der Tat: Das böse Vorurteil wird durch den 5.Teil des 3. Buches (553-571) in keiner Weise widerlegt.

Es war schon frühzeitig angedeutet worden, daß die Grenze »zwischen den einzelnen Methoden der Rechtsgewinnung praktisch fließend ist« (470 Anm. 143), ein Mißgeschick, das jetzt (564) noch dahingehend verschärft wird, daß der Autor feststellt, »die einzelnen juristischen Methoden« seien »in der Praxis der Rechtsgewinnung häufig gar nicht streng zu unterscheiden« (!!), wodurch das Problem, welcher Rang ihnen jeweils zuzubilligen ist, nicht gerade verkleinert wird. Panta rhei, alles fließt, das sagten schon die Alten, und das dürfte, um mit dem Autor zu sprechen, eine »unleugbare Erfahrungstatsache « sein, die »ganz und gar evident « ist.

Bei dieser Lage der Dinge konnte Bydlinski schlechterdings nicht mehr zustande bringen als die Empfehlung, der interpretierende Jurist solle sich vorrangig an »die jeweils einfachere, d. h. mit dem leichter und verlässlicher zu ermittelnden normativen Prämissenmaterial arbeitende Methode« wenden, ein Ratschlag, auf den ein Interpret hoffentlich auch ohne Bydlinskis Gedankenarbeit gekommen wäre. Führt der leichte Weg zum Ziel, bedarf es keiner weiteren Worte, denn der Rechtsanwender solle nur dann seine »methodischen Bemühungen « fortsetzen, wenn der »Bedarfsfall « eingetreten sei, »d. h. wenn noch keine Lösung erreicht ist (561 ff.). Sollten sich auf diesem Wege bedauerlicherweise »Argumente von durchaus unterschiedlicher Stärke ergeben«, wird am Ende eine »Gesamtabwägung der Auslegungsargumente« dem Juristen das gewünschte Ergebnis bescheren.

Da alle diese »Wertungen«, d. h. also: Entscheidungen (!) zur Frage, was »einfach«, »leicht«, »verläßlich«, »Bedarfsfall«, »stark/schwach« usw. sein könnte, offenkundig auf der von Bydlinski mit unermüdlicher Abscheu zitierten »Eigenwertung « des Entscheiders beruhen, ist jetzt auch der methodologische Konkurs angemeldet, ein Umstand, den sogar Zippelius in seiner ansonsten nur positiv referierenden Rezension (Juristische Methodenlehre und Rechtsbegriff, ARSP 69, 1983, 406-415) mit der feinsinnigen Bemerkung versah, daß die Rangfolge zwar gesucht worden sei, allerdings »ohne erwartungsgemäß den Stein der Weisen zu finden « (ARSP 69, 1983, 414). Eine nachdrückliche Zurückweisung des Konzepts auf der Grundlage der (von einigen kakanischen Vorbehalten abgesehen) affirmativ übernommenen Basisüberzeugungen Bydlinskis kann bei Rudolf Strasser (Rechtsdogmatik, Rechtstheorie und juristische Methodologie. $\mathrm{Zu}$ einem neuen wichtigen Buch von Franz Bydlinski, DRdA 33, 1983, 240-247) nachgelesen werden.

Im 3. Buch des opus maximum glimmt das polemische Feuer durchgehend nur noch schwach. Da auch keine überraschenden Gedanken für die nötige Wärme sorgen, ver- 
langt dieser heute abgestanden wirkende Teil vom Leser besonders viel fachliches Pflichtbewußtsein und Geduld.

Im Vorwort wünschte sich der Autor von seinen studentischen Lesern, daß sein Buch von ihnen nur gelesen, nicht aber gelernt werde. Das war ein billigenswerter Wunsch, denn es wäre betrüblich, wenn diese Lehren sich durch Lernen in vielen schwachen Köpfen festgesetzt hätten. Andererseits war (und ist) schon das Lesen der 650 Seiten eine deftige Zumutung, denn der Autor formuliert ungemein weitschweifig und würzt, wie so mancher geschwätzige Proselyt der Redundanz, seinen Text mit zahlreichen ermüdenden Stammtischweisheiten. Wer sich gleichwohl ohne Strapazen ein eigenes Bild machen will, kann an der Besprechung von Heinz Peter Rill (Juristische Methodenlehre und Rechtsbegriff. Gedanken zum gleichnamigen Buch von Franz Bydlinski, Zeitschrift für Verwaltung 10, 1985, 461-473 und 577-590) sein Genügen finden. Da der Autor die Vorstellungen Bydlinskis umfassend und präzise referiert, wird auch der, welcher die Kritik von Rill vielleicht nicht teilen will, erschöpfend informiert.

Substantielle und profitable Stellungnahmen gibt es außerdem von Karl Engisch, Subsumtion und Rechtsfortbildung, in: Richterliche Rechtsfortbildung. Festschrift der Juristischen Fakultät zur 600-Jahr-Feier der Ruprechts-Karls-Universität Heidelberg, C. F. Müller, 1986, 3-9; Ulfrid Neumann, JuS 1989, 335-337, und Robert Walter, Österreichische Juristen-Zeitung 39, 1984, 137-140.

\section{Einführungen}

»Einführung « - das ist schnell gesagt und schwer getan. Es ist kein Geheimnis, daß gute Einführungen in eine Disziplin oder ein Fach so selten sind wie die Meister in denselben. Umfänglich, kompliziert, schwer verständlich, langatmig, umständlich das sind Eigenschaften von Texten, zu denen es keiner besonderen Begabung bedarf. Knapp, klar und leicht begreiflich können nur jene sich äußern, denen die Probleme vertraut, aber noch nicht über den Kopf gewachsen sind, die einen sicheren Stil schreiben und die Herr ihrer Gedanken sind.

»Grundrisse «, »Überblicke«, »Abrisse«, »Lehrbücher«, »Einführungen« sollten daher nur von jenen geschrieben werden, die der jahrzehntelange Umgang mit dem Thema, in das sie einführen wollen, nicht nur in Kennerschaft, sondern auch in einen gewissen Zustand der Distanz versetzt hat, ohne daß die Leidenschaft in der Routine erstickt wäre.

Die »Einführung in Rechtsphilosophie und Rechtstheorie der Gegenwart « herausgegeben von Arthur Kaufmann, Winfried Hassemer und Ulfrid Neumann ist mit ihrer jetzt 7. Auflage (Heidelberg: C. F. Müller, 7. Auflage 2004, 515 S.) zweifellos das erfolgreichste Lehrbuch der Rechtsphilosophie und Rechtstheorie der Nachkriegszeit.

Begonnen hat alles 1971. Damals erschienen bei Athenäum von Kaufmann und Hassemer die »Grundprobleme der zeitgenössischen Rechtsphilosophie und Rechtstheorie« (ein »Leitfaden« auf der Grundlage zweier Aufsätze) und bei C.F. Müller, von Kaufmann allein herausgegeben und heute als Nukleus der »Einführung « identifizierbar, die »Rechtstheorie. Ansätze zu einem kritischen Rechtsverständnis«. Hier wa- 
ren bereits das Prinzip Sammlung, aber nicht Sammelsurium selbständiger Abhandlungen, und das Prinzip der Selektion der Autoren (seinerzeit: Baratta, Callies, Ellscheid, Haag, Hassemer, Kaufmann, Kunz, Leicht, Paul, Philipps, Priester, Schroth, Tammelo) nach ihrer Zugehörigkeit zum Schülerkreis von Kaufmann verwirklicht.

1977 erschien dann die 1. Auflage der »Einführung « mit Beiträgen von Büllesbach, Ellscheid, Haft, Hassemer, Kaufmann, Marx, Mazurek, Neumann, Schild, Schneider, Schroth und Tammelo. Der Einleitungsaufsatz (Rechtsphilosophie, Rechtstheorie und Rechtsdogmatik) stammte von Kaufmann. Er wurde, von Formulierungsänderungen und (nicht uninteressanten) zeitbedingten Akzentuierungen oder Abschwächungen abgesehen, in allen Auflagen beibehalten.

Im Übrigen ist jedoch im Laufe der 30 Jahre, die seitdem vergangen sind, nicht mehr allzu viel von der ersten Auflage übrig geblieben. So ist etwa in der 4. Auflage von 1984 (die 2. und 3. Auflage enthielten keine Änderungen) der schwer verdauliche Abschnitt »Recht und Gerechtigkeit in schematischer Darstellung « (Kaufmann) verschwunden und durch die rechtschaffene »Problemgeschichte der Rechtsphilosophie « (Kaufmann) ersetzt worden. Die »marxistische und sozialistische Rechtstheorie « (Mazurek) hat sich erst für die jetzige, die 7. Auflage verabschiedet. Aber das gilt auch für ihren großen Widersacher, die »analytische Rechtstheorie« (Mazurek). Der klägliche Beitrag von Haft (»Recht und Sprache«) ist vorübergehend (4.- 6. Auflage) aufgeblüht und dann (leider ersatzlos) eingegangen. Die historischen Abhandlungen über die Pandektistik (Marx), Interessenjurisprudenz und Freirecht (Marx), Reine Rechtslehre (Schild) wurden - nicht unbedingt zum Vorteil des Ganzen - der »Problemgeschichte« geopfert. Philipps kam in der 5. Auflage mit einem Kapitel »Normentheorie« hinzu. Die Rechtsinformatik (Schneider), in der 1. (bis 3.) Auflage noch mit einem eigenen Abschnitt vertreten, hatte sich in der 4. Auflage sogar aus dem Sachregister geschlichen; in der 5. Auflage (1989) taucht sie erneut, wenn auch im Kleinformat unter den »Tendenzen «, auf; in der 6 . Auflage darf sie einen Triumph von 40 Seiten feiern; in der 7. Auflage ist sie mitsamt ihrem Abschnitt verschwunden; das Stichwort »Rechtsinformatik « ist nur noch zweimal (bei Büllesbach) nachgewiesen.

Insgesamt also ein Buch, das lebendig geblieben ist, das heftigen Bewegungen ausgesetzt war, bei dem von »Fortschreibung « keine Rede sein kann und das, um dem Titelprädikat »Gegenwart« gerecht zu werden, diese Haltung beibehalten sollte.

Die Zahl der Autoren ist um ein Drittel (von 12 auf 8) geschrumpft (Büllesbach, Ellscheid, Hassemer, Kaufmann, Neumann, Philipps, Schneider, Schroth). Neumann ist, wie es dem sachlichen Gewicht seiner Beiträge entspricht, unter die Herausgeber aufgerückt.

Zwei Hoffnungen verbanden sich mit der ersten Auflage: Zum einen sollte das Buch »Mittel zur Vorbereitung auf das Wahlfach Rechtsphilosophie« und darüber hinaus »jedem rechtsphilosophisch Interessierten eine Hilfe zur Orientierung und ein Angebot zum Mitdenken« sein. Zum anderen »hoffen die Verfasser, auch außerhalb der Bundesrepublik Deutschland Gehör zu finden«.

Beide Hoffnungen sind in Erfüllung gegangen: Bei den rechtsphilosophisch ambitionierten Studenten ist das Buch schnell angekommen; durch die große Nachfrage waren bis zur ersten Überarbeitung 1984 zwei unveränderte Neuauflagen nötig. Auch das 
Ausland hat das Werk erreicht: Bereits 1979 erfolgte die erste Übersetzung ins Japanische; seither wurde das Buch (zum Teil auszugsweise) ins Spanische, Polnische, Chinesische, Türkische, Slowenische und Portugiesische übersetzt.

Der Inhalt des erfolgreichen Buches präsentiert eine für viele Klassiker typische, vermutlich unvermeidliche Eigenschaft: Er ist konservativ. Revolutionen finden anderswo statt.

Bei Kaufmann/Hassemer/Neumann landet, was hinreichend etabliert und kanonisierbar ist, um als eigene Strömung zu gelten. Mindermeinungen, Seitenzweige und Nebenflüsse können in einer solchen Darstellung nicht mit einem eigenen Beitrag versehen, von Theoriebaustellen kann erst berichtet werden, wenn sich abzeichnet, wie das fertige Gedankengebäude aussieht. Das ist kein Versäumnis, das dem Buch vorzuhalten wäre, sondern ein den Erfordernissen eines Einführungsbuches geschuldeter Umstand: dort kann nur über Theorien informiert werden, von denen sichergestellt ist, daß sie die Information wert sind.

In einigen Beiträgen - sie herauszufinden wird Hassemer und Neumann auch ohne Lektüre der folgenden Referate nicht schwer fallen - sind allerdings die Altersringe so dick und dicht geworden, daß man auf eine Erneuerung mittels Fehlerkorrektur und Literaturnachtrag zukünftig verzichten sollte. Hier dürften nur noch neue Konzeption, neuer Text und (vielleicht) neuer Autor Abhilfe versprechen.

Wer Theorieangebote erkunden möchte, deren Ertrag noch nicht als gesichert gelten kann, findet seit 2006 in dem von Sonja Buckel, Ralph Christensen und Andreas Fischer-Lescano herausgegebenen Band »Neue Theorien des Rechts« eine nützliche Ergänzung zur »Einführung« von Kaufmann, Hassemer und Neumann.

[BL/DS]

\subsection{Rechtsphilosophie, Rechtstheorie und Rechtsdogmatik}

\section{Arthur Kaufmann}

Über das Einleitungskapitel von Arthur Kaufmann sind nicht viele Worte zu verlieren. Eine Abgrenzung von Rechtsphilosophie und Rechtstheorie hält Kaufmann - durchaus zulässig - für entbehrlich, übernimmt aber doch die übliche Richtschnur, Rechtstheorie habe es eher mit formalen und Rechtsphilosophie eher mit materialen Fragen zu tun; wie in der Überschrift angedeutet, spielt die Rechtssoziologie in Kaufmanns Ausführungen ebenso wenig eine Rolle wie die Rechtsgeschichte, deren Fruchtbarkeit für die Rechtstheorie - wie auch sonst üblich - unterschlagen wird. Zur Differenzierung zwischen Dogmatik und Reflexion heißt es, die Dogmatik operiere systemimmanent, während die Rechtsphilosophie das Ganze des Rechts im Blick habe (eine Charakterisierung, die freilich nur dann plausibel ist, wenn man sie als Teil der Selbstbeschreibung des Rechts begreift).

Von dem in dieser Aussage zum Ausdruck kommenden Pathos sind auch die weiteren Ausführungen getragen. So erfährt man beispielsweise, »dass das Sein von Ursprung an Ordnung und Gestalt in sich birgt«, was zwar tröstlich sein mag, dadurch aber kaum einleuchtender wird. Genauso wenig kann es überzeugen, wenn es heißt, »nur Geschlechter, die Zutrauen zu sich und zur Welt haben, wenden sich dem Naturrecht zu«. Ein Blick in die jüngere Geschichte legt sehr viel eher nahe, daß das Natur- 
recht genau in den Epochen Konjunktur hatte, als für das Zutrauen in die selbstordnenden Kräfte von Natur und Mensch kein Grund ersichtlich war.

Als Einführung in die verschiedenen Denkweisen in der Philosophie im Allgemeinen und der Rechtsphilosophie im Besonderen leistet der Text aber durchaus gute Dienste. Bevor er sich in die Weiten eines ausführlichen Literaturverzeichnisses ergießt, besänftigt Kaufmann das philosophische Stimmengewirr und harmonisiert es im raunenden Wohlklang der Synthese, dessen Tragweite sich freilich nicht unmittelbar aufdrängt: »Person und ebenso auch Recht sind gegeben und aufgegeben zugleich, sind unaufhebbar Objektivität und Subjektivität in einem, sind sowohl das ,Was ‘ als auch das ,Wie' des personalen Gestaltungsprozesses, durch den sie zu ihrer konkreten Daseinsgestalt gelangen, ohne ausschließlich das Produkt dieses Prozesses zu sein.«

$[\mathrm{BL}]$

\subsection{Problemgeschichte der Rechtsphilosophie}

\section{Arthur Kaufmann}

Als der Text 1984 in das Werk aufgenommen wurde, notierte Arthur Kaufmann im Vorwort, er habe »jedem Trend zum Perfektionismus widerstanden«, um dem Buch den exemplarischen Charakter einer Einführung zu erhalten. Diese Feststellung hat ihren guten Sinn, wenn auch vermutlich nicht auf die vom Autor intendierte Weise.

Exemplarischen Charakter jedenfalls hat Kaufmann seiner Problemgeschichte in geradezu beispielhafter Manier verliehen, denn sie schreibt Geschichte, wie Geschichte sonst auch geschrieben wird: theoriefrei. Insofern ist auch der Titel des Beitrags nicht ganz zutreffend, denn von Problemen ist im Verlauf der immerhin 122 Seiten so gut wie gar nicht die Rede.

Statt Problemen oder anderen mehr oder weniger innovativen Erklärungsprinzipien wählt sich diese theorie- und problemfreie Problemgeschichte das einfachste und zugleich am wenigsten aussagekräftige Deutungsschema zur Darstellung historischer Abläufe: den Zeitstrahl (»In der zeitlichen Folge betreten wir jetzt die Welt der attischen Philosophie ...«). Im Ergebnis führt dies freilich nur dann zu einer Geschichte, wenn man sich darunter die chronische Auflistung der üblichen Denker samt ihrer in herkömmlicher Weise stichwortisierten Gedanken vorstellt. Da historische Einführungskapitel jedoch selten von dieser Auffassung von Geschichte abweichen, behält Kaufmanns Abriß tatsächlich exemplarischen Charakter.

Wer jedoch auf dem Zeitstrahl durch das Universum der Vergangenheit reist, dem bleibt oft nichts anderes übrig, als das Fortbewegungsmittel selbst für Änderung und Wandel verantwortlich zu machen (»Die Zeit war jetzt auch reif geworden, das aufklärerische Naturrecht in Kodifikationen zu transformieren.«). Damit können aber weder die historischen Abläufe noch das Abgelaufene erklärt werden. Der Ritt auf dem Zeitbesen ruft vielmehr unweigerlich den Eindruck hervor, Philosophen seien im wesentlichen alte Männer mit mutmaßlich dichten Rauschebärten, in welche sie den ganzen Tag möglichst unverständliche Sätze hineinbrummen, um rechtschaffene Bürger (und Jura-Studenten) in ihrem anständigen Leben weitestgehend zu belästigen (»zum anderen lehrte er [Aristoteles] die Einheit von Form und Stoff bei allem Seienden«). 
Was um alles in der Welt Aristoteles dazu veranlaßt haben könnte, solche Weisheiten von sich zu geben, aus welchem Grund »der Rationalismus [...] den Bogen überspannt« hatte oder warum »der Zeitgeist des 19. Jahrhunderts [...] überwiegend ein anderer « war, das alles erfährt man in dieser Geschichte nicht - eine Geschichte übrigens, die mittlerweile selbst Geschichte geworden ist. Denn seit der Beitrag 1984 in das Werk aufgenommen wurde, hat sich doch einiges in der rechtsphilosophischen Welt verändert: Die von Kaufmann vorgetragene Radbruch-Verehrung etwa (»der Erste, der den aussichtslosen Stellungskrieg zwischen Naturrecht und Positivismus überwunden hat «) wird man so wohl kaum mehr vertreten wollen. Und genauso wenig reichen heutzutage die Stichworte »Reduktion von Komplexität« aus, um das Werk von Niklas Luhmann angemessen zu würdigen (außerdem ist Legitimation durch Verfahren mittlerweile wohl nicht mehr als sein bekanntestes Werk anzusehen).

Statt Geschichte also eine Fahrt mit dem Zeitstrahl und statt Problemen ein Blick in den Zettelkasten der Vergangenheit, um aus beidem einen Argumentehaufen zu konstruieren, aus dem man sich künftig nach Belieben bedienen kann. Für die Vorbereitung auf die Wahlfachprüfung im ersten juristischen Staatsexamen ist das allemal genug.

[BL]

\subsection{Strukturen naturrechtlichen Denkens}

\section{Günter Ellscheid}

Im Jahre 1934 veröffentlichte Carl Schmitt einen Vortrag, in dem er drei Arten des rechtswissenschaftlichen Denkens voneinander unterschied: Regeldenken, Entscheidungsdenken und konkretes Ordnungs- und Gestaltungsdenken. Ersteres könne sich darauf berufen, unpersönlich und objektiv zu sein. Entscheidungen dagegen seien immer persönlich, konkrete Ordnungen jedoch überpersönlich.

Die unpersönliche Ordnung des Normativismus mache »König, Führer, Richter, Staat « zu bloßen Normfunktionen, womit in concreto nichts anderes erreicht werde, »als daß die Norm oder das Gesetz politisch-polemisch gegen den König oder Führer ausgespielt wird «. Der Dezisionist dagegen betrachte alles Recht als Entscheidungen des Souveräns. Souverän sei aber nicht »ein legitimer Monarch oder eine zuständige Instanz, sondern eben der, der souverän entscheidet «.

1934 passten solche Denkfiguren nicht mehr. »Das neue Staats- und Verwaltungsrecht hat den Führergrundsatz durchgesetzt und mit ihm Begriffe wie Treue, Gefolgschaft, Disziplin und Ehre, die nur aus einer konkreten Ordnung und Gemeinschaft heraus verstanden werden können. «In dem neuen Gemeinschaftsleben konnte man sich des rechtlichen Axioms sicher sein, »daß Treue, Disziplin und Ehre von der Führung nicht abgetrennt werden dürfen «, und man endlich eine Ordnung errichtet habe, in der kein Eid auf eine Verfassung zu leisten sei, sondern vielmehr auf einen Führer, dem die staatstragende Bewegung bereits unverbrüchliche Treue geschworen hatte.

Eigentlich ein einfacher Gedanke: »Wir wissen, daß die Norm eine normale Situation und normale Typen voraussetzt.« Der Normalfall muß nur entsprechend kognitiv untermauert werden, und schon kommt man über die Mystik konkreter Ordnungen zum gewünschten Ergebnis. Was das konkrete Ordnungsdenken diskreditiert hat, wa- 
ren jedoch weniger seine basale Simplizität als die politischen Assoziationen, die sich damit verbanden. Schließlich war bekannt, welch grauenhafte Folgen programmatische Ankündigen wie die folgende gezeitigt hatten: »Sobald Begriffe wie ,Treu und Glauben', ,gute Sitten' usw. nicht auf die individualistische bürgerliche Verkehrsgesellschaft, sondern auf das Interesse des Volksganzen bezogen werden, ändert sich in der Tat das gesamte Recht, ohne daß ein einziges ,positives' Gesetz geändert zu werden brauchte. Ich bin deshalb der Überzeugung, daß sich in diesen Generalklauseln eine neue juristische Denkweise durchsetzen kann.«

$\mathrm{Da} ß$ diese neue juristische Denkweise sich nur deshalb durchsetzen konnte, weil es genügend juristische Denker gab, die entsprechenden Gedanken nachhingen, ist kein Geheimnis; gleichwohl machten nach 1945 auch Theorien, deren Anhänger ganz andere Gedanken in sich trugen, nur noch ungern Gebrauch von der Schmittschen Terminologie. Wer im Register bei Kaufmann/Hassemer/Neumann den Begriff »Ordnung, konkrete « nachschlägt, wird deshalb auf keine Abhandlung zum konkreten Ordnungsdenken verwiesen, sondern landet auf den Seiten 198 und 200 und damit im Kapitel zur »Natur der Sache« inmitten des Beitrags von Günter Ellscheid zu den Strukturen naturrechtlichen Denkens.

Außer nach der Natur in der Sache wird dort vor allem die Natur im Recht gesucht. Heutzutage bedeutet dies überwiegend, nach Unverfügbarem zu suchen, das der Willkür des staatlichen Gesetzgebers entgegengehalten werden kann. Damit werden nicht nur diejenigen zu Naturrechtlern, die der Ansicht sind, sie hätten das Naturrecht bereits gefunden (in Form von Grund- und Menschenrechtskatalogen etwa); vielmehr verfährt auch die große Zahl der Prozeduralisten naturrechtlich, wenn sie meint, durch bestimmte formale Vorgaben ließen sich materiale Einsichten gewinnen, die fürderhin gewillkürter Änderung entzogen seien: Kant und sein kategorischer Imperativ etwa oder Rawls und sein Schleier des Nichtwissens, der mit einiger Ausführlichkeit behandelt wird.

Indem sie auf diese Weise die Empfänger des Naturrechtsetiketts vergrößert, verspricht Ellscheids umfassende Darstellung auch demjenigen Gewinn, dem die Annahme von Seinsimmanenzen des Sollens, sachgesetzlichen Strukturen, fundamentalen Ontologismen und nicht zuletzt: von konkreten Ordnungen schon immer suspekt war.

[BL]

\subsection{Recht und Moral}

\section{Günter Ellscheid}

Das Verhältnis von Recht und Moral zueinander kann man ohne weiteres als schwierig bezeichnen. Schon die Frage nach dem Wesen dessen, was man da miteinander in Beziehung setzt, bringt einige Probleme mit sich. Über die Spezifika von rechtlichen Normen - Gesetztheit und staatliche Sanktionierung - mag man sich noch verständigen können. Eine Definition der Moral ist weniger eindeutig: »Auf die Frage, was Moral ist, muss man in modernen Gesellschaften mit unterschiedlichen Antworten rechnen.«, meint Günter Ellscheid. Er selbst identifiziert einen gesellschaftlichen (»allgemein verbreitete Auffassungen [...] über gutes und schlechtes Verhalten«), ei- 
nen autoritären (»elitär verwaltete Gemeinschaftsideologien«) und einen autonomen Moralbegriff. Letzterer sei vor allem kritische Instanz, relativiere dadurch alle Formen der heteronomen Moral und mache vor allem jede Form von Moral von ständiger Kommunikation abhängig.

Was nun das Verhältnis von Recht und Moral zueinander angeht, so gibt es bekanntermaßen zwei Positionen: die rechtspositivistische Trennungsthese und die wertbezogene Vereinigungsthese. Auch die ausgetauschten Argumente sind im wesentlichen geläufig: Rechtssicherheit, Orientierungssicherheit, Rechtsfriede, Möglichkeit und Freiheit der rechtstheoretischen Reflexion einerseits, Hitlerargument, gesetzliches Unrecht und richterliches Selbstvertrauen andererseits. Auch bei Ellscheid finden sich diese Argumente gegenübergestellt und am Ende aufgelöst in einer friedlichen Sowohl-als-auch-Koexistenz, in der die Trennungsthese von moralischen Erwägungen getragen wird, solange das Recht beabsichtigt, den Rechtswerten zu dienen. Der pflichtschuldige Verweis auf Radbruch und seine Formel bleibt nicht aus.

Mit der Einsicht, die Geltung von Recht könne nur dann von moralischen Erwägungen abgelöst werden, wenn »das positive Recht bereits eingelebte und noch lebendige fundamentale moralische Prinzipien integriert hat«, gelangt Ellscheid zur Frage, welche moralischen Prinzipien dem Rechtssystem zugrunde liegen und wie sie zum Ausdruck kommen. Dieser Frage widmet sich die zweite Hälfte des Beitrags. Neben dem Recht als Garanten für persönliche und kommunikative Freiheiten beschreibt Ellscheid hier insbesondere den Gleichheitssatz, dessen Erscheinungsform als Rechtsprinzip detailliert ausgebreitet wird. Angereichert mit der kantischen Autonomie der Moral identifiziert Ellscheid den Bezugspunkt des Gleichheitsgebotes in »einer einheitlichen Struktur des Menschseins«: »dem bewussten Sich-Verhalten zu sich selbst«.

Dagegen ist nichts einzuwenden. Ob daraus aber auch »juristische Ergebnisse ableitbar sind, die über das hinausgehen, was durch Rechtsprechung und juristische Dogmatik [...] geleistet ist«, läßt Ellscheid ausdrücklich offen. Sicher darf die konkrete juristische Fruchtbarkeit philosophischer Reflexion (auch in diesem Fall) bezweifelt werden. Da es jedoch nicht Aufgabe der Rechtsphilosophie ist, Fälle zu lösen, sind solche Zweifel in keiner Weise schädlich und tun dem pädagogischen Nutzen des Beitrags keinerlei Abbruch.

[BL]

\subsection{Rechtssystem und Kodifikation: Die Bindung des Richters an das Gesetz.}

\section{Winfried Hassemer}

Hassemers souveräner Beitrag setzt, was erstaunlicherweise ziemlich selten geschieht, überzeugend mit Wert und Wirkung der Kodifikation ein und nicht mit »dem« Gesetz oder gar einer einzelnen Rechtsnorm. Die Funktion und die Folgen der Entscheidung für eine umfassende Kodifikation der Normen werden knapp und klar an den Stationen »Subsumtionsideologie«, Entscheidungsdeterminierung, Rechtssicherheit, Ordnung des Wissens, Verkürzung der Legitimationserfordernisse, Positivierung des Rechts aufgezeigt und beschrieben. Der vielleicht wichtigste, jedenfalls aber der am meisten diskutierte Aspekt einer Rechtskodifikation ist der mit ihr verfolgte Gedanke einer Bindung des Richters an das gesetzgeberische Produkt. 
Auf den Umstand, daß diese »Bindung « in einem strikten Sinne - etwa indem dem Richter die Entscheidung für bestimmte Alternativen, Argumente oder Argumentformen vorgeschrieben würde - nicht möglich ist, verschwendet Hassemer erfreulicherweise kaum noch ein Wort. Was bleibt, ist tatsächlich, will man seine Zuflucht nicht zu Heuchelei oder trotziger Aufklärungsverweigerung nehmen, eine Neubestimmung des Bindungspostulats zu versuchen. Denn daß eine achselzuckende Preisgabe der Bindung an das Willkürsyndrom normativ nicht in Betracht kommen kann, liegt mit allen Vernünftigen auch für Hassemer auf der Hand.

Er prüft und verwirft die Bindung durch Auslegungsregeln, bejaht die (faktische) Bindung durch Richterrecht und Dogmatik und weist mit größter und berechtigter Bestimmtheit auf die informellen Programme (vor allem im Verfahrensrecht) und den Bindungsdruck, der von »Habitus « und »Betriebswissen « ausgeht.

Von den »altständischen « Beiträgen der ersten Stunde hat dieses Teilstück am wenigsten den Anschluss an den gegenwärtigen Stand der Diskussion eingebüßt - offenkundig die Folge einer besonders aufmerksamen Pflege und Erneuerung des Textes.

\subsection{Hermeneutik, Norminterpretation und richterliche Normanwendung}

\section{Ulrich Schroth}

Der Schwerpunkt dieses Überblicksartikels liegt auf einem Abschnitt mit dem Titel »Probleme der Anwendung von Rechtsnormen auf den Einzelfall «. Der hiervon wenig einleuchtend abgesetzte Teil »Richterliche Normanwendung « umfasst nur $2 \frac{1}{2}$ Seiten, deren letzte obendrein überwiegend und fast wörtlich mit der ersten Seite des Beitrages von Jochen Schneider (Theorie juristischen Entscheidens) übereinstimmt - ein Umstand, der der Umorganisation des Manuskripts Schneider/Schroth aus der Vorauflage geschuldet ist.

Der einleitende »Hermeneutik«-Teil berichtet korrekt von Schleiermacher, Dilthey, Heidegger und Gadamer und notiert die Gewinne (weniger überzeugend: die Probleme), welche die philosophische Hermeneutik der juristischen Methodendiskussion eingetragen hat.

Der Hauptteil referiert Fragen und Antworten aus dem Bereich der klassischen Rechtsanwendungslehre. Er stimmt den Leser melancholisch, was freilich weniger dem Autor Schroth als dem Zustand der Methodenlehre als solcher zur Last zu legen ist - eine Bemerkung, mit der man auch Schroth selbst zitieren kann, der sie seinem Referat über den Umstand anhängt, »daß den Auslegungscanones überhaupt kein Erkenntniswert zugesprochen werden kann« (289). Allerdings muß man auch darauf hinweisen, daß die Fassung mancher Passagen den Zustand der Lehre in einem noch trüberen Licht erscheinen läßt als es tatsächlich gerechtfertigt ist.

»Ein ungerechtes Ergebnis als Folge eines Auslegungskriteriums wird von einem

Teil der Methodenliteratur als Indiz gegen die Richtigkeit des Auslegungskriteriums angesehen. Ein anderer Teil der Methodenliteratur sieht ein ungerechtes Ergebnis als entscheidendes Argument gegen die Richtigkeit eines Auslegungskriteriums. Einigkeit dürfte jedoch darüber bestehen, daß Auslegungskriterien die 
üblicherweise zu ungerechten Ergebnissen führen, inhaltlich nicht zu akzeptieren $\operatorname{sind} \ll(293)$.

So naiv war die Welt der Rechts»findung« schon im letzten Viertel des 20. Jahrhunderts nicht mehr.

Im Übrigen referiert Schroth umsichtig und ohne größeren kritischen Aufwand das bekannte Schicksal der Auslegungscanones von Savigny bis Friedrich Müller (wer sich später äußerte, bleibt unerwähnt). Das geschieht durchgehend aus der Perspektive des Strafrechtlers, was umso legitimer ist als der Verfasser sich explizit zu einer rechtsgebietsbezogenen Methodologie bekennt, d.h. also zu einer juristischen Methode bei der sich die Regeln mit den Problemen ändern. Manche Urteile werden deshalb für Juristen des Zivilrechts oder des Öffentlichen Rechts ziemlich erstaunlich klingen. Zum Beispiel, wenn diese ihre Kenntnisse von den Entscheidungen der Schrott-Immobilien-Senate des BGH mit der Feststellung Schroths vergleichen:

»Ein BGH-Senat darf von einem anderen BGH-Senat nur dann abweichen, wenn überwiegende Gründe gegen dessen Entscheidung sprechen (gleich gute Gründe genügen nicht $) \ll(278)$

Der Verfasser entwickelt keine eigenen Ansichten und verzichtet auch auf die Pointierung der Ansichten anderer. Für einen Einführungstext ist das eine gut vertretbare Haltung.

\subsection{Juristische Logik}

\section{Ulfrid Neumann}

Wenn juristische Fakultäten ihre Studienanfänger nach den Motiven für die Studienwahl befragen, erhalten sie in etwa $25 \%$ der Fälle die Antwort, daß es die »logische Struktur «, das »logische Denken der Juristen«, die große »Rolle der Logik « gewesen seien, die die Entscheidung für das Fach beeinflußt hätten. Wenn der erwachsene Jurist in akademischen oder anderen Gremien das Wort ergreift, hört er nicht selten das Kompliment, daß die »logische Schulung « eines Juristen die gemeinsame Arbeit doch außerordentlich fördere.

Solche Erfahrungen deuten auf ein weit verbreitetes Urteil über die Arbeit von Juristen, das diese selbst in der Regel für ein Vorurteil halten. Zwar reden sie gelegentlich von $»$ juristischer Logik «. Aber dabei denken sie - soweit der Ausdruck nicht als ironische Metapher nach dem Muster »weibliche Logik « verwendet wird - an ein bestimmtes Segment aus ihrem Pool von Standardargumenten, nämlich an die traditionsreichen »typisch juristischen Schlüsse « (argumentum a fortiori, e contrario, a pari etc.). Ansonsten werden Anteil und Beitrag der »juristischen « Logik zur täglichen Arbeit - verstanden als die Anwendung der allgemeinen Logik auf das Recht durch die Juristen eher niedrig bewertet. Tatsächlich dürfte in erster Linie der Umstand, daß Juristen abstraktionserfahrene Experten im Argumentieren unter Relevanzgesichtspunkten sind, für das Logik-(Vor)Urteil ihrer Umwelt verantwortlich sein.

Was nicht heißen soll, daß die Rechtsarbeiter auf Logik verzichten würden oder ihrer nicht bedürftig wären. Das Gegenteil ist der Fall. Denn die »Denkgesetze«, wie der altertümliche, aber das Gedachte bestens bezeichnende Ausdruck lautet, spielen 
selbstverständlich nicht nur bei der Revision von Urteilen (vgl. 546 ZPO) eine erhebliche Rolle.

Dazu steht zweifellos in einem bedauerlichen und schon peinlichen Missverhältnis der Umstand, daß es so gut wie keine für Juristen geschriebene Einführungen in die Logik gibt und daß - wesentlich gravierender - die Nutzung der entsprechenden Ressourcen der philosophischen Fakultäten der unintegrierten und unkoordinierten Eigeninitiative aufgeweckterer Jurastudenten überlassen bleibt.

So sind denn die 20 Seiten (298-319), die Ulfrid Neumann dem Thema »Juristische Logik « gewidmet hat, schon unter dem Gesichtspunkt ihrer Seltenheit ein willkommener Bestandteil einer Einführung in Rechtstheorie und Rechtsphilosophie. Und da der Rechtsphilosoph Ulfrid Neumann schreibt, kann man erwarten, daß der Text auf Juristen zugeschnitten wurde, daß er originell ist, daß er sich nicht als trockener Auszug aus einer philosophischen »Einführung in die Logik« entpuppt und daß er die gehörige Portion kritischer Fragen vermittelt. Die Erwartungen werden nicht enttäuscht.

Der Justizsyllogismus tritt selbstverständlich prominent in die Arena. Er wird in der klassisch-scholastischen ([1] M a P; [2] S a M; [3] S a P), aber auch in einer modernen Symbolisierung ([1] $\Lambda \mathrm{x}(\mathrm{Tx} \rightarrow \mathrm{Rx})$; [2] Ta; [3] Ra) präsentiert.

Trotz aller geläufigen Vorbehalte (die 1. Prämisse ist keine Konstatierung, sondern eine Norm, die 2. Prämisse ist - jedenfalls im Syllogismus - kein kategorischer, sondern ein singulärer Satz) hat sich diese Darstellung bis heute gehalten.

Neumann fügt dem traditionellen Arsenal weitere Vorbehalte hinzu. Die erste Prämisse als logischen Allsatz zu formulieren, ist mindestens ungeschickt, da man im juristischen Regel-Ausnahme-Diskurs zwangsläufig hinter »wenn $\mathrm{x}$ die Eigenschaft besitzt, Mörder zu sein « (Mx) und vor der Rechtsfolge ( $F x-» d a n n$ gilt für $\mathrm{x}$ die Folge $\mathrm{F} \ll)$ die sogenannte Angstklausel »und für $\mathrm{x}$ keine Ausnahme eingreift $\ll(\neg \mathrm{Ax})$ einfügen muß, um die widerspruchsfrei brauchbare Formalisierung: $\Lambda \mathrm{x}(\mathrm{Mx} \wedge \neg \mathrm{Ax} \rightarrow \mathrm{Fx})$ zu erhalten.

Auch wer dem Autor nicht bei der These folgen möchte, der Allsatz $\Lambda \mathrm{x}(\mathrm{Mx} \rightarrow \mathrm{Fx})$ begründe den singulären Satz $\mathrm{Ma} \rightarrow \mathrm{Fa}$ nicht, sondern behaupte ihn lediglich, was für den praktischen Syllogismus allerdings durchaus einleuchtet, der wird kaum an der abschließenden Feststellung Neumanns vorbeikommen, »daß die Rekonstruktion der Begründungsstruktur juristischer Entscheidungen im Prädikatenkalkül zu undifferenziert und damit inadäquat ist «. Konsequent empfiehlt Neumann die Verwendung des Argumentationsschemas von Toulmin.

Die Vermutung, daß die traditionelle syllogistische Deutung - wenigstens ad usum Delphini - weiterhin verwendet werden wird, dürfte gleichwohl begründet sein. Schließlich steckt in dieser Kritik keine leichtfertige Absage an die Logik überhaupt, sondern nur ein Hinweis auf die Möglichkeit, in diesem Bereich geistige Ressourcen zu schonen.

Neumann widmet deshalb zu Recht auch einige Seiten der Logikbegründung und spricht sich - so deutlich wie das für eine Einführung statthaft ist, die möglichst viele Positionen berücksichtigen muß - für eine dialogische Begründung der Logik aus. Damit werden nicht nur an einer weiteren Stelle die zählebigen ontologischen Anker gelichtet, sondern auch die Übergänge zur Argumentationstheorie geebnet (»Logik als 
Theorie des vernünftigen Dialogs«). Das ist wichtig, denn wenn der juristischen Methodologie noch zu helfen ist, dann - so sieht es jedenfalls gegenwärtig aus - nur durch und über eine (auch logisch) anspruchsvolle Argumentationslehre.

Die Altersringe der Überarbeitungen für die verschiedenen Auflagen sind sichtbar, aber im Allgemeinen nicht geeignet, den Genuß an dieser glänzenden Skizze zu mindern.

Verblüffend und irritierend ist allerdings die Feststellung auf Seite 305, daß »die Implikation immer nur dann wahr ist, wenn der Vordersatz falsch ist«, und das, obwohl Neumann die Wahrheitswertverteilung der Implikation (richtig) wie folgt angibt (1 für wahr, 0 für falsch):

$$
\begin{array}{lll}
\mathrm{p} & \rightarrow & \mathrm{q} \\
1 & 1 & 1 \\
1 & 0 & 0 \\
0 & 1 & 1 \\
0 & 1 & 0
\end{array}
$$

Die 6. Auflage enthält dieselbe Privilegierung der 3. und 4. Zeile (= ex falso sequitur quodlibet!), so daß die Interpreten der Implikation, die unisono auf das unverwüstliche Implikans »wenn es regnet ...« zurückgreifen, äußerst besorgt sein dürften.

In der 5. Auflage fehlt das »nur«, und da der Satz als Begründung dafür steht, daß der Implikator (»da die Implikation immer dann wahr ist, wenn der Vordersatz falsch ist«) bei falscher Prämisse gültige Normen impliziert, kann man sich bei der älteren Fassung wieder beruhigen.

[DS]

\subsection{Normentheorie}

\section{Lothar Philipps}

Zwischen den Sätzen »Es ist verboten zu töten« und »Es ist geboten, nicht zu töten « besteht offenkundig ein Unterschied in der Formulierung. Ob es damit sein Bewenden hat, wie dem ungeübten Verstande scheinen mag, oder ob mehr dahinter steckt, ist umstritten. Lothar Philipps meint, es handele sich um »entgegengesetzte Arten von Normen«. Die Anhänger der deontischen Logik gehen davon aus, daß »es ist verboten, daß« jederzeit transformiert werden kann in »es ist geboten, daß nicht $\ll$.

Wem die Beweislast in dieser Frage auferlegt werden muß ist ungeklärt. Die Strafrechtsdogmatiker (etwa: Armin Kaufmann) gehen offenbar schon viele Jahrzehnte davon aus, daß es einen materialen Unterschied zwischen Geboten und Verboten gebe, die mit der klassischen Logik startenden Deontiker (etwa: Georg Henrik von Wright) sind - nicht minder lang - vom Gegenteil überzeugt.

Der Versuch von Philipps, mittels der Venn-Diagramme seine Position zu festigen, kann wegen der Knappheit seiner Ausführungen nicht eben als überwältigend gelungen bezeichnet werden. So ist etwa nur behauptet, aber nicht bewiesen, daß die von Venn eingeführten Kreise, mit denen man zum Beispiel symbolisieren kann, daß alle Gegenstände in A auch in B sind, sich uneingeschränkt für die Symbolisierung von Handlungen eignen - und darüber hinaus sogar für eine Norm des Inhalts, daß alle Gegenstände aus A auch in B sein sollen. Die »schlichte Evidenz normativer Venn-Dia- 
gramme «, auf die sich Philipps beruft, hat den Nachteil, daß manchmal manchem schlicht unevident ist, was einem anderen ohne weiteres einleuchtet.

Pädagogisch nicht eben glücklich ist der Umstand, daß zunächst mit den Venn-Diagrammen ausführlich operiert wird und anschließend (!) im Exkurs-Wege eine kurze Einführung in die Handhabung dieser Diagramme geboten und ihre Differenz zu den Euler'schen Kreisen erläutert wird, mit denen man in der Regel den klassischen Syllogismus interpretiert (vgl. etwa Herberger/Simon, Wissenschaftstheorie).

»Ein paar Bemerkungen zur deontischen Logik « und die Feststellung, daß »einige zentrale Phänomene des positiven Rechts « - gemeint sind: einige strafrechtsdogmatische Nominaldefinitionen - »erklärt « werden könnten, wenn man Normen als Gebote und Verbote »und übrigens auch Erlaubnisse« betrachtet, sind für einen Einblick in normentheoretische Bemühungen zu wenig.

Der Textbaustein »Normentheorie « könnte eine deutliche Erweiterung und Umorganisation vertragen, wenn er denn den Absichten des Buches gerecht werden soll. Dabei wäre vielleicht auch ein kleiner Hinweis nützlich, zu welchem Ende und mit welchem Gewinn der künftige Jurist sich mit Normentheorie, Normlogik und Deontik befassen sollte.

[DS]

\subsection{Theorie der juristischen Argumentation}

\section{Ulfrid Neumann}

Neumann segelt mit gewohnter Kennerschaft und Souveränität auf dem Weltmeer juristischer Argumentslehren und legt besonnen nur dort an, wo es die »Einführung « gebietet. »Ziel«, »Struktur«, »Standards« und »Theorie« der Argumentation heißen seine Haltestellen. Dazwischen schiebt sich - eher überflüssig und vorwiegend den hierzulande völlig überschätzten Einfällen von Ronald Dworkin geschuldet - ein Kapitel über »das Problem der einzig richtigen Entscheidung«. Ihr (der »Herkules-Entscheidung «) wird, um diesen Punkt vorweg zu resümieren, als »regulative Idee« der Praxis ein psychologisch einleuchtendes Plätzchen angewiesen, und im übrigen besteht Neumann auf dem richtigen Umstand, daß das Problem nicht in den Defiziten von »Herbert «, sondern in der Unbestimmtheit des Rechts siedelt.

Als Ziel juristischer Argumentation ermittelt Neumann die »Richtigkeit« (die »Wahrheit« wird gottlob nicht einmal erwähnt) einer Entscheidung oder eines Gutachtens. Als Richtigkeitskriterien werden die Erzielung der besten Folgen oder die Übereinstimmung mit der überpositiven Gerechtigkeit beziehungsweise dem positiven Recht benannt. Die Überzeugung aller am Rechtsdiskurs Beteiligten von der Haltbarkeit der Entscheidung und das bekannte dezisionistische (C. Schmitt-)Muster wonach eine Entscheidung richtig ist, wenn ein anderer Richter ebenso entschieden hätte, vermisst man an dieser Stelle.

Nachdem Neumann für eine Richtigkeit, die dem positiven Recht entspricht, votiert hat, wendet er sich der Struktur des Argumentierens zu. Hier steht die Orientierung an Begründungsregeln, die sich allmählich gegenüber den Findungsregeln durchgesetzt haben dürften, im Vordergrund. Die Alexy-Unterscheidung zwischen interner und externer Rechtfertigung wird rezipiert, und schon ist man bei den »Standards« angelangt. 
Der für den Juristendiskurs dominante Unterschied zwischen auctoritas und res, Autoritätsargument und Sachargument, wird kurz dargelegt und dann die vieldiskutierte Sonderfall-These (Alexy) zugunsten der doch viel sympathischeren Eigenständigkeit des Rechtsdiskurses zurückgewiesen.

Die heutigen Theorien des juristischen Argumentierens haben zwei Wurzeln. Die Rhetorik und die praktische Philosophie. Beide Muster sind analytisch und normativ, wobei sich ebenso trefflich wie nutzlos über Umfang und Bedeutung des Normativen und des Deskriptiven in diesen Strängen streiten läßt. Ohne große eigene Überzeugung klassifiziert Neumann nach normativ (präskriptiv), analytisch-rekonstruktiv und analytisch-kritisch und steckt dann die üblichen Verdächtigen in diese drei Schubladen, wo sie von den Studierenden bequem wieder hervorgeholt werden können.

Abschließend wird richtigerweise auf die historische und kulturelle Relativität der Argumentationsstandards hingewiesen. Neumanns Vorstellung allerdings, daß heute anders als früher - »in einer juristischen Argumentation die Behauptung einer ethnisch bedingten geringeren oder größeren intellektuellen Leistungsfähigkeit (oder: besonderen charakterlichen Disposition etc.) bestimmter Personengruppen undenkbar « sei, zeigt, daß das Pfälzer-Urteil des LG Mannheim (NJW 1997, 1995 f.) die idealistische Studierstube des Theoretikers noch nicht erreicht hat.

[DS]

\subsection{Theorie juristischen Entscheidens}

\section{Jochen Schneider}

Von einer Theorie juristischen Entscheidens erwartet Jochen Schneider, daß sie darauf zielt, »dem Juristen zumindest einen größeren Pool an Handlungsalternativen zu vergegenwärtigen, so daß er sich bewusst entscheiden kann, eine Entscheidung im Sinne eines Aufbrauchens von Wahlmöglichkeiten [zu] treffen« (383). Natürlich soll die Vermehrung der Entscheidungsmöglichkeiten nicht die Chance zur Willkür eröffnen, sondern die Aussicht auf bestmögliche Qualität der Entscheidung steigern. Schneider mustert die gegenwärtig zur Verfügung stehenden Theorien und kommt schließlich im Hinblick auf die Erwartungen - zu einem durchweg negativen Bild und Ergebnis.

Gleichgültig ob man sich an Theorien des präskriptiven (ökonomische Kosten/Nutzen-Analyse), des deskriptiven (Attitüden, Rollen, Vorverständnisse aller Art) oder des verstehenden (»Psychologie der Rechtsgewinnung «) Typs wendet, immer sind diese Unternehmungen durch den Versuch der Forschung gekennzeichnet, sich in irgendeiner Weise an den Herstellungsprozess der Entscheidung heranzupirschen. Man zerlegt ihn in Phasen - ganz simpel: linear, von der Problemdefinition bis zur Ausführung; etwas anspruchsvoller: Ablaufschema mit Rückkoppelungseffekt -, man identifiziert verschiedene Einflussfaktoren (Rolle, Alltagstheorie, Schichtzugehörigkeit o.ä.), man steigert (richtiger: ermöglicht zu steigern) das Informationsniveau etc. Leitend ist immer die Hoffnung, die Identifikation von Determinanten könne, so sie als schädlich betrachtet werden, zu ihrer Eliminierung, so sie als günstig gelten (bessere Information!), zu ihrer Verstärkung führen. Eine typische 70er Jahre-Illusion - und das nicht nur deshalb, weil ein Kausalnexus zwischen eher als positiv (etwa: umfassendes Wissen) und eher als negativ (etwa: politische oder religiöse Bindung) einge- 
stuften Faktoren und den je gefällten Entscheidungen bislang nicht schlüssig nachgewiesen werden konnte.

Der Beitrag liefert einen ebenso klaren wie schlüssigen Überblick über die einschlägigen Bemühungen und ist als Einführung auf hohem Niveau bestens geeignet. [DS]

\subsection{Wissenschaftstheorie der Rechtswissenschaft}

\section{Ulfrid Neumann}

Eine »Wissenschaftstheorie « der Jurisprudenz scheint vorauszusetzen, daß es sich bei dieser um eine »Wissenschaft« handelt. Das ist allerdings keineswegs selbstverständlich, denn wie wir von Jan Schröder gelernt haben, hat die alte iurisprudentia mehr als 2000 Jahre gebraucht, bevor sie sich im 18. Jahrhundert endgültig den Namen »Wissenschaft « zulegte.

Auf allgemeine Zustimmung ist dieser Versuch der Selbsterhöhung niemals gestoßen, wenn auch der schon seit der Antike lodernde Streit über den »wissenschaftlichen« Wert des juristischen Wissens (M. Herberger) allmählich erlosch. Das 20. Jahrhundert hat dann in erster Linie die Juristen selbst mit der Frage beschäftigt gesehen, ob ihre Tätigkeit eine wissenschaftliche sei. Bei »Tätigkeit« ist hier nicht an Gutachten oder Urteil, sondern an die Pflege und Fortentwicklung der Dogmatik zu denken, also an eine Arbeit, die heutzutage, wenn nicht ausschließlich, so doch ganz überwiegend von den beamteten Rechtsprofessoren an den Universitäten verrichtet wird. Bei ihnen ist naturgemäß wegen der doch nicht ganz geringen gesellschaftlichen Gratifikation, die der Titel »Wissenschaftler « mit sich bringt, das Interesse an der Frage, ob die »Rechtswissenschaft« denn wirklich eine Wissenschaft sei, am größten.

Daran hat auch der Umstand nichts geändert, daß es sich bei dieser Frage offenkundig um ein aussichtsloses Unternehmen handelt. Denn es zielt auf eine Wesensdefinition dessen, was eine Wissenschaft ist, womit die Tür ins Land der unbegrenzten Antworten aufgestoßen wurde.

Stellt man um auf die Frage, ob es zweckmäßig ist, die Jurisprudenz als Wissenschaft zu bezeichnen, lassen sich verschiedene (sachimmanente, institutionelle, psychologische) Gesichtspunkte für eine rationale Bezeichnungsdiskussion entdecken - wenn man denn wirklich diesem Gegenstand eine solch ungebührliche Aufmerksamkeit widmen will.

Neumann geht diesen Weg nicht. Er wählt aus den zahllosen Wissenschaftsdefinitionen die Bestimmung »auf die Gewinnung von Erkenntnissen gerichtete planmäßige Tätigkeit« und unternimmt von hier aus einen Subsumtionsversuch für die Jurisprudenz. Der scheint schnell an dem Kriterium rationaler Überprüfbarkeit zu scheitern, dem sich - wenigstens nach den Prinzipien der sprachanalytischen Wissenschaftstheorie - »Erkenntnisse « stellen müssen, wenn sie denn als solche gelten wollen.

Wird »rationale Überprüfbarkeit« als »empirische Überprüfbarkeit « verstanden, muß die Rechtsdogmatik, wie Neumann mühelos zeigt, ihre Hoffnungen auf das Wissenschaftsprädikat aufgeben. Ein Ausweg könnte sich, wie Neumann zurückhaltend andeutet, vielleicht dann ergeben, wenn man auf die empiristische Beobachterevidenz verzichtet und mit Eicke von Savigny »Rechtsgefühl « und »Wertevidenz« der »Wissenschaftler« als Garanten der geforderten Intersubjektivität einsetzt. 
Beruhigenderweise wird diese Lösung von Neumann aber nicht empfohlen, sondern lediglich weiterer Prüfung anheim gegeben (»bliebe noch zu untersuchen«) - eine Prüfung die vernünftigerweise bislang unterblieben ist.

Problematisch wie der Status der Jurisprudenz als Wissenschaft ist auch die Kennzeichnung der in ihr in großer Zahl vorfindlichen dogmatischen »Theorien « als wissenschaftliche Theorien. Dogmatische Theorien konstituieren ihren Gegenstandsbereich und erklären ihn nicht. Neumann schreibt ihnen »normpropositiven Charakter « $\mathrm{zu}$ - mit anderen Worten, es handelt sich um Meinungen. Neumann weicht diesem Urteil mit der Bemerkung aus, daß »eine klare Antwort auf die Frage, ob rechtsdogmatische Theorien als Theorien im technischen Sinne zu verstehen sind, außerordentlich schwierig« sei.

Abschließend befasst sich der Überblick über die Wissenschaftstheorie der Rechtswissenschaft mit der Deutung der Jurisprudenz als sozialtechnologische oder - antithetisch - kritische Wissenschaft. Beide Positionen sind inzwischen eher Reminiszenzen als lebendige Ansichten. Der von Neumann selbst vielfach in Erinnerung gebrachte Umstand, daß die Jurisprudenz eine argumentierende Disziplin ist, hätte an dieser Stelle die Prüfung veranlassen sollen, ob die Juristen nicht besser bedient wären, wenn sie an die große Tradition, ihre Tätigkeit als Kunst (ars) zu begreifen, anknüpfen würden.

[DS]

\subsection{Rechtswissenschaft und Sozialwissenschaft}

\section{Alfred Büllesbach}

»Wo Juristen mit Annahmen über die gesellschaftliche Realität operieren, werden sie dies auf dem Niveau der Sozialwissenschaften tun.«, prophezeite Rüdiger Lautmann im Jahre 1976. Die Zeiten waren turbulent, die Juristen verunsichert und die Sozialwissenschaften Hort der Kritik und Heilsbringer in Personalunion: gnadenlos in der Enttarnung realitätsenthobener Machtverwaltung, versöhnlich durch die Andienung der eigenen, Wirklichkeitsnähe versprechenden Methoden.

Folgerichtig wurden die Sozialwissenschaften gleich in der ersten Auflage des Werkes mit einem eigenen Beitrag bedacht. »Rechtswissenschaft ist ein Teil der Sozialwissenschaften«, heißt es dort lapidar. Unter dieser Prämisse liegt es nahe, in dem Teil (Recht) die Methoden des Ganzen (Sozialwissenschaft) ungefiltert zu adaptieren. An welchen Stellen konkret adaptiert werden könnte, wird von Büllesbach aufgelistet. Dabei ergibt sich ein nicht zu übersehendes Übergewicht der empirischen gegenüber den theoretischen Sozialwissenschaften: Alles, was sich rund um die sogenannte Rechtswirklichkeit anordnen läßt, wird dem wißbegierigen Juristen zum Studium anempfohlen; auf der einen Seite die rechtskritischen Forschungen (an Dogmatik und Methode, an der Sozialisation der Juristen, der Sanktionstätigkeit der Polizei, an labeling approaches und Alltagstheorien), auf der anderen Seite die Strömungen, die Immunisierung gegen weitere Rechtskritik versprechen (Rechtstatsachenforschung, Gesetzgebungslehre, Kriminologie).

Seinen Abschluß findet dieser Beitrag in einigen Ausführungen zur Rechtsanthropologie, in denen die Handschrift des Lehrers Kaufmann deutlich lesbar bleibt: »Die 
Frage nach der Natur des Menschen, seine Personalität, ist daher maßgebend für das Wesen des Rechts. Maßstab des Rechts, die Idee des Rechts selbst, ist der Mensch.«

Der Beitrag wurde verfaßt, als sich die methodischen Debatten in der Rechtswissenschaft auf ihrem Höhepunkt befanden. Auf diesem Gipfel scheint es Büllesbach gut zu gefallen. Seit 1977 hat er seinen Text nicht nennenswert überarbeitet (davon auszunehmen ist der Abschnitt über die Selektivität von Sanktionstätigkeit). Die Anmerkungen sind gewachsen, verweisen aber noch immer weithin auf die Siebziger. Der Textkorpus selbst wurde überwiegend unangetastet gelassen; die wenigen Ergänzungen, die sich finden lassen, können freilich kaum als geglückt bezeichnet werden (»Die Diskussion, ob Rechtswissenschaft als Sozialwissenschaft, bzw. Rechtswissenschaft und Sozialwissenschaft ist vor Jahrzehnten in Deutschland heterogen geführt worden.«). Mit anderen Worten: Der Beitrag ist nicht nur alt, er ist auch veraltet. Hinweise auf andere Kapitel des Buches verweisen wegen zwischenzeitlich erfolgter Neuordnungen ins Nichts, die dogmatischen und methodologischen Skeptiker werden noch immer mit dem Pauschalverweis »vgl. Fr. Müller, Esser, Kriele« benannt, die vielen »gegenwärtigen«, »aktuellen« oder »heutigen Diskussionen«, auf die Büllesbach seit 30 Jahren Bezug nimmt, werden seit dieser Zeit unverändert beschrieben. Daß dem Fach damit inzident attestiert wird, es habe sich durch all die Jahre hindurch nicht erwähnenswert weiterentwickelt, scheint Büllesbach nicht zu stören.

Grotesk wird dieser Verzicht auf Überarbeitung dort, wo ein konkreter Zeitpunkt in der Vergangenheit in seiner Distanz zur Gegenwart in Bezug genommen wird. So ist seit 1977 zu lesen: »Im Strafrecht wurde schon vor ca. 70 Jahren von der Humanisierung und Rationalisierung und von der Ablösung des Prinzips der Vergeltung durch das der Resozialisierung gesprochen.« Die ersten strafrechtlichen Humanisierungsbestrebungen werden in den verschiedenen Auflagen also zunächst im Kaiserreich, dann bei Ausbruch des Ersten Weltkriegs, anschließend während der Anfänge der Weimarer Republik, später zur Zeit der Inflation und zuletzt zu Beginn des »Dritten Reiches « vermutet. Man kann nur hoffen, daß ein »vor ca. 100 Jahren« nicht die einzige Änderung ist, die diesem Text bis zur Neuauflage widerfährt.

$[\mathrm{BL}]$

\subsection{Systemtheorie im Recht}

\section{Alfred Büllesbach}

Die Systemtheorie wurde von Büllesbach bereits 1977 beschrieben. Teile der damaligen Darstellung sind bis heute unverändert nachzulesen; insbesondere die zwischenzeitlichen Entwicklungen in der Systemtheorie von Niklas Luhmann und die Habermas'sche Kritik daran haben jedoch zu umfangreichen Ergänzungen des Originaltextes geführt. Trotz dieser Ergänzungen bleibt sichtbar, daß es dem Text ursprünglich in erster Linie um eine Darstellung der allgemeinen Systemtheorie ging und deren heute wohl prominenteste Spielart, die funktional-strukturelle Systemtheorie Luhmanns, lediglich als eine von vielen möglichen Ausprägungen Berücksichtigung fand. Im Originaltitel »Systemtheoretische Ansätze und ihre Kritik« fand dieses Anliegen seinen Ausdruck. 
Obwohl sprachlich unschön, hat der alte Titel gewisse Vorzüge gegenüber dem jetzigen. »Die Systemtheorien erheben den Anspruch, Gesellschaft im Ganzen (in ihrer Totalität) zu begreifen«, heißt es zu Beginn des Beitrags. Dies bedeutet vor allem, daß die Systemtheorie - insbesondere in der Fassung von Luhmann - eine Gesellschaftsund keine Rechtstheorie ist. Systemtheorie kann deshalb nie im Recht stattfinden. Statt Systemtheorie im Recht wäre ein Titel wie Recht in der Systemtheorie in dieser Hinsicht vermutlich weniger mißverständlich.

In der Darstellung der allgemeinen Systemtheorie sind die lange zurückreichenden Wurzeln des Beitrags gut zu erkennen. Wenn dort von »Formalisierbarkeit von Rechtssystemen« oder von »automationsgerechter« Gesetzgebung die Rede ist, so kommen darin Hoffnungen zum Ausdruck, die in den siebziger Jahren des vergangenen Jahrhunderts eine kurze Blütezeit erlebt haben, mittlerweile aber kaum mehr ernsthaft verfolgt werden. Die Feststellung Büllesbachs, »die allgemeine Systemtheorie« sei »innerhalb der Rechtswissenschaft nicht explizit aufgegriffen worden«, läßt sich deshalb auch auf andere Strömungen ausweiten, die zu Beginn des Beitrags dargestellt werden: in der heutigen Diskussion kommt weder der kybernetischen Systemtheorie noch dem Input-Output-Modell des politischen Systems grundlegende Bedeutung zu.

Ausgehend von Parsons' Systemtheorie widmet Büllesbach den weit überwiegenden Teil seiner Darstellung der Rechtssoziologie Luhmanns. Wegweiser sind dabei freilich eher klassisch rechtstheoretische Fragen denn die gesellschaftstheoretischen Probleme, von denen sich Luhmann bei der Ausarbeitung seiner Theorie leiten ließ. So heißt es etwa, »problematisch bzw. ungelöst blieben bei Luhmann die Fragen nach der Richtigkeit (Gerechtigkeitsgehalt), der Wahrheit, der Akzeptanz der Rechtentscheidung (Unterwerfung unter dieselbe)«, was zwar (teilweise) zutrifft, aber kein Vorwurf ist, von dem sich eine Theorie beirren lassen müßte, die an diesen Fragen kein unmittelbares Interesse hat. Die Skizze der Autopoiesis und ihrer systemtheoretischen »Anwendung « bei Luhmann und Teubner ist als Einführung in die Materie jedoch gut gelungen.

Die abschließend wiedergegebene Kritik an Luhmanns Systemtheorie besteht ebenfalls aus ursprünglichen und später hinzugefügten Teilen, von denen die ersteren nur noch teilweise nachvollziehbar sind. Die allgemeine Kritik ist durch den Verweis auf Krauses Luhmann-Lexikon kurz und zuverlässig zusammengefaßt; die Kritik von Habermas dagegen speist sich zu einem großen Teil aus älteren Schriften, deren empörte Anklage (»Sozialtechnologie«) genauso ermüdend ist wie sie an den eigentlichen Problemen vorbeigeht. Der Rest der Darstellung besteht denn auch nicht aus einer Kritik an Luhmann, sondern aus einem sympathisierenden Blick auf die Diskurstheorie von Habermas. In den Kontext der Systemtheorie fügt sich dieser Seitenblick freilich nur ein, sofern man das Portrait des Spielers erst dann für komplett hält, wenn auch der Gegenspieler gezeichnet wird. 


\subsection{Medizin-, Bioethik und Recht}

\section{Ulrich Schroth}

1994 wurde die Rechtsinformatik zur Tendenz. Sie blieb es für eine Auflage. 2004 wurde am Puls der Zeit das Verhältnis von Medizinethik und Recht zueinander erfühlt und folgerichtig in den Rang einer Tendenz erhoben. Es ist die einzige Tendenz, zu der sich das Werk bekennt. Und wieder ist fraglich, ob das Thema bis zur nächsten Auflage die Frische versprüht, die die Aktualität heischende Rubrik der Tendenzen erfordert, ob es sich zwischenzeitlich zum Schwerpunkt mausert, oder ob zum Zeitpunkt der nächsten Auflage nur die Feststellung bleibt, man habe es hier mit einem Thema zu tun gehabt, das aufgetaucht ist, als seine Zeit gekommen war, und wieder verschwinden mußte, als diese Zeit abgelaufen war.

Für solche saisonal präsenten Fragestellungen steht das Wort »Modeerscheinung « bereit. Die Verzahnung ethischer und rechtlicher Fragen im Medizinrecht fällt insoweit sicher nicht in diese Rubrik, als viele der damit aufgeworfenen Probleme bei weitem noch keiner konsensfähigen Lösung zugeführt sind und das Interesse daran vorerst kaum abebben dürfte. Gleichwohl ist nicht zu übersehen, daß sich die anfängliche Aufgeregtheit nach den intensiven Debatten der letzten Jahre gelegt hat und das ursprünglich recht spekulative Raisonnieren über anzustrebende oder abzulehnende staatliche Regulierungsversuche durch zahlreiche gesetzgeberische Entscheidungen nicht unerheblich strukturiert wurde.

Es gibt also Tendenzen, die beschrieben werden können. Das macht den Gegenstand für eine Behandlung im Kaufmann/Hassemer/Neumann geeignet, bedeutet aber zugleich den Verzicht auf Themen, die einer Überführung in lehrbuchförmige Behaglichkeit noch nicht zugänglich sind: das Recht der Terrorismusbekämpfung etwa, dessen ungelöste Probleme sich womöglich auch vor der nächsten Auflage noch mit einer Dringlichkeit stellen, die eine Behandlung bei den »Tendenzen« rechtfertigt.

Die einstweilen als Tendenz ausgemachte Medizinethik - gleich ob Modethema oder nicht - wird jedenfalls zuverlässig beschrieben. Ein kurzer Überblick über Aktualität und Genese, ein Abriß über die Methoden und anschließend eine detailliertere Schilderung zentraler Probleme: Lebendspende, Organverteilung, embryonale Stammzellenforschung und Mehrlingsreduktion.

Die eingangs erwähnten Prinzipien der Medizinethik - Patientenautonomie, Schadensvermeidung, Fürsorgepflicht, Gerechtigkeit - dienen dabei als Raster für die von den verschiedenen Lagern vorgebrachten Argumente.

Das Spannungsfeld, in dem sich medizinethische Debatten bewegen, zeichnet sich auf diese Weise deutlich ab. Daß der Darstellung wesentliche Argumente entgangen sind, steht nicht zu befürchten. Schroth selbst scheut auch nicht davor zurück, Stellung zu beziehen, und zwar in aller Regel gegen die Entscheidungen des Gesetzgebers. Da diese Opposition aber als solche gekennzeichnet ist und den von beiden Seiten vorgetragenen Gründen ausführlicher Raum zugestanden wurde, sind seine vielen Abweichungen von den legislativen Ansichten nicht schadhaft.

Weniger einleuchtend sind dagegen die abschließend zum Thema »Ethik und Recht in der Medizin« vorgetragenen Erwägungen, die sich überwiegend auf Gemeinplätze 
(»Ethische Reflexionen kritisieren juristische Regeln«) und Skurrilitäten beschränken (beispielsweise wird gezeigt, »dass juristische Regeln dem medizinethischen Diskurs eine Basis geben und Grenzen setzen «).

Was folgt, bleibt offen. Die Rechtsinformatik mußte, wie erwähnt, nach drei Auflagen eine Runde aussetzen, wurde dann zur Tendenz und ist nun wieder verschwunden. Die andere Tendenz der letzten Auflage allerdings ist mittlerweile zum doppelten Schwerpunkt mutiert: Theorie der juristischen Argumentation und Theorie juristischen Entscheidens. Der Medizinethik stehen alle Möglichkeiten offen.

[BL]

\section{Wahr ist, was gut ist}

»Objektivität von Idealität durch Positivität!« - das ist die Losung, die Walter Ott am Ende seines Buches ${ }^{11}$ als Folgerung und Forderung aus seinen Studien erhebt.

»Sein Buch«, das heißt hier: die zweite Auflage (1991) seiner Habilitationsschrift aus dem Jahre 1976. Sie enthält noch manche Referenzen und Exempel, die der Autor, wenn er erst 1991 zur Feder gegriffen hätte, vermutlich nicht gewählt hätte. Ansonsten handelt es sich aber doch um eine so gründliche Bearbeitung (z. B. ist weit mehr als ein Drittel der rund 200 Titel umfassenden Literaturnachweise erst nach 1976 erschienen), daß nahezu von einem neuen Buch gesprochen werden kann.

Das Echo in der rechtstheoretischen Lesergemeinde war eher dürftig. Es gab allfälliges Lob (»Klassiker«) und den (vermutlich unabsichtlich) die Habilitationskultur dekuvrierenden Hinweis, daß es sich hier um den »nicht gerade häufigen « Fall einer zweiten Auflage einer Habilitationsschrift handele. Ansonsten ließ sich zu diesem »Standardwerk « anscheinend nichts sagen - was aber keineswegs, wie man vermuten könnte, mit einer umfassenden Rezeption der Erstauflage zu erklären ist.

Die Arbeit geht in einem einprägsamen Dreischritt vor. Sie beschreibt zunächst die auf dem Wissenschaftsmarkt mehr oder weniger häufig angebotenen Arten des Rechtspositivismus und filtert aus ihnen eine allgemeine Charakterisierung heraus. Alsdann stellt der Autor die Frage, ob die rechtspositivistischen Theorien, die allesamt mehr oder weniger deutlich auf dem philosophischen Positivismus beruhen, nach dessen erkenntnistheoretischen Prämissen bewiesen werden könnten. Da diese Frage verneint werden muß, bleibt drittens und abschließend lediglich zu erörtern, ob es gleichwohl Gesichtspunkte gibt, die das rechtstheoretische Unternehmen »Positivismus « als sinnvoll rechtfertigen können.

Zum ersten, analytischen und deskriptiven Teil des Buches ist wenig zu bemerken. Es handelt sich um eine klare, knappe und das Feld umfassend beschreibende Darstellung. Daß der Autor sich nicht auf den - in der Regel allein behandelten und von ihm »etatistisch « genannten - Positivismus beschränkt, sondern auch die psychologischen und soziologischen Positivismen einbezieht, ist dankenswert. Die Monographie be-

11 Der Rechtspositivismus. Kritische Würdigung auf der Grundlage eines juristischen Pragmatismus, 2. Auflage, Berlin: Duncker \& Humblot 1992 (Erfahrung und Denken. Schriften zur Förderung der Beziehungen zwischen Philosophie und Einzelwissenschaften, Band 45), $282 \mathrm{~S}$. 
stellt sich dadurch zum zuverlässigen und pädagogisch wertvollen Leitfaden durch alle Spielarten des Rechtspositivismus von John Austin bis Ota Weinberger.

In diesem Punkt sind sich auch alle Rezensionen, die sich (wenn auch in der Regel nur wenig) über das Niveau einer klappentextähnlichen Beschreibung hinausbegeben, einig (Engisch [Ztschr. Strafrwiss. 3/78], Hoerster [DJZ 34, 1979, 823 f.], Rüssmann [ARSP 60, 1978, 594 ff.] für die 1. Auflage und Graf [Jur. Blätter, 1995, 609], Hilgendorf [ARSP 80, 1994, 446 f.], Krawietz [Rtheorie 24, 1993, 249] für die 2. Auflage).

Die Gewaltsamkeiten, denen eine solche Taxinomie unausweichlich anheimfällt, werden von Ott durch den Vorschlag gemildert, zwischen einem starken Rechtspositivismus (rationale Wertbegründung ist ausgeschlossen) und einer schwachen Version (kein ethischer Relativismus, da rationale Moralbegründung akzeptiert wird) zu unterscheiden - eine Unterscheidung, von der er selbst allerdings im folgenden keinen Gebrauch macht.

Der von Ott aus den Beschreibungen abgezogene »Begriff des Rechtspositivismus « (104 ff.) kann angesichts der Vielzahl von Definitionen, Beschreibungen und Vorschlägen nur ein synthetisch-semantischer im Sinne der modernen Definitionslehre sein, also ein möglichst zweckmäßiges Konzept.

Ott weist darauf hin, daß in der Literatur mit dem Ausdruck »Positivismus « im wesentlichen auf drei Komplexe gezielt wird: zunächst auf den Rechtsbegriff (Geltungsfragen, Recht/Moral etc.), dann auf die Rechtsanwendung (Gesetzesinterpretation, Lücken etc.) und schließlich auf die Axiologie (Sein/Sollen, Werterkenntnis).

Er selbst richtet seine Definition begründet am Problemkreis »Bestimmung des Begriffs des Rechts« aus und arbeitet im Folgenden mit der Festsetzung, wonach er als rechtspositivistisch jede Theorie betrachtet, »die unter Vermeidung metaphysischer Annahmen den Begriff des Rechts mit Hilfe empirischer Merkmale bestimmt, die jeweils veränderlich sind «. Die »empirischen Merkmale« - zuvörderst Positivität und die Trennung von Recht und Moral - sowie deren Relativität und Historizität werden abschließend vorgestellt.

Im zweiten Teil seiner Arbeit (117-162) richtet Ott an den dergestalt fixierten Rechtspositivismus die Wahrheitsfrage, d. h. er prüft, ob sich auf der Grundlage der Erkenntnistheorie des »artverwandten« philosophischen Positivismus eine Entscheidung darüber treffen läßt, ob eine der rechtspositivistischen Theorien beweisbar und damit in diesem Sinne die »richtige « ist.

Man wird bezweifeln dürfen, daß es zu diesem Zweck erforderlich war, die Axiomatik und den Falsifikationismus extensiv zu entfalten, denn schließlich handelt es sich um alte Bekannte, die in einer Monographie keiner erneuten lehrbuchartigen Vorstellung bedurft hätten, sondern der unexplizierten »Anwendung « hätten zugeführt werden können. Der Hinweis des Autors, daß die Kenntnisse, welche »wir für den weiteren Fortgang unserer Untersuchung nicht unmittelbar benötigen werden «, gleichwohl »für ein tieferes Verständnis« nützlich seien (118), ist wenig überzeugend. Er würde auch die Einfügung einer vollständigen Geschichte der abendländischen Erkenntnistheorie legitimieren können.

Es kommt hinzu, daß das Vorhaben, Rechtspositivismus-»Theorien « lediglich aufgrund des Etiketts »Positivismus « einem Beweisverfahren zu unterwerfen, das sich für 
naturwissenschaftliche Fragestellungen bewährt hat, auf den Versuch hinausläuft, mit Bohrungen und chemischen Analysen beweisen zu wollen, daß jemand entgegen solcher Kennzeichnung kein Holzkopf ist. Da Ott die ermittelten Positivismus-Theorien ausschließlich nach dem »vorausgesetzten Rechtsbegriff« (143) differenziert, hätte es außerdem genügt und dem logischen Gang der Erörterung deutlich gut getan, wenn er lediglich mit Hilfe neuerer definitionskritischer Arbeiten den vorfindlichen Wesensdefinitionen zum Rechtspositivismus zu Leibe gerückt wäre.

Andererseits erhält man auf diese Weise einen bald unmittelbar, bald mittelbar aus den Klassikern (Bocheñski, Hilbert, Kraft, Popper) geschöpften Abriß von mustergültiger Klarheit und pädagogischer Zuverlässigkeit, der, einschließlich der geschickten Präsentation der modernen Definitionslehre, unverkürzten Eingang in den juristischen Unterricht an jenen Stellen verdiente, wo von empirischen Beweisverfahren die Rede ist.

Am Ende kommt es, wie es kommen muß: Die positivistischen Definitionen des Rechts erweisen sich als Festsetzungen, d. h. die Frage »was ist Recht? « wird zu Recht als sinnlos suspendiert, es geht »nicht mehr um eine Wahrheitsfrage, sondern darum, einen mehr oder weniger fruchtbaren Begriff des Rechts zu entwerfen. Es gilt nicht einen bestimmten Begriff zu entdecken, sondern einen bestimmten Begriff zu konzipieren«(159).

Was jetzt noch bleibt, ist die Frage, welchen praktischen oder theoretischen Nutzen eigentlich Konzepte haben können, die kein Wissen und keine Erkenntnis vermitteln. Dieser Frage wendet sich Ott im dritten und letzten Teil seiner Arbeit zu (163-267).

Die Antwort, die er gibt, ist naheliegend, vernünftig und durch den philosophischen Pragmatismus vorgeprägt, der bekanntlich die Bewertung der Folgen und praktischen Wirkungen einer Theorie der Suche nach der ewigen Wahrheit vorzieht. Begrifflicher Pragmatismus (158) und juristischer Pragmatismus (171) reichen sich die Hand, um die positivistischen Theorien nach ihrer Leistungsfähigkeit zur Behandlung theoretischer und praktischer Probleme der Jurisprudenz zu befragen. Wobei dem Verfasser als »theoretisch « jene Fragestellungen gelten, denen er, wie den rechtshistorischen, rechtssoziologischen etc., eine »mittelbar praktische Bedeutung « zuschreibt.

Ins Zentrum seiner Prüfung hat Ott die Trennungsthese gerückt. Zu Recht, denn an diesem Langzeitvorhaben der europäischen Rechtsphilosophie scheiden sich noch immer die theoretisierenden Geister. Außerdem können unter diesem Stichwort alle Spielarten des Rechtspositivismus undifferenziert erörtert werden, denn die Trennungsthese ist schließlich ein per definitionem gemeinsames Merkmal. Was also sind die Vorteile, wenn »Recht« so konzipiert wird, daß Recht und Moral zwei verschiedenen Welten angehören?

Daß man diesem Entwurf nicht schon mit der Behauptung entgegentreten kann, zwischen Recht und Moral bestehe ein begrifflich notwendiger Zusammenhang, weil man dann einfach ohne Terraingewinn mit Postulat x gegen Postulat y anrennt, hat der Verfasser schnell dargetan (173).

Zwar ist ihm an dieser Stelle inzwischen in Robert Alexy ein gewichtiger Widerpart erwachsen, der sich 1991 erst skizzenhaft zu Wort gemeldet hatte (Zur Kritik des Rechtspositivismus, ARSP, Beiheft 37, 1990, 9 ff.), bald danach aber mit einem gan- 
zen Buch (Begriff und Geltung des Rechts, Freiburg i. Br./München: Verlag Karl Alber 1992) gegen die Trennungsthese vorgegangen ist.

Daß die Position Otts durch diese Schrift nachhaltig erschüttert worden sei, wird man allerdings kaum behaupten wollen. Das mit der zermürbenden Gründlichkeit eines Anhängers der sprachanalytischen Philosophie verfasste Werk verteidigt unter der Bezeichnung »schwache Verbindungsthese« im Kern die Position Radbruchs. In geschickter Umkehr der Beweislast kommt Alexy zu der Überzeugung, daß er die Einwände gegen die Verbindung von Recht und Moral »mindestens so weit entkräftet « habe, »daß sich ein Gleichstand ergab «.

Selbst wer das zugibt, würde dann erst wieder bei Ott und seiner Frage landen, ob Positivismus oder Nonpositivismus vorzuziehen sei. Aber schon das Zugeständnis des »Unentschieden« dürfte manchem Leser nicht leicht fallen. Der rechtshistorisch nicht eingetrübte, fröhliche Idealismus, mit dem Alexy etwa beim »Relativismusargument « (= Gerechtigkeitsargumente sind keiner objektiven Erkenntnis fähig) der Skepsis Hoersters (Zur Verteidigung des Rechtspositivismus, NJW 1986, 2480 ff.) entgegentritt, wirkt geradezu frivol angesichts des Umstandes, daß das OLG Bamberg noch 1949 (!!) ein Gesetz, das für abfällige Äußerungen über einen Diktator die Todesstrafe zulässt, nicht als extrem ungerecht ansah.

Gegenüber der Begrifflichkeitsfrage größeres, jedoch nicht dezisives Gewicht legt Ott der These von Dworkin bei, der mit seinen haltlosen Behauptungen über die Unidentifizierbarkeit von Prinzipien und der von ihnen gesteuerten allein richtigen Entscheidung durch den Rechtspositivismus den vergeblichen Versuch unternommen hat, zwischen positivem Recht und gesellschaftlicher Moralität einen notwendigen Zusammenhang zu stiften.

Nachdem so die Einwände gegen die Möglichkeit des Konzepts ausgeräumt sind, diskutiert Ott den Nutzen.

Als Vorteil erkennt er den Umstand, daß Rechtshistoriker, Rechtssoziologen und andere Beobachter des Rechts nicht um ihren Gegenstand gebracht werden, was zweifellos schnell der Fall sein würde, wenn man von Recht nur noch dann sprechen sollte, wenn die historischen Normen sich zunächst vor einem moralischen Tribunal der Gegenwart verantwortet hätten.

Ferner glaubt er, daß die Trennungsthese die Rechtssicherheit fördere, weil sie verhindere, daß die Rechtsgeltung unter Berufung auf politische, religiöse, moralische etc. Meinungen angefochten werde.

Als nachteilig gilt ihm demgegenüber der Umstand, daß der Positivismus »keine Anleitungen an den Gesetzgeber oder an den Richter« enthält, wie neues Recht zu schaffen sei. Deshalb würde er ein ethisch angereichertes Recht vorziehen (222).

Für ein solches Konzept soll auch der Umstand sprechen, daß sich nach Zusammenbruch eines Unrechtsstaates die »Bewältigung gesetzlichen Unrechts« einfacher gestalten lasse und daß die Zurückweisung kraß inhumaner Anordnungen vom Richter aus Rechtsgründen statt aus »bloß« moralischen Gründen möglich sei. Schließlich zollt er auch noch dem Rechtsgefühl der »Laien« seinen Tribut, wenn er feststellt, diese hätten kein Verständnis für die These, »daß ,Recht` nichts mit ,Gerechtigkeit` zu tun haben soll«. 
Das ist allerdings ein besonders schwaches Argument, denn kein Rechtspositivist, der davon ausgeht, daß Recht und Gerechtigkeit in verschiedenen Welten siedeln, wird behaupten wollen, daß sie deshalb nichts miteinander »zu tun haben« sollten. Er wird im Gegenteil behaupten, daß die eine Welt der anderen zu dienen habe. Und daß die »Laien« sehr wohl zwischen den getrennten Sphären zu unterscheiden wissen, konnte nicht nur der deutsche Jurist dem überraschenden Diktum der ostdeutschen Künstlerin Bärbel Bohley entnehmen: »Wir wollten Gerechtigkeit und haben den Rechtsstaat bekommen $\ll$.

Aber auch die anderen Argumente des Verfassers dafür, daß die »ethische Anreicherung « wünschenswert sei, sind wenig überzeugend. Daß der Positivismus keine Anleitungen zur »Rechtsfortbildung « gibt (was er allerdings auch nicht will und was als sein größter Vorzug erscheinen könnte), wird den nicht beeindrucken, der davon ausgeht, daß der Richter überhaupt nichts anderes betreibt als »Rechtsfortbildung « und daß er dazu keinerlei »Anleitungen« braucht - nicht zuletzt deshalb, weil eine Einigung über mehr als äußerst abstrakte und damit ziellose Maximen nicht zu erwarten steht. Daran wird auch die Erwartung von Ott, daß am Ende verworfen werde, »was jedenfalls im sittlichen Bewußtsein der überwiegenden Zahl aller Menschen als verabscheuungswürdig gilt«, wenig ändern.

Desgleichen scheinen mir die praktischen Gewinne für den (ohnehin mehr als unwahrscheinlichen) Richter, der aufgrund moralisierten Rechts aus juristischen (statt »bloß« aus moralischen) Gründen die inhumane Rechtsanwendung verweigern darf oder dem eine erleichterte Konstruktion zur juridischen Bewältigung der Vergangenheit angeboten wird, doch reichlich dürftig und vor allem extrem unrealistisch zu sein.

Viel zu viel Worte widmet Ott schließlich der inzwischen abundant erörterten Frage, inwieweit die von Radbruch unglücklich zur Welt gebrachte These von der Mit-, Teiloder Hauptverantwortung des Rechtspositivismus (hier in der Form des Gesetzespositivismus) für die justiziellen Verbrechen der Nationalsozialisten rechtshistorisch bestätigt werden kann. Auch 1976 war schon für jedermann ersichtlich, daß es sich hier um eine impertinente Rechtfertigungsideologie der deutschen Richterschaft gehandelt hat, die sich damit das Weiterjudizieren und ihre Pensionen sicherte. Schließlich hatte sich Bernd Rüthers schon 1967 mit der vielfach wieder aufgelegten Arbeit über die »Unbegrenzte Auslegung « habilitiert und dabei minutiös nachgewiesen, daß die Justiz des »Dritten Reiches « nicht etwa durch ein Zuviel, sondern durch ein Zuwenig an Positivismus ihre Ehre verloren hatte.

Mittlerweile kann man auf alle Beschreibungen, Untersuchungen und weitläufigen Erwägungen verzichten und zu der zeitsparenden Lektüre der Ogorek'schen Analyse der Rechtsprechung zum Blutschutzgesetz greifen, weil dann der Gedanke an das Regiment eines Gesetzespositivismus als zynischer Scherz erscheint (»Rassenschande« und juristische Methode. Die argumentative Grammatik des Reichsgerichts bei der Anwendung des Blutschutzgesetzes von 1935, in: Kritische Vierteljahresschrift für Gesetzgebung und Rechtswissenschaft 2003, 279 ff.).

Am Ende seiner Ausführungen (206-221) gelangt freilich auch Ott zu der Feststellung: »Der Vorwurf, der Rechtspositivismus, insbesondere der Gesetzespositivismus, sei schuld an der nationalsozialistischen Rechtsverwüstung, ist nachweislich falsch.« 
Damit ist er zugleich am Schluß seiner Rezension der gebündelten rechtspositivistischen Lehren angekommen und kann sich jetzt der Musterung der »übrigen Vor- und Nachteile der rechtspositivistischen Theorien« Stück für Stück (wieder von John Austin bis Ota Weinberger) widmen (224-264).

Da alle diese Theorien auf eine mehr oder weniger lange Geschichte zurückblicken können, schieben sie in der Regel auch kritische Stellungnahmen in beachtlicher Menge vor sich her. Ott kann also erneut sein Talent für Vereinfachung ohne Simplifizierung, für Klarheit ohne Verdünnung, für Kürze ohne Verkürzung unter Beweis stellen. Die Schwierigkeiten, welche die Theoretiker mit ihrer Imperativentheorie (Austin), mit der rechts»fortbildenden« Justiz (Gesetzespositivismus), mit dem subjektiven Recht und der Deontik (Kelsen), mit ihren Anerkennungstheorien (psychologischer Positivismus) usw. haben, werden konzentriert und fair dargestellt, so daß der bereits im geistigen Besitz des neutralen Eingangsreferats befindliche Leser sein Wissen jetzt mit Hilfe der nachgelieferten kritischen Einwände vervollständigen kann.

Das Resumée des juristischen Pragmatismus ist nicht sonderlich ermutigend (265267). Gezeigt werden konnte, daß man auf der Grundlage jeder einzelnen rechtspositivistischen Theorie höchst divergente (praktische und mittelbar praktische) Ergebnisse erzielen wird und daß keine dieser Theorien als DIE richtige erwiesen werden kann. Das gilt allerdings auch von den Naturrechtslehren, die sich nach Ott folgerichtig der gleichen Prozedur zu unterwerfen hätten wie die positivistischen Theorien: Bewährung im Angesicht ihrer Folgen! Wobei sich zweifellos zeigen wird, daß diese Folgen, je nach Naturrechtstheorie, manchmal erfreulich, manchmal erschreckend ausfallen werden.

Was also tun, wenn eine Theorie bald gute, bald schlechte Ergebnisse liefert und eine andere vielleicht gerade dort gute Resultate erzielt, wo die erste versagte, während sie Schlechtes leistet, wo ihre Vorgängerin sich als gut erwies? Man könnte beide nehmen oder besser: zielorientiert immer diejenige, welche man für das fragliche Problem benötigt.

Eben das empfiehlt der juristische Pragmatismus: »Man sollte [...] versuchen, mit einer Pluralität von Theorieansätzen zu arbeiten; und zwar nicht einfach in willkürlicher Art und Weise, sondern im klaren Bewusstsein, warum man zur Lösung eines bestimmten Problems gerade diesen und nicht einen anderen Ansatz wählt« (266).

Die Theorie als Rezept, um der Praxis zu ihrem Recht zu verhelfen. Das möchte dann freilich eine fröhliche Justiz werden. Wenn es nicht gelingt, die vom Verfasser geforderte Versöhnung von Idealismus und Realismus in der Positivität zu erreichen, dann werden also die Richter montags ihre Fälle mit Hans Kelsen lösen, dienstags mit Alf Ross, mittwochs mit H. L. A. Hart, donnerstags mit Ota Weinberger, und am heiligen Freitag genehmigen sie sich eine kleine rechtsethische Anreicherung.

Zuzugeben ist dem Verfasser allerdings, daß man gelegentlich den Eindruck hat, daß dies bereits die Wahrheit unserer justiziellen Praxis ist. Das würde zugleich erklären, warum sich diese Praxis so wenig aus allen jenen Kerlen und ihren Theorien macht. Es geht, wie beim Dorfrichter Adam, bald so, bald anders - aber eben auch ohne sie.

Auch die scheinbar weit in die Zukunft weisende, abschließende Forderung des Autors »Objektivität von Idealität durch Positivität!« hat bereits deutlich Fuß gefasst. 
Denn schließlich hat die Verfassung der Bundesrepublik und die angeschlossene justizielle Grundrechtsinterpretation aus der üppigen Positivierung zeitgemäßer Rechtsethik reiches Kapital geschlagen. Es ist schließlich kein Zufall, daß ein Naturrechtler der ersten (Nachkriegs-)Stunde wie Helmut Coing nach Erlaß des Grundgesetzes keine Notwendigkeit mehr sah, noch einmal auf das Naturrecht zurückzukommen.

Alles in allem empfiehlt sich für den Umgang mit diesem Buch der status quo: Wann immer die Rede auf die verschiedenen »Spielarten« des Positivismus kommt, taucht eine Fußnote auf: Vgl. hierzu Ott, Positivismus.

\section{Terra incognita}

Tief sei der Brunnen der Vergangenheit, schrieb einmal ein selbsternannt Unpolitischer, der freilich zu der Zeit, als er aus dem Quell der Geschichte seine gewaltige Joseph-Tetralogie schöpfte, auch in der Außendarstellung nicht mehr für unpolitisch gehalten werden konnte. Seine Politisierung entscheidend beeinflußt hatten die Ereignisse aus dem Jahr 1933. Zwar waren die Verhältnisse für unpolitische Umtriebe 15 Jahre zuvor, als die Welt die »Betrachtungen eines Unpolitischen« erstmals zu Gesicht bekam, angesichts der weltkriegerischen Auseinandersetzungen ebenfalls nicht besonders günstig gewesen, doch reichte die Notwendigkeit, sich 1918 öffentlich zu positionieren, längst nicht an die Erfordernisse nach den Fackelzügen von 1933 heran.

Sigrid Emmenegger ${ }^{12}$ nimmt diese frühen Bekenntnisse zu politischer Abstinenz beim Wort und weist ihnen einen Platz in guter (wenngleich epochal nicht ganz passender) Gesellschaft zu: »Antirationalismus und ,Boykott" des politischen Lebens durch viele Intellektuelle « seien Ausdruck und Erscheinungsform »des europaweit unter dem Schlagwort Fin de siècle firmierenden Krisenbewusstseins der Jahrhundertwende« (283). Thomas Mann verhielt sich also 1918 nicht anders als viele Intellektuelle vor ihm und reagierte damit auf eine "grundlegende Verunsicherung des Bürgertums « (285), die neben Nihilismus und Irrationalismus »weiter Teile der Intellektuellen im Kaiserreich« (283) auch ein großes Bedürfnis nach wissenschaftlichem und gesellschaftlichem Orientierungswissen hervorrief - ein Bedürfnis, das eine bisher nur wenig erforschte rechtswissenschaftliche Disziplin zu stillen sich seit 1888 anschickte: die Gesetzgebungslehre.

Nun mag man von dieser Deutung vorläufig halten, was man wolle; mehr Interesse wird zunächst der zu deutende Befund hervorrufen, Aufstieg und Fall der Gesetzgebungskunst um 1900 nämlich. Denn so grundlos, wie der Brunnen der Vergangenheit ist, so endlos ist auch die Zahl der historiographischen Gefäße und Eimerchen, die täglich in seine Tiefen gelassen werden, um bisher unentdeckte Vergangenheitsbewohner ans Licht der Gegenwart zu zerren und einer wissenschaftlichen Behandlung zuzuführen. Wirklich Neues ist deshalb nur selten in den Fässern der Forscher; sofern die Zug-

12 Sigrid Emmenegger, Gesetzgebungskunst. Gute Gesetzgebung als Gegenstand einer legislativen Methodenbewegung in der Rechtswissenschaft um 1900 - Zur Geschichte der Gesetzgebungslehre (Grundlagen der Rechtswissenschaft Band 5), Tübingen: Mohr Siebeck, 2006, $365 \mathrm{~S}$. 
schnur nicht besonders lang (Deutschland ohne Deutsche: Geschichte Germaniens von 500.000-380.000 v. Chr.) oder der Topf außergewöhnlich klein ist (Wirtschaften in bewegter Zeit: Die Sparkasse Baindlkirch zwischen »Machtergreifung « und Reichstagsbrandverordnung), besteht die Gefahr, daß in den Kesseln nicht mehr enthalten ist als ein müder Aufguß des hinlänglich bekannten Geschichtssuds, den sich nochmals aufzukochen kaum lohnt. Im andern Fall jedoch ist davon auszugehen, daß die Unerhörtheit der Forschungsergebnisse bestenfalls durch ihren spekulativen Charakter und schlechtestenfalls durch die gähnende Langeweile des Forschungsgegenstandes umfassend kompensiert wird.

Vor diesem Hintergrund muß als kleine Sensation gelten, was Emmenegger mitzuteilen hat. Trotz kurzer Leine und geräumigem Kübel hat sie »in der deutschsprachigen Rechtswissenschaft um 1900 eine bisher völlig unbekannte Methodenströmung « (6) aufgestöbert: die Gesetzgebungskunst als unmittelbare Vorgängerin der vermeintlich geschichtslosen Gesetzgebungslehre der Gegenwart. Eine große Bewegung, keine hundert Jahre alt, mitten unter uns, gleichwohl unentdeckt bis heute - ein historiographischer Glücksfall.

Sofern sich denn alles so zugetragen hat, wie von Emmenegger beschrieben. Damit soll nicht angedeutet werden, daß die Präsentation ihrer Ergebnisse Anlaß gibt, die Sorgfalt ihrer Forschungen zu bezweifeln. Kundig führt Emmenegger den Leser durch die Quellen und Sekundärschriften der methodologischen Streitigkeiten zur Zeit der Wende vom 18. zum 19. Jahrhundert und belegt dabei jede ihrer Aussagen mit einer bemerkenswerten Vielzahl von Fundstellen und Zitaten, die sie mit eindrucksvoller Gründlichkeit zusammengesammelt hat. Die Lesbarkeit des Textes freilich wurde durch dieses gründliche Vorgehen nicht immer positiv beeinflußt; die Fußnoten etwa sind manches Mal zu solcher Größe angeschwollen, daß nur noch wenige Zeilen des eigentlichen Textkorpus auf den Seiten Platz finden (exemplarisch: 248). Außerdem sieht sich Emmenegger durch die Fülle ihrer Materialsammlung in der Lage, jede ihrer Thesen mit mehreren inhaltsgleichen Zitaten aus der Sekundärliteratur zu untermauern. Der reichliche Gebrauch, den sie von dieser Möglichkeit macht, wirkt auf Dauer allerdings ein wenig ermüdend, schließlich muß man auf diese Weise alles mindestens zweimal lesen: erst findet sich eine kurze Zusammenfassung der eigenen oder fremden Ansicht und anschließend zwei oder drei längere Aussprüche mehr oder weniger bekannter Autoren, die das eben Gelesene mit anderen Worten umschreiben (exemplarisch: 265).

Ist an der Akkuratesse der Schilderung auch nicht zu zweifeln, so bleibt dennoch fraglich, ob die verkündeten Entdeckungen wirklich in dem Maße neu und unbekannt sind, wie Emmenegger es suggeriert. Zwei Umstände stimmen mißtrauisch: Zum einen ist Emmenegger augenscheinlich von einer solchen Sympathie für den »brillanten Schachzug « ihrer legislativen Rechtswissenschaftler (292) getragen, daß sie manche bloß terminologische Neuerung mit dem Glanz inhaltlichen Fortschrittes ausgestattet zu haben scheint. Und zum anderen drängt sich bei der einen oder anderen Bemerkung zur Forschung der letzten Jahre der Verdacht auf, daß einzelne jüngere Entwicklungen für Emmenegger nicht relevant waren und sie sich aus diesem Grund nur deshalb über die Neuheit einzelner Entdeckungen freuen kann, weil bereits geleistete Arbeit auf den 
Nachbarfeldern der Gesetzgebungslehre für sie eine weniger prominente Rolle gespielt haben.

Dies zeigt sich etwa an den methodologischen Vorbemerkungen, die Emmenegger ihrer Arbeit vorausschickt (»Eine Arbeit über Methode kann nicht umhin, auch die eigene Methode zu reflektieren«, 8). Abschließend heißt es dort, »in der Rechtsgeschichte « werde »oft die Auffassung vertreten, dass rechtshistorische Untersuchungen allein zum Zweck der Klärung dessen, ,wie es eigentlich gewesen“, stattfinden dürfen« (10), um der Gefahr eines applikativen Geschichtsverständnisses vorzubeugen. Diese Gefahr soll darin liegen, daß ein gegenwartsbezogener Blick auf die Geschichte den historischen Quellen Aussagen zu Themen entlocken könnte, zu denen etwas auszusagen sie aufgrund ihrer Vergangenheit eigentlich gar nicht in der Lage sind. Man darf nur hoffen, daß mit der darin angedeuteten Differenzierung von sammelwütiger Geschichtsmetaphysik einerseits und anwendungsbezogener Rechtsgeschichte andererseits basale Meinungsverschiedenheiten innerhalb der Disziplin allenfalls andeutungsweise wiedergegeben sind.

Ähnliches gilt für die Ausführungen zu Begriffsjurisprudenz und Positivismus, zwei Begriffe, mit denen Emmenegger eine tendenziell gesetzgebungsfeindliche Epoche während der ersten drei Viertel des 19. Jahrhunderts treffend charakterisiert glaubt (18-29). Dort wird früh Windscheids berüchtigte Wendung vom »Juristen als solchen« eingeführt (22) und im folgenden allen vermeintlich oder tatsächlich positivistisch (was immer das heißen mag) geneigten Rechtswissenschaftlern als Klotz ans Bein gehängt (exemplarisch: 28), gerade so, als sei nach den verschiedenen Erkundungen zur politischen Funktion des Positivismus oder der philologischen Bedeutung des logischen Elements in der juristischen Methode des 19. Jahrhunderts keine differenziertere Betrachtung der Geschehnisse möglich. Insbesondere für Windscheid darf als gesichert gelten, daß er sich schon ab der Mitte des 19. Jahrhunderts nicht in rechtspolitischer Enthaltsamkeit geübt hat.

Insofern bleibt die Berechtigung von Aussagen wie derjenigen, der »Jurist als solcher « habe seine Begriffsbildungen »im Ergebnis zwar schöpferisch, aber methodisch streng im Wege eines formallogischen Verfahrens« (28) durchgeführt, nicht nur in sachlicher Hinsicht zweifelhaft. Gleichfalls nur schwer nachvollziehbar ist der gegen den Positivismus gerichtete Vorwurf, es sei ihm aufgrund seines Postulates der Methodenreinheit theorieimmanent unmöglich, sich zu Fragen der Gesetzgebungstechnik zu äußern (65).

An solchen Einschätzungen wird deutlich, daß sich Emmenegger im Hinblick auf Recht und Rechtswissenschaft im 19. Jahrhundert von mancher theoretischen Altlast noch nicht in dem Maße befreit hat, wie dies durch jüngere Forschungen möglich wäre. Dies relativiert denn auch das Überraschungspotential ihrer eigenen Entdeckungen.

Gleichwohl ist der synthetischen Kraft, mit der sie die vielen Strömungen zu einer eigenständigen Lehre der Gesetzgebung verbindet, Anerkennung zu zollen. Emmenegger lokalisiert den Beginn der legislativen Rechtwissenschaft im Jahr 1888, zu der Zeit also, als der erste Entwurf des BGB veröffentlicht wurde (29). Die umfassenden Reaktionen aus der Wissenschaft auf die gesetzgeberischen Vorhaben hätten neben 
den bekannten inhaltlichen Debatten zur Folge gehabt, daß eine »legislative Perspektive im Hinblick auf das ,gute " und also ,seinsollende' Rechtsgesetz in die Rechtswissenschaft « integriert wurde (30). Aus allen Winkeln der Rechtswissenschaft seien nach 1888 Forderungen laut geworden, die »gute Gesetzgebung « zum Gegenstand juristischer Auseinandersetzung zu machen, wie Emmenegger mit zahlreichen Zitaten von zivil- (33-41) und strafrechtlichen (41-44) Protagonisten belegen kann.

Den anfänglichen Appellen sei nach 1900 eine Phase der allgemeinen Anerkennung gefolgt, in der es immer selbstverständlicher wurde, legislative Fragestellungen als rechtswissenschaftliche Probleme aufzufassen (44-80). Stammlers Lehre vom Richtigen Rechte identifiziert Emmenegger hier als »Eröffnungsfanfare « (44), mit der neben der Etablierung des Faches selbst auch dessen »diskursives Leitmotiv« (45) Einzug in die Rechtswissenschaft gehalten habe: »Richtiges Recht« als »terminologische Revolution « (46), die ausreichend Distanz zum diskreditierten Naturrecht schafft und der rechtspolitischen Debatte dennoch als erstrebenswertes Ideal vorausgehen kann. Unter dem Titel »Gesetzgebungskunst« sei auf diese Weise eine eigenständige Methodenbewegung innerhalb der Rechtswissenschaft entstanden, die sich sowohl für inhaltliche (60 f.) als auch für formale (62-66) Fragen zuständig gesehen habe. Zu einer Institutionalisierung sei es allerdings nicht gekommen (74-80).

$\mathrm{Zu}$ beiden Teilbereichen der Gesetzgebungskunst finden sich nähere Erläuterungen. Die Gesetzgebungspolitik als materiell orientierter Zweig der legislativen Rechtswissenschaft sei um die Bestimmung guter Regelungszwecke bemüht gewesen sowie um die Formulierung geeigneter Mittel zur Verfolgung dieser Zwecke. Wie zu vermuten, kursierten über die richtige Methode der Zweck- und Mittelsuche etwa so viele Meinungen wie Meinungsträger: geschichtsphilosophische, evolutionistische, kulturwissenschaftliche, soziologische und materialistische Orientierungen auf induktiver, idealistische und metaphysische Vorstellungen auf deduktiver Seite und beiden gegenübergestellt die grundsätzliche Kritik an der Behauptung, objektiv richtige Ziele könnten tauglicher Gegenstand werturteilsfreier Erkenntnis sein (137-154). Wer - wie »die wohl überwiegende Zahl der Autoren « - das Postulat der Werturteilsfreiheit ernstnahm, verzichtete auf Stellungnahmen zum Regelungsziel und beschränkte sich auf den unbestrittenen Kern der legislativen Rechtswissenschaft: die Suche nach geeigneten Mitteln, durch die der vorgegebene Zweck erreicht werden könnte (154-160). Und auch hier wieder: Statistisches, Ökonomisches, Psychologisches, Rechtsvergleichendes, Rechtshistorisches, Experimentelles, kurz: bunt Gemischtes (163-183).

Herausragende Bedeutung bei der Bestimmung des richtigen Regelungsziels weist Emmenegger Stammler und seinen Versuchen zu, zur Unterscheidung von richtigem und unrichtigem Recht den übergeordneten Leitstern des »sozialen Ideals « heranzuziehen (102-120). Diese Sonderbehandlung rechtfertigt sich sicherlich durch die zentrale Rolle seines »richtigen Rechtes « in der rechtspolitischen Diskussion. Zugleich wird hier jedoch deutlich, daß grundlegende Überlegungen der Gesetzgebungslehre bereits ausführlich gewürdigt wurden: in philosophiegeschichtlichen Zusammenhängen ist Stammlers Beitrag zur »Wiederbelebung der Rechtsphilosophie« (111) allgemein bekannt. Insofern bleibt unklar, inwieweit die von Emmenegger ausgemachte Gesetzgebungskunst sich tatsächlich von der Rechtsphilosophie emanzipiert hat (die 
Ansichten der Zeitgenossen zu dieser Frage können auf 239-255 nachgelesen werden) und inwieweit hier bloß terminologische Differenzen festzustellen sind. In Teilen dürfte die von Emmenegger entdeckte Methodenbewegung jedenfalls nicht »völlig unbekannt « (6) sein.

Die Darstellung von Stammlers Lehre freilich gelingt sehr gut. Emmenegger arbeitet präzise den Zeitpunkt heraus, an dem Stammler das »soziale Ideal « von einer Möglichkeitsbedingung der Erkenntnis richtigen Rechts in ein inhaltliches Postulat verwandelt (105; 117-120) und damit genau den Fehler begeht, der Kelsen gerne (fälschlicherweise) vorgeworfen wird. Leider überträgt Emmenegger die Gründlichkeit ihrer Auseinandersetzung auf die von ihr als »positivistisch« oder »begriffsjuristisch« eingestuften Autoren nur zum Teil (siehe etwa 291).

Deutlich weniger Raum nehmen die Ausführungen zum formellen Zweig der Gesetzgebungskunst, der Gesetzgebungstechnik, ein (184-228). Hier findet sich allerdings auch kaum etwas, was nicht schon Gegenstand rechtshistorischer Untersuchungen gewesen wäre. Die Frage nach der richtigen Gesetzessprache, die Rolle des Allgemeinen deutschen Sprachvereins bei der Entstehung des BGB und die Debatte um eine anzustrebende oder auch nur mögliche Allgemeinverständlichkeit des Gesetzessprache (184-202) sind bereits eingehend erörtert. Dies gilt ebenso für die verschiedenen Probleme, die sich um die angemessene Strukturierung des Gesetzes (202-213) ranken, etwa die Debatte um den Allgemeinen Teil (209-211). Die Schilderung der Gesetzgebungstechnik zeichnet sich deshalb durch ein nicht zu übersehendes Übergewicht synthetischer gegenüber inhaltlichen Entdeckungen aus.

Womit abschließend ein Blick auf die eingangs erwähnten Deutungsversuche Emmeneggers geworfen werden kann, warum »es ab $1888 \mathrm{zu}$ einer Abkehr vom Methodenreinheitsgebot der späteren historischen Schule« kam und gefordert wurde, die Frage nach der guten Gesetzgebung in die Rechtswissenschaft einzubeziehen (256). Vier Hypothesen bietet Emmenegger an: Neben der erwähnten allgemeinen Krisenstimmung im Bürgertum, die durch eine wissenschaftlich fundierte Gesetzgebungslehre gemildert werden sollte (282-287), sieht Emmenegger die legislative Rechtswissenschaft als Antwort auf eine fehlende verfassungsrechtliche Richtigkeitskontrolle der Gesetzgebung (287-296), als Versuch, sich innerhalb des immer enger werdenden Netzes positiver Gesetze neue Betätigungsfelder zu erschließen (269-282), sowie als Beitrag der Rechtswissenschaft zur durch die soziale Frage immer dringlicher werdenden bürgerlichen Sozialreform (256-269).

Diese Erklärungen sind sicherlich mehr oder weniger plausibel. Fraglich ist allerdings, ob sie die Version einer Gesetzgebungslehre, wie sie Emmenegger vor Augen schwebt, wirklich stützen. Denn die von Emmenegger ausgemachte »Blütephase der legislativen Literatur « in der Zeit zwischen der Veröffentlichung des ersten BGB-Entwurfs im Jahr 1888 und dem Beginn des Ersten Weltkriegs ist durch eine eigentümliche Konzentration auf inhaltliche Fragen der Gesetzgebung gekennzeichnet, welche nahe legt, daß es der Gesetzgebungslehre weniger um eine legislative Methodologie als um die Umsetzung konkreter rechtspolitischer Absichten ging.

Dies macht es verständlich, warum die Gesetzgebungslehre auftrat, als das Gesetz die angemessene Form für die Verbreitung von Gesellschaftsentwürfen wurde und da- 
mit seine zentrale Stellung im politischen Betrieb einzunehmen begann, und wieder verschwand, als die großen Kodifikationsvorhaben abgeschlossen waren. Zudem erklärt sich aus den politischen Motiven der Gesetzgebungslehrer, weswegen sie sich für die großen Prozeßgesetze der Zeit augenscheinlich nicht erwärmen konnten: ZPO, StPO oder GVG spielen im Schatten des übermächtigen BGB (und der Reformbemühungen des Strafrechts; 47-52) allenfalls eine untergeordnete Rolle.

Von dem von Miloš Vec erhobenen Vorwurf der »kulturellen Verspätung « wird man die Rechtswissenschaft deshalb entgegen der Meinung Emmeneggers nicht freisprechen können (267). 1888 war die Kodifikationsbewegung bereits in vollem Gange und hatte schon einige beeindruckende Ergebnisse gezeitigt, und die theoretische Verarbeitung dieser Vorgänge geschah gerade nicht systematisch oder planvoll, sondern sehr viel eher als ad hoc-Reaktion auf ausgewählte Bestandteile der legislativen Bemühungen.

Als eigenständige Schule ist die Gesetzgebungslehre um 1900 aus diesen Gründen nur schwerlich zu definieren. Dieser Befund wird von Emmenegger bestätigt, wenn sie schreibt, man habe es »von Anfang an « nicht mit einem »gezielt initiierten Projekt miteinander kooperierender Rechtswissenschaftler « zu tun, sondern eher mit »einer parallelen Bewegung heterogener Autoren in dieselbe Richtung « (80). Eine Bewegung immerhin, die viel darüber erzählen kann, wie konkrete politische Absichten im Recht am besten verfolgt werden: im Gewand rein formaler Kritik nämlich. Wer politisch als unvoreingenommen und damit als unverdächtig gelten will, muß sich darum bemühen, seine inhaltliche Unzufriedenheit in die vermeintlich neutrale Form des Rechts zu bringen. Folgerichtig wird nicht das Urteil oder der Inhalt der Rechtsnorm zum Gegenstand rechtswissenschaftlicher Kritik gemacht, sondern die Verfahren, in dem die Inhalte produziert werden.

Eine Gesetzgebungsmethodik wird man in diesem Vorgehen kaum erblicken können. Lohnender ist es vermutlich, die legislativen Bestrebungen der Juristen im Rahmen einer umfassenderen Justiz- und Rechtstheorie daraufhin zu untersuchen, inwieweit sie die Wertschätzung widerspiegeln, welche die Rechtsverwalter der ihnen im Kaiserreich zugedachten Rolle in Staat und Gesellschaft entgegenbrachten. In dieser Hinsicht lassen sich Emmeneggers Buch zwar auch einige Hinweise entnehmen, doch liegt ihr Schwerpunkt auf der Entdeckung nicht ganz unbekannter Sachverhalte, garniert mit einer auch in dieser Diffusität nicht zum ersten Mal vorgetragenen Positivismusfama. Der Brunnen bleibt tief.

\section{Der Seher}

Mit dem Sehen ist es so eine Sache. Im »Baum der Erkenntnis« von Maturana und Varela liest man dazu: »Wir sehen nicht, was wir sehen«, an anderer Stelle: »Wir sehen nicht, was wir nicht sehen«, und zuguterletzt: »Wir sehen, was wir nicht sehen.« Heinz von Foerster fügt dem hinzu: »Wir sehen nicht, daß wir nicht sehen«, was Luhmann wiederum zur Mitteilung veranlaßt, man könne nicht sehen, daß man nicht sieht, was man nicht sieht. - Mit dem Sehen ist es also so eine Sache.

Wenn aber das Sehen als Mittel der Erkenntnis dazu dienen soll, Wissen über die Welt zu sammeln, dann sieht man, daß es auch mit dem Wissen so eine Sache ist. Die 
Krise des Sehens hat sowohl das Projekt Erkenntnis als auch das Projekt Wissen zum Scheitern gebracht: Die Welt kann weder erkannt noch gewußt werden. Das alte »Was kann ich wissen? « ist deshalb für erledigt zu erklären: Wir wissen nicht, daß wir nicht wissen, was wir nicht wissen. Für die Beobachtung des Wissens von der Welt kann dies nur heißen, daß die Beschäftigung mit dem, was von der Welt gewußt wird, abgeschlossen ist. Lohnend bleibt einzig die Frage, wie dieses Weltwissen gewußt und auf welche Weise es kommuniziert wird.

Im Falle des Rechts steht diese Umstellung vom Was zum Wie freilich noch aus. Das Interesse der Rechtswissenschaft zielt ausschließlich darauf, was vom Recht gewußt wird; wie diese Expertise gewußt und weitergegeben wird, ist Juristen herzlich gleichgültig. Umso erstaunlicher ist deshalb, daß es eine juristische Fakultät war, die Rainer Maria Kiesow mit seinem »Alphabet des Rechts ${ }^{13}$ habilitiert hat: einer rechtshistorischen Studie darüber, wie das Wissen vom Recht durch die Zeit getragen wurde.

Ein rechtsgeschichtliches Werk also. Doch auch geschichtliches Wissen ist Wissen von der Welt und damit der Erkenntnis verschlossen. Der Forschungsansatz, der dies berücksichtigt, kommt aus Frankreich und heißt Foucault ( $7 \mathrm{ff}$.): ein »gnadenloser Historismus « (Kiesow zitiert Habermas, 12), der »nicht mehr zwischen Gegenstand und Gegenstandserkenntnis zu unterscheiden vermag« (12). Und dennoch wählt sich das Buch einen Gegenstand: den Transport des Wissens vom Recht in Alphabeten, Enzyklopädien, Lexika, Fallsammlungen, Nachschlagewerken, dictionnaires -»Aufschreibesysteme« (23), die »dem Recht ein geordnetes, gesammeltes, komplettes Zuhause zu geben « (20) bestimmt waren.

Das Recht in seiner Gänze ist allerdings nur faßbar in einer zum Stillstand gekommenen Welt. Erst wenn die Zeit aufhört, der zwischen zwei Buchdeckeln verpackten Einheit des Wissens immer neue »Urteiler, Deuter, Ausleger, Erklärer, Glossatoren, Kommentatoren, Professoren « (26) zu bescheren, fallen Buch und Welt tatsächlich in eins. Da dies auf absehbare Zeit nicht zu erwarten steht, kann der Verfasser mit vollem Recht feststellen: »Das Ganze der Welt und das Ganze der Teile der Welt war und ist nicht mehr zu fassen.« (19) Für sein Buch bedeutet dies jedoch noch vor dem ersten Lemma (Anbruch, 21 ff.) doppeltes Ungemach durch zweifaches Nichts: Zur gescheiterten Geschichtserkenntnis gesellt sich die gescheiterte Rechtserkenntnis und bildet mit ihr zusammen eine Schicksalsgemeinschaft im unheilvollen Strudel rechtshistorischer Paradoxien, in dem der Historiker selbst historisiert wird (12) und auch das Existierende nicht existiert (11).

Bei so viel Nichts bleibt nur noch, den Teufel mit dem Beelzebub auszutreiben, oder anders gesagt: sich durch den Kunstgriff des re-entry am eigenen Schopf wieder aus dem Sumpf zu ziehen. Die zerbrochenen Enzyklopädien, die »Schädelstätten der vergangenen Vergangenheit « (19), können in ihrem Scheitern nur durch ihresgleichen angemessen beschrieben werden: durch eine weitere zerbrochene Enzyklopädie. Um das Verschwinden der juristischen Wörterbücher aus dem Rechtshimmel (257) darzustellen, nutzt der Autor deshalb die verschwundene Form selbst: »das Alphabet des

13 Rainer Maria Kiesow, Das Alphabet des Rechts. Frankfurt a. M.: Fischer 2004, 320 S. 
Rechts« (14), »fünfundzwanzig Facetten, alphabetisch geordnet« (20). Ein Alphabet des Rechts? Der Geschichte? Oder doch der Rechtsgeschichte?

Ein Wissensbuch jedenfalls, das für Wissen nicht viel übrig hat und dennoch eine Unmenge an Wissen zu vermitteln hat, rechtshistorisches Wissen allemal, aber auch rechtstheoretische, rechtsphilosophische und rechtsmethodologische Einsichten, die weit über das hinausgehen, was so manches selbsternannt einschlägige Lehrbuch zu bieten hat.

Das Lemma Jurisprudenz etwa ist ein wahrer Steinbruch für jede Methodenlehre, welche die »entscheidende Frage « (Kiesow zitiert Carl Schmitt, 144) eines funktionierenden Rechtssystems beantworten möchte: »Wann ist eine richterliche Entscheidung richtig? « Man findet dort Erkenntnisse über die Autonomie des Rechtssystems (144), die Folgen des Rechtsverweigerungsverbots (145), die paradoxe Struktur des Entscheidens (146), die Unmöglichkeit einer Rückkopplung der Entscheidung an Wissen oder Wahrheit (146) oder den blinden Fleck des Rechtssystems (151), und kann über die Souveränität des Verfassers im Umgang mit den zeitgenössischen Theorieangeboten aus den sogenannten juristischen Grundlagenfächern nur staunen. - Ein Alphabet der Rechtstheorie? Der Methodenlehre?

Eher nicht, jedenfalls nicht im herkömmlichen Sinn. Der Reichtum an Theorie und Methodik, der aus jedem Winkel des Werkes dringt, ist direkte Folge der historischen Fragestellung, nicht aber Produkt eigenständiger rechtstheoretischer Analysen. Das große Thema des Buches, das Speichern von Wissen bei aller »grundsätzlichen Kontingenz, Bedingtheit, Endlichkeit, Unerreichbarkeit, ja Inexistenz des Wissens und der Wahrheit« (149 f.), hat offensichtlich immense rechtstheoretische Implikationen, die der Verfasser als das benennt, als was sie in seinem Werk erscheinen: historische Konsequenzen der Uferlosigkeit des Wissens. So kann er sich bei der Darstellung seiner rechtstheoretischen Einsichten auf knappe Thesen (»Recht ist Praxis«, 214), vergessene Selbstverständlichkeiten (»Juristen müssen schreiben können«, 206) und prägnante Bilder (»Juristen sind gefräßig«, 113) beschränken und dabei zurecht darauf vertrauen, daß seine Befunde alleine durch die historische Darstellung plausibel werden. Dies birgt in zweierlei Hinsicht Überraschungen:

Zunächst gibt es in der Rechtstheorie der Gegenwart kaum ein Werk, das die aktuellen Befindlichkeiten der Grundlagenreflexion so überzeugend und geradlinig auf die Geschichte des Rechts zurückführen kann. Darüber hinaus läßt das ausnahmslose Scheitern der Jahrhunderte währenden Versuche, das Recht in einem Buch zusammenzufassen, die Jämmerlichkeit einer auf Wortlautgrenzen und Justizsyllogismen gegründeten Rechtstheorie in einem ganz neuen Licht erscheinen. - Rechtsgeschichte als Grundlage der Grundlagenfächer? Die außerordentliche Kunstfertigkeit des Verfassers läßt den Leser gerne daran glauben.

Und so verliert man sich in seinen Geschichten und Geschichtchen von den Unternehmungen, »dem Wissen ein Zuhause zu geben « (17): von den unermüdlichen französischen Arretisten und Enzyklopädisten, von den eifrigen deutschen Sammlern und Aufschreibern, von den Einführungen, Grundrissen und civilistischen Cursus (insb. 98 ff.), von Diderot (insb. 76 ff.) und Pitaval (195 ff.), von Martin Guerre (152) und General Stumm von Bordwehr (134 f.), von Josef K. (36 f., 54 f.) und Malte Laurids 
Brigge (26), von hunderten Enzyklopädievorhaben, tausenden Lemmata und zehntausenden Seiten, von der Überforderung des Sammelmediums Buch, die schließlich zu seiner Auflösung führt und es im neuen Medium Internet wieder aufgehen läßt (Lemma Online, 190 ff.), vom großen deutschen Enzyklopädisten Georg Krünitz, der beim Artikel »Leiche« verstarb (94 f.), und schließlich vom Kyrmischack, einem am Kaspischen Meer lebenden Katzentier, dessen Eintrag - obwohl mit K beginnend der letzte der Deutschen Encyclopädie aus Gießen ist und das Projekt damit zu einem unvollendeten macht (95).

Doch wovon handeln diese Geschichten? Wovon redet der Geschichtenerzähler, wenn seine Sicht auf die Welt, die er kundtut, eben diese Welt nicht mehr erreichen kann? »Wenn Welt und Wahrheit zum Diskurs [werden ...], dann bleibt nur noch Stil.« (13) Dies legt zunächst die Vermutung nahe, die Historiographie als Beobachtung einer unbeobachtbaren Welt verrate vorrangig etwas über den Historiker selbst. So mag man denn dem Schwanengesang von der Einheit des Wissens lauschen und dabei herumdeuteln an dem »Geschichten-Macher « (14) Kiesow, an seiner abundanten Sprache, seinem enormen Ausdrucksreichtum und seinem teils humorvollen, teils melancholischen und mitunter redundanten Stil. Wer ist er? Ein Historiker? Ein Literat? Ein Träumer?

Doch das ist nur ein Teil der Geschichte. Der andere handelt von der Historie selbst, die die Fesseln der Vergangenheit längst gesprengt hat und nur noch jetzt passieren kann: »die Gegenwart [ist] die unhintergehbare Erzeugerin der Vergangenheit [...], das Jetzt der Herrscher des Wissens. «(19) Die Geschichtsschreibung kann sich deshalb immer nur auf die Gegenwart beziehen. Damit aber ist sie »Menschenwissenschaft« (11); sie kann nicht länger von dem erzählen, was sich in einer irgendwann vergangenen Vergangenheit zugetragen hat, sondern nur davon, wie diese Vergangenheit im Jetzt beobachtet wird: »Historiographie ist Gegenwart.« (11) Was immer also das Werk über seinen Autor preiszugeben hat, vor allem erlaubt es Einsichten in dessen Gegenwart. Und über diese Gegenwart gibt es in der Tat Bemerkenswertes zu berichten: von einer rechtswissenschaftlichen Arbeit, die ohne eine einzige Fußnote auskommt (stattdessen: »Accessoires « am Ende jedes Artikels), von einem Begriffsindex (291 ff.), der Einträge auflistet wie Wahnsinn, Irre (gehen/sein), Irrsal, Verrückt (Spinner), Wust (Wirrnis, Wirrwarr, Unordnung, Konfusion), Denkzwang, Bibliotheksaffe oder Sudelbuch; von Worten wie »Verschafung « (165) oder »byxsadqert bnhgtsfdr dbaäüöportz« (244) und von Sätzen wie »Die (Rechts)Ordnung wird durch Denkverbote hergestellt« (150), oder »Das Recht hat den Verstand verloren« (271); schließlich von einer juristischen Fakultät, die dieses Alphabet von anderen Ansichten, Außenbetrachtungen und Abseitigkeiten in den Rang einer Habilitationsschrift erhoben hat und damit die Hoffnung nährt, der Zeit der Dürre in der juristischen Grundlagenforschung werde eine Ära folgen, in der ähnlich reiche Werke wie das vorliegende die rechtstheoretische Armut der Gegenwart vergessen lassen.

$»$ Man sieht nur, was man sieht«, liest man bei Kiesow (32). Ein wunderbares Buch. ${ }^{14}$

14 Ganz anders sieht Filippo Ranieri die Dinge; vgl. ZRG (GA) 124 (2007). 